NBER WORKING PAPER SERIES

\title{
HETEROGENEITY IN THE IMPACT OF PRIVATIZING SOCIAL HEALTH INSURANCE: EVIDENCE FROM CALIFORNIA'S MEDICAID PROGRAM
}

\author{
Mark Duggan \\ Craig Garthwaite \\ Adelina Yanyue Wang \\ Working Paper 28944 \\ http://www.nber.org/papers/w28944 \\ NATIONAL BUREAU OF ECONOMIC RESEARCH \\ 1050 Massachusetts Avenue \\ Cambridge, MA 02138 \\ June 2021
}

We are grateful to Anna Aizer, Jon Gruber, Atul Gupta, Emilie Jackson, Timothy Layton, Ajin Lee, Boris Vabson, Amanda Starc, and seminar participants at the 2019 ASHEcon Conference, the 2020 NBER Health Care Meeting, and University of Maryland for very helpful feedback. We also thank Betty Henderson-Sparks, Aaron Maggetti, Amy Peterson, and Jon Teague of the California Office of Statewide Health Planning and Development for their assistance in providing the hospital / ER discharge data. All remaining errors are our own. The views expressed herein are those of the authors and do not necessarily reflect the views of the National Bureau of Economic Research.

NBER working papers are circulated for discussion and comment purposes. They have not been peer-reviewed or been subject to the review by the NBER Board of Directors that accompanies official NBER publications.

(C) 2021 by Mark Duggan, Craig Garthwaite, and Adelina Yanyue Wang. All rights reserved. Short sections of text, not to exceed two paragraphs, may be quoted without explicit permission provided that full credit, including $(\odot$ notice, is given to the source. 
Heterogeneity in the Impact of Privatizing Social Health Insurance: Evidence from California's Medicaid Program

Mark Duggan, Craig Garthwaite, and Adelina Yanyue Wang

NBER Working Paper No. 28944

June 2021

JEL No. H0,H1,I1,I10,I13,I18

\section{ABSTRACT}

State governments face the classic "make or buy" decision for the provision of Medicaid services. Over the past two decades, the majority of states have outsourced the provision of social health insurance through Medicaid Managed Care (MMC) programs. These programs have been extensively studied in the literature - with little evidence of large positive or negative effects. However, most states initially allowed older and sicker enrollees to remain enrolled in the government run fee for service (FFS) programs. It is possible that these more fragile enrollees could have a different experience in managed care. In this paper we study California's mandatory enrollment of the senior and persons with disabilities (SPD) population in MMC. We find this mandatory enrollment caused an increased use of the emergency department and transfers between hospitals. This was not simply a hassle cost for enrollees - we also estimate an increase in mortality for the affected population. These effects were strongest for the sickest enrollees the types of enrollees that might be expected to have a different experience with managed care. Our results suggest the adverse impact of MMC varies by the enrollee health, which should inform the optimal outsourcing decision for governments.

Mark Duggan

Stanford University

Department of Economics

579 Serra Mall

Stanford, CA 94305-6072

and NBER

mgduggan@stanford.edu

Craig Garthwaite

Kellogg School of Management

Northwestern University

2211 Campus Drive

Evanston, IL 60208

and NBER

c-garthwaite@kellogg.northwestern.edu
Adelina Yanyue Wang

National Bureau of Economic Research

1050 Massachusetts Ave.

Cambridge, MA 02138

adywang@nber.org 
Since its creation in the 1960 s, Medicaid has grown from a small program covering roughly 20 million indigent and disabled individuals to its current size of nearly 73 million enrollees (CMS, 2019). ${ }^{1}$ This makes Medicaid the largest health insurer in the United States and one of the largest in the world. Unlike other social insurance programs such as Social Security and Medicare, Medicaid is administered and partially funded by state governments and as a result the program varies greatly across states.

One dimension of variation is the degree of privatization. As Medicaid expanded, each state debated its own proverbial "make or buy" decision, i.e. is it optimal for the government to directly provide insurance services or should they instead outsource these economic activities to private firms. ${ }^{2}$ Over time, states have increasingly chosen outsourcing through the creation and expansion of Medicaid managed care (MMC) programs. Under MMC, state governments contract with (often forprofit) managed care firms. Payments are made on a "capitated" basis, with private firms receiving a lump sum payment and assuming responsibility for all beneficiary medical spending. Firms retain any difference as profits (or suffer losses if spending exceeds the capitated payment). ${ }^{3}$

MMC's growing popularity can be seen in Figure 1a, which shows that by 2016 the share of Medicaid enrollees covered by these programs stood at nearly 80 percent. These initial MMC programs have been extensively studied, with a resulting literature providing little evidence that privatization caused either great benefits or harms (e.g. Aizer, Currie and Moretti 2007; Currie and Fahr 2005; Duggan 2004; Lee 2020; Kuziemko, Meckel and Rossin-Slater 2018).

Despite the growth of MMC over time, a number of beneficiaries remained in the traditional government run fee-for-service (FFS) system. These FFS enrollees were primarily sicker and/or older

\footnotetext{
1 This expansion happened in several waves, starting with the inclusion of more pregnant women in the late-80s, children from higher income families in the mid-90s, and culminating with the passage of the Affordable Care Act (ACA) in 2010. Along with covering more people, the Affordable Care Act (ACA) changed the program from one of categorical eligibility to an entitlement available to all lowincome individuals residing in states adopting the expansion.

${ }^{2}$ There is a similar debate in Medicare regarding the creation and operation of the Medicare Advantage program - which is a voluntary managed care program for the elderly.

${ }^{3}$ In most cases these payments are risk adjusted so firms get larger payments for insuring individuals who have medical conditions that are expected to lead to higher spending.
} 
individuals that policymakers exempted from mandatory MMC enrollment. Though small in number, the complexity involved in treating these patients made them exceptionally costly. As a result, Figure 1b shows that, despite the massive MMC enrollment growth, the majority of Medicaid spending remained in the FFS system.

Searching for potential savings on these expensive patients, and perhaps comforted by the lack of meaningful harms from the initial MMC programs covering healthier and younger patients, many states have recently expanded privatization to include disabled and elderly Medicaid patients. Such policy decisions, however, may be premature. If the effect of privatization systematically varies across patients based on their health status, then the existing literature likely sheds little light on the optimality of these expanded privatization efforts.

In this paper, we directly examine heterogeneity in the effect of privatizing social health insurance. Specifically, we examine California's decision to mandate MMC enrollment for the 240,000 seniors and persons with disabilities (SPD) that had not already voluntarily enrolled in such programs. ${ }^{4}$ We identify the causal effect of mandatory MMC enrollment by exploiting both variation in when beneficiaries were required to enroll in MMC and geographic variation in MMC exposure.

The optimality of privatizing government services is the subject of a rich theoretical economics literature that extends well beyond healthcare. The primary goal of privatization is often to leverage the fact that as the residual claimant on spending, private firms have a greater incentive than government employees to control costs. Of course, such cost reduction efforts could have negative consequences. Of particular relevance to this paper, Hart, Shleifer and Vishny (1997) demonstrate that in a world of incomplete contracts, this potential for negative consequences makes the optimal

\footnotetext{
${ }^{4}$ While California had previously mandated SPDs to enroll in MMC in 14 of the 30 counties where such programs were available, this policy reform expanded that program to the remaining 16 counties. This was undertaken as part of the state's preparations for implementing the Affordable Care Act and implemented under the auspices of the "Bridge to Reform" section 1115 waiver. Part of this waiver mandates SPD Medicaid beneficiaries to enroll in Medicaid Managed Care in a selection of counties where SPDs previously could voluntarily choose whether or not to enroll in MMC.
} 
solution unclear. ${ }^{5}$ The authors predict that while outsourcing is optimal in many settings, states will prefer government control of services where there is a greater concern about adverse consequences resulting from decreased quality. Therefore, our question of heterogeneity in the consequences of “contracting out" is central to economics of the government's optimal policy decision.

Consider our setting of privatizing social health insurance. Ideally, the cost reductions created by private firms would result from better preventive care, early diagnosis and treatment, and more efficient care management. There is, of course, also a fear that firms may lower costs by reducing quality in ways that cannot be easily governed by the contract with the government. This could occur for several reasons. Capitated payments may create inappropriately strong incentives to cut costs in a setting where firms are not forced to internalize the full impact of lower quality - perhaps because such cost cutting is unobservable and is affecting vulnerable patients who may be less vocal about the adverse consequences. Compounding this concern, firms may find it profitable to provide low quality services to enrollees who are expected to generate higher costs than the capitated payment. ${ }^{6}$ This concern is even more salient if higher spending patients were more likely to move across plans in response to low quality care, perhaps because they place greater value on access to higher cost medical services (Shepard, 2016).

Regardless of the mechanism, it is conceivable that the impact of the lower quality caused by cost reduction efforts might be more consequential for high acuity patients who could suffer meaningful harms (up to and including death) from even minor disruptions in access to care. The insights from Hart, Shleifer and Vishny (1997) suggest that it is precisely such concerns about adverse

\footnotetext{
${ }^{5}$ In a complete contracting environment, the state is indifferent between government control and private ownership. After all, it can use these complete contracts to motivate its employees or private firms.

${ }^{6}$ States attempt to counteract this gaming by risk adjusting payments. This was not a feature of many initial MMC programs, and could have led to adverse consequences (Kuziemko, Meckel and Rossin-Slater 2018). That said, even in a system where capitated payments are risk adjusted, within each risk score there are enrollees who have above average spending that firms may attempt to persuade to switch to another plan (Geruso, Layton, and Prinz, 2019).
} 
consequences that drove states to continue to directly provide insurance services to their older, sicker, and most vulnerable beneficiaries.

If such concerns about variation in the adverse consequences of cost reductions based on the health of patients were valid, we would predict two patterns in our setting that focuses on the most complicated Medicaid patients. First, privatization should cause greater harms than in the existing literature, which primarily focuses on programs covering largely healthier populations. Second, privatization should differentially impact enrollees within our sample based on actual underlying patient health — with sicker enrollees suffering greater harms. Our empirical results are broadly consistent with both predictions.

We first find a meaningful negative effect of MMC on these older and sicker Medicaid enrollees, effects that were largely absent from the estimated effects of the original MMC programs. Requiring California's SPD beneficiaries to enroll in MMC caused an increase in visits to the hospital emergency department (ED), which would be consistent with a change in access to other medical services and/or a decrease in the underlying health of patients. Examining the conditions that led to increased ED visits, we find evidence that suggests they result (at least in part) from a lack of access to other medical services. For example, we find consistent evidence of an increase in preventable ED visits, non-emergent ED visits, and visits for psychiatric care - visit categories likely to be impacted by more restrictive non-hospital provider networks.

We also observe an increase in the number of inpatient visits that began as transfers from another hospital. This would be consistent with the implementation of stricter provider networks leading to a dislocation in the usual source of hospital care. Such disruption was a common concern expressed by patients and their advocates prior to the reform (Harbage \& King, 2012). Further supporting that these transfers are likely the result of differing networks, we find that most of these transfers began as visits to the ED of the transferring hospital. 
Consistent with concerns about adverse consequences for sicker patients, we find these changes in patterns of care represent more than just a hassle cost for enrollees. Indeed, we estimate that mandatory MMC enrollment caused an approximately 12 percent increase in mortality for the affected population. This increase begins immediately after a beneficiary's was required to enroll in MMC. Supporting that a lack of access to care is a potential mechanism driving the immediate mortality increase, we find the most consistent evidence of such an effect for patients suffering from circulatory conditions. These medical conditions, which include hypertension and coronary artery disease, are a plausible source of an immediate mortality effect from a decrease in access to medical services. In contrast, we find no increase in mortality among those with conditions that should be less likely to result in such immediate dire consequences from a temporary dislocation in care (such as cancer patients).

We further demonstrate the importance of heterogeneity in the impact of privatization by examining systematic differences within our sample based on patient health. We measure patient health based on both whether a patient had an above median use of inpatient and ED hospital services and on the nature of the patient's underlying health conditions. ${ }^{7}$ Across both of these measures, we find the estimated increase in ED visits, transfers, and mortality was concentrated among sicker beneficiaries, precisely the beneficiaries that policymakers were likely concerned would suffer greater adverse consequences from MMC. ${ }^{8}$

Our results contribute to a better understanding of the optimal system for providing health insurance to society's most vulnerable individuals. It joins work by Layton et al. (2019) which examines similar expansions to older and disabled populations in Texas and New York. These authors find the

\footnotetext{
${ }^{7}$ Both measures are calculated using data from prior to the reform and therefore are not influenced by features of MMC enrollment such as limited access to care or more intensive coding of medical conditions.

${ }^{8}$ For mortality, there is stronger and more consistent evidence for this heterogeneity when patient health is measured by the Elixhauser score (i.e a measure based on the number of conditions) rather than utilization. This is discussed in more detail below.
} 
expansion either had relatively little effect (New York) or generally increased access to services (Texas). They find no evidence of negative health effects in either state.

The divergence in results across these studies reflects the economically meaningful variation in the effects of Medicaid policies across states. Such variation makes it difficult to broadly generalize from the estimated effects of a particular policy choice (Garthwaite et al. 2019). Instead, policymakers and economists interested in making such comparisons must consider the specific economic factors that may be similar across contexts.

Our results also contribute to the growing literature about the health and mortality effects of health insurance. Numerous studies found few health effects of increased insurance coverage (Levy and Meltzer 2008; Finkelstein and McKnight 2008; Finkelstein et al., 2012). However, more recent work has demonstrated decreased mortality among individuals gaining access to insurance (Sommers, Baicker and Epstein, 2012; Sommers, Long, and Baicker, 2014; Miller et al. 2019; Goldin, Lurie and McCubbin 2019). Our work expands this literature by demonstrating the importance of the form of the insurance contract and not simply the extensive margin of insurance. In this way, it joins the work of Abaluck, Bravo, Hull, and Starc (2021) which finds differential mortality for enrollees based on which firm manages their Medicare Advantage (i.e. voluntary managed Medicare) plans.

\section{The Medicaid Program}

The Medicaid program was created in 1965 and since that time has provided health insurance for an increasing number of low-income Americans. By 2018, the monthly enrollment for Medicaid was 73 million individuals and the annual total spending was $\$ 597$ billion (CMS, 2019).

While required to comply with federal guidelines and jointly funded by the federal government, each state administers Medicaid independently and has a considerable degree of autonomy in terms of eligibility requirements, service provision, delivery networks, and payment schemes. Meanwhile, even within each state, Medicaid covers a population with a wide array of health conditions and care 
intensity, resulting in a highly skewed cost distribution. ${ }^{9}$ This results in marked heterogeneity in Medicaid's operations both across and within states.

\section{A. Medicaid Managed Care}

Increasingly confronted with the challenge of rising and unpredictable costs as well as fragmented care delivery systems, states have been shifting enrollees from the traditional fee-forservice (FFS) system to Medicaid managed care (MMC) plans since the early 1990s. Prior to the implementation of the ACA in 2014, the share of Medicaid recipients enrolled in MMCs rose from 10.6 percent in 1991 to 55.6 percent in 1999 and 73.5 percent in 2013. Accordingly, payment to MMC plans as a share of total Medicaid expenditures also rose steadily from 11.0 percent in 1999 to 30.1 percent in 2013 (Duggan and Hayford 2013; CMS 1999; CMS 2014; CMS 2015). Following the expansion of Medicaid under the Affordable Care Act, the scope of managed care grew as these programs covered both the majority of newly eligible Medicaid recipients as well as wider groups of existing Medicaid enrollees with more complicated needs and health conditions. As can be seen in Figures 1(a) and 1(b), by 2016 approximately 80 percent of Medicaid beneficiaries were enrolled in managed care, and payments to managed care plans accounted for 45 percent of total Medicaid expenditures.

MMC changes the economic incentives within this social insurance program. Instead of directly reimbursing providers for all services provided to Medicaid recipients, under MMC states contract with insurance plans and pay a fixed (usually risk-adjusted) capitation amount for each covered Medicaid enrollee. The various MMC plans then manage the purchase of healthcare goods and services for their enrollees and bear the marginal cost of each service. The goal is to give private

\footnotetext{
${ }^{9}$ For example, in fiscal year 2014 the average spending per recipient (including both full and partial benefit) was $\$ 13,063$ for seniors and $\$ 16,859$ for people with disabilities, but only $\$ 2,577$ for children and $\$ 3,278$ for adults. In other words, even though seniors $(\sim 7.4$ million enrollees) and people with disabilities ( 11.1 million enrollees) account for around $23 \%$ of total Medicaid recipients, they cost roughly $61 \%$ of total expenditure due to the complexity and severity of their health conditions (Kaiser Family Foundation 2014a; Kaiser Family Foundation 2014b).
} 
payers stronger incentives to eliminate unnecessary services, increase efficiency, and improve the coordination of care among different providers within the same network. However, the impacts of managed care are still largely unclear on the fronts of both access and quality improvement and actual cost saving.

From the perspective of care quality and coordination, $\mathrm{MMC}$ is inevitably subject to the problem of incomplete contracting that affects many other government procurement programs. The more complicated the health condition of enrollees, the more challenging it is for the government to write a complete contract with the managed care organizations. Having a government agency administer these programs directly does not solve the incomplete contracting problem for complex patients. It does, however, decrease the incentives to cut costs in ways that could cause adverse consequences for the sickest patients. This could tilt the optimal decision in favor of the government run fee-for-service program for especially vulnerable populations where there are greater concerns about adverse health consequences (Hart, Shleifer, Vishny, 1997).

\section{I.B. Existing Evidence on Medicaid Managed Care}

The initial MMC programs requiring enrollment only for healthier populations has produced a substantial literature examining a variety of outcomes. Some studies find no significant impacts of MMC on the health outcomes of newborns (Duggan 2004; Lee 2020), while others have found evidence for both worse health outcomes likely due to reduced quality of prenatal care (Aizer, Currie, \& Moretti, 2007) and risk selection arguably through differential quality of services (Currie and Fahr 2005; Kuziemko, Meckel and Rossin-Slater 2018).

Given that most states did not require seniors or disabled individuals to enroll in MMC, these initial studies are unable to examine whether these programs have different effects for these more complicated patient populations. That said, there have been many papers examining the impact of 
Medicare Advantage (MA) plans on care utilization and health outcomes. ${ }^{10} \mathrm{MA}$ is the voluntary managed care program for Medicare, which covers virtually all seniors in the U.S. This may lead some to believe that estimates from the MA literature can provide insight into the likely effect of requiring MMC enrollment for older and sicker Medicaid beneficiaries. Before extrapolating from the MA literature, however, it is important to recognize the substantial differences between these markets in terms of the competitive structure and underlying regulations. At a minimum, MA is a voluntary program, where both the decision to take part in managed care and the selection of the plan is made by the individual. There is existing evidence that those signing up for coverage are healthier on average than those that remain in the traditional FFS Medicare program (Brown et al, 2014; Geruso \& Layton, 2020).

In many ways, this makes MA more similar to the initial MMC programs requiring younger and healthier enrollees to enroll but giving aged and disabled beneficiaries the option to do so. Therefore, our paper complements existing studies of MA by providing insights into the impacts of managed care for the less healthy seniors and persons with disabilities who opted to remain in Medicaid FFS. This may be particularly important as there are policy discussions about a wider use of MA style plans through premium support or other programs (Chandra \& Garthwaite, 2019). Such policies would force all Medicare enrollees into managed care without clear evidence of the likely impact on the sickest beneficiaries.

\section{California's Medicaid Managed Care Reform}

Created in 1966, the Medicaid program in California (aka Medi-Cal) provides health insurance coverage to low-income families, children, pregnant women, and persons with disabilities. By 2016,

${ }^{10}$ For example, exploiting MA plan exits in New York counties, Duggan, Gruber and Vabson (2018) show that MA plans are associated with a significant reduction in utilization by limiting access to nearby hospitals and reducing elective admissions. However, these authors find no evidence of increased quality or improved health outcomes from this change in utilization. Analyzing Medicare claims data, Curto, et al. (2019) find evidence consistent with MA plans encouraging substitution into less expensive care, though traditional Medicare and MA plans have similar level of spending per encounter/hospital admission. 
after decades of reforms and expansions, Medi-Cal had become the state's largest health care purchaser and offered health insurance for more than 13 million individuals (roughly 1 out of every 3 Californians), costing more than $\$ 83$ billion in total government expenditures (CMS 2018a; CMS 2018b).

Currently, all 58 counties in California offer MMC plans and all but one (San Benito County) has mandated either certain groups or all Medicaid beneficiaries enroll in these plans. The types of MMC plans adopted and characteristics of the mandates differ substantially across different counties in California and over time. By July 2016, there were 6 different models of MMC plans covering more than 10.6 million individuals in California, roughly 77 percent of all (nearly 14 million) Medicaid beneficiaries and 50 percent of all Medicaid expenditures (CMS 2018a; CMS 2018b).

MMC was first mandated in California in 1983 with the introduction of a County Organized Health System (COHS) in Santa Barbara County. By 2012, 14 counties had adopted COHS Medicaid managed care plans where all Medicaid recipients (including seniors and persons with disabilities) were mandated to enroll in the single MMC plan administered by the county (with few exceptions such as undocumented immigrants). In these COHS counties there is no competition, i.e. enrollees have only one plan choice. ${ }^{11}$ In the additional 16 counties that serve as the focus of our study, competition among MMC plans existed and the SPD population was not previously mandated to enroll in these plans. ${ }^{12}$ As of 2012, an estimated 140,000 SPD beneficiaries in these counties had voluntarily opted into these MMC plans (Harbage \& King, 2012).

In 14 of these 16 counties with competition, the market consisted of only two plans: (1) a "local initiative" plan that was organized by the county and focused on maintaining access to safety

\footnotetext{
11 In 2013, MMC was expanded into rural counties where 8 counties adopted COHS model, 18 counties adopted regional model, and Imperial and San Benito counties each adopted their own model. In the regional and Imperial model, the government contracts with two commercial plans and mandates MMC enrollment for a subset of Medicaid beneficiaries. In the San Benito model, MMC enrollment is voluntary for all individuals.

12 Our sample is composed of counties that implemented the Bridge to Reform mandate and had no other concurrent MMC-related reforms during our analysis period.
} 
net providers and (2) a commercial plan. While the local initiative plan was organized by the county, in some of the counties these services were administered by a commercial entity. Sacramento and San Diego implemented a Geographical Managed Care (GMC) model, in which Medicaid managed care enrollees could choose among several commercial plans contracting with the government and competing for enrollees.

The policy change that we study in this paper is the 2010 SPD Medicaid Managed Care mandate for Two Plan and GMC counties. ${ }^{13}$ This policy was intended to reduce costs as well as improve care coordination. It was implemented between June 2011 and May 2012 according to the month of birth for the affected individual (Harbage \& King, 2012). For example, all Medicaid recipients born in July were transferred to MMC plans in July 2011, and all those born in January were transferred in January 2012. ${ }^{14}$ Those born in the month of May were the first ones required to enroll and those born in April were shifted last.

The government sent out plan information and enrollment instructions three months before the designated transfer month for each Medicaid enrollee according to her birth month and conducted extensive outreach programs to ensure timely and effective implementation. ${ }^{15}$ Figure 2 shows the variation in MMC discharges in our sample based on birth month and demonstrates the impact of this staggered enrollment process on actual enrollment.

\footnotetext{
13 This policy was part of the Bridge to Reform (BTR) Section 1115 Waiver that started California's transition into the full implementation of the Affordable Care Act, the policy mandates all SPD Medicaid recipients (except for dual eligibles, children in foster care, and beneficiaries in long term care) in the affected counties to enroll in managed care plans.

${ }^{14}$ Note that in our data individuals born in May appear to be the first group to move into MMC (as early as May 2011), though by policy documentation they should have been the last group to switch. In our empirical analysis we follow the policy adoption pattern observed in the data to construct policy change indicators, rather than the government documentations.

${ }_{15}$ Enrollees who failed to sign up for MMC plans on their own were automatically signed up in default plans. Approximately 40 percent of affected beneficiaries actively chose a plan. Among those not making an active selection, the state attempted to match them to a plan based on their previous use of medical services. Initially, the majority of those not selecting a plan were assigned to a random default plan. However, over time the state was able to better match beneficiaries based on past providers and as a result a smaller fraction were randomly allocated to a plan and provider network (Harbage \& King, 2012).
} 


\section{Data}

Our main data sources are the official records of all hospital patient discharges and emergency room (ED) visits in California from 2008 until 2013. Each year, there are approximately 4 million hospital discharges and 10 million ED visits (excluding those transferred to inpatient care and instead captured by the hospital patient discharge data). For each discharge and ED visit, we observe detailed information on the demographics of the patient, main source of payment, diagnoses and procedures, along with admission and disposition routes. Additionally, for the patient discharge data, we also observe charges and enrollment status in MMC. ${ }^{16}$ Importantly, both datasets contain (encrypted) social security numbers of the patients, which enables us to link the two datasets together and to track each individual over time. This includes the ability to track patients across payers over time. Therefore, if a patient moves into Medicare (e.g. through eligibility under the Social Security Disability Insurance Program) or into commercial health insurance coverage, she would still be present and accounted for in our data. ${ }^{17}$

We augment the patient discharge data (PDD) with official California death records from 2009 until 2013. For all individuals with a hospital discharge between 2009 and 2013 and who have died by the end of 2013 (either in hospital or after discharge), we link their death record to our inpatient utilization data through the encrypted social security number. As a result, our sample for the mortality analysis only includes individuals who had at least one inpatient stay (either before or after the reform). ${ }^{18}$ These linked death files enable us to construct a sample of panel data that tracks healthcare utilization for each patient over time that correctly accounts for the lack of observed utilization after

\footnotetext{
${ }^{16}$ Note that managed care indicator is only available in hospital discharge data. Thus in ER records we cannot tell apart MMC and Medicaid fee-for-service. Additionally, it appears that some discharge and especially ER visits paid by MMC may have been miscoded as "private" in the datasets, and thus may explain why we observe first-stage effect of the mandate on private payers as well.

17 Table 1 shows that, while no one in the analysis sample had any Medicare covered hospital discharge in 2009Q2-2010Q1, by the end of 2013, around 14 percent of hospital discharges in treatment counties (19 percent in COHS counties) have Medicare as the main payer. ${ }^{18}$ We run a robustness check of the mortality analysis limiting to just those with an inpatient stay prior to reform. The main results are qualitatively similar, though more transitory with the more restrictive sample. We also find smaller differences between the high vs. low baseline utilizers, likely driven by the smaller differences in baseline health condition when compared with the larger sample.
} 
death. It also allows us to estimate the mortality effects of mandating MMC enrollment for the SPD population of beneficiaries. Having complete death records (rather than solely claims data) is critical for our analysis since approximately two-thirds of the deaths among individuals in our sample occur outside of the hospital.

Our main analysis sample is a person-quarter level linked panel data set of hospital discharges, ED visits, and mortality for the individuals most likely affected by the SPD mandate. In order to determine initial insurance status, we restrict our sample to individuals who ever had one or more hospital discharges or ED visits covered by Medicaid (and no discharge or ED visit covered by Medicare $\left.^{19}\right)$ between the second quarter of 2009 and the first quarter of 2010. We also restrict our sample to those who were born before 1969 to focus on the older individuals most likely affected by the policy change and to individuals who were born after 1950 to ensure that all individuals are below age 65 (to avoid the transition via aging to Medicare) in our sample period. Some individuals in our sample do transition into Medicare because of enrollment in the Social Security Disability Insurance (SSDI) program. Importantly our data still allows us to capture the health care use of these "dually eligible" (for both Medicare and Medicaid) individuals.

To further restrict our sample to those most likely affected by the reform, we exclude several groups from the data. The largest excluded group includes all birth or pregnancy related discharges, a category of beneficiaries which is discussed extensively in the existing literature and were largely unaffected by the reform. ${ }^{20}$ To minimize the confounding effects of concurrent policy changes, most notably the implementation of the ACA since January 2014, we restrict the analysis period to April 2009 until December 2013, and restrict residence to Two-Plan, GMC, and COHS counties that had

\footnotetext{
19 To reduce confound from Medicare policies, especially since dual-eligible beneficiaries are exempt from the mandate.

${ }^{20}$ We also drop observations with missing social security number and those with multiple birth dates associated with the same social security number to improve accuracy and comparability with the analysis sample. We also winsorize length of stay at 365 days in the hospital discharge data since stays longer than 365 days are very likely to be errors. The constructions of working samples are identical for PDD and ED, except that the restriction on length of stay is not applicable to the ER visits.
} 
no other concurrent changes in MMC policies. ${ }^{21}$ After merging the PDD and ED data, we drop individuals with disagreeing birth dates. We then drop person-quarter level observations after the recorded death, after dropping individuals with erroneous death records (e.g. individuals with multiple death records or with observed discharge and ED visit after recorded death, which occurs for less than 0.03 percent of our observations).

Each person-quarter cell contains information on individual characteristics (age, gender, county of residence) and healthcare utilization (total number of hospital discharges by payer, total number of ER visits by payer, total length of stay, and number of procedures associated with hospital discharges). We then construct policy change indicators based on individual birth month, county of residence, ${ }^{22}$ and quarter of observation. Table 1 contains descriptive statistics for our sample. Panel A contains data for only individuals living in treatment countries while Panel B contains data on those living in COHS counties. Overall, our final sample begins with 132,635 patients and declines over time to 128,245 with individuals exiting our sample as they die. ${ }^{23}$

An important consideration caused by our selection criteria is that individuals enter our sample only if they have an inpatient hospital or ER visit between the second quarter of 2009 and the first quarter of 2010. As would be expected, these individuals exhibit some degree of mean reversion. This can be seen in the relatively large decline in utilization between the sample selection and the prereform time periods detailed in Table 1 . For three reasons this is unlikely to cause economically

\footnotetext{
${ }^{21}$ In the 16 Two-Plan and GMC counties that implemented the mandate, 3 counties (Fresno, Madera, and Kings) are excluded from the analysis sample since they formed Regional Two-Plan model in March 2011. In the 14 COHS counties that implemented MMC before 2012, 5 counties (Ventura, Sonoma, Merced, Marin, and Mendocino) are excluded from the analysis sample since they adopted COHS MMC in 2009-2011. Hence the treatment counties in our analysis sample include: Los Angeles, San Diego, Riverside, San Bernardino, Santa Clara, Alameda, Sacramento, Contra Costa, Kern, San Francisco, San Joaquin, Stanislaus, and Tulare. The COHS control counties in our analysis sample include: Orange, San Mateo, Santa Barbara, Solano, Monterey, San Luis Obispo, Santa Cruz, Yolo, and Napa. In our raw hospital discharge data, $86 \%$ of observations are for residents in these counties in 2009Q2-2013Q4 (similar ratio when restricting to those with Medicaid as primary payer). In our raw ER visit data, $84 \%$ of observations are for residents in these counties in 2009Q2-2013Q4 (80\% when restricting to those with Medicaid as primary payer).

${ }^{2}$ Note that there are around 5\% individuals in the PDD analysis sample and 10\% individuals in the ED analysis sample who have been observed in multiple counties. We drop all individuals who have been observed in more than one county throughout our analysis period.

23 One limitation of our data is that we do not know if an individual moved out of state.
} 
meaningful problems for our analysis. First, we exploit the staggered enrollment of individuals into MMC based on their month of birth. Since mean reversion is occurring for all members of the sample and should be unrelated to birth month, this plausibly exogenous variation should limit any bias. Second, similar mean reversion is happening in the COHS county sample in Panel B - which serves as an additional control in our second set of specifications. To the extent we were concerned about a relationship between birth month and the timing of mean reversion, this additional control group should help to address that issue. Finally, in our empirical analyses, we do not use data from the sample selection period, so the higher utilization during that time period does not directly affect our estimation. In particular, the baseline utilization of medical services that we use to interpret the magnitude of our coefficients is based on the pre-reform and not the sample selection period in Table 1.

\section{Demographics of the Seniors and Persons with Disabilities Fee-for-Service Population}

The primary contribution of our paper is estimating heterogeneity in the effect of privatization based on patient health. In particular, we are interested in whether there are adverse consequences for the sicker and more vulnerable populations originally exempted from mandatory MMC enrollment. We begin by demonstrating that those affected by the reform were in fact meaningfully different from California's original MMC enrollees on many dimensions that may influence the effect of contracting out the coordination and financing of care to private insurers.

Prior to the reform studied in this paper, SPD beneficiaries in reform counties were not required to enroll in MMC. While approximately 140,000 beneficiaries did voluntarily enroll, an additional 240,000 remained in FFS (Harbage and King, 2012). Our treatment group is comprised of these FFS enrollees. Table 2 contains data on three groups of enrollees: beneficiaries in MMC before 
and after the reform, those switching from FFS to MMC because of the reform, and those who remained in FFS before and after the reform. ${ }^{24}$

Table 2 documents that individuals moving from FFS to MMC were meaningfully older than those already enrolled in MMC. We then examine measures of health status including the average length of stay in the hospital and total hospital charges (which provide an approximate measure of the intensive margin of the use of hospital services). Overall, individuals who moved from FFS to MMC had longer lengths of stay and greater hospital charges on average prior to the reform than those who were already in MMC.

\section{Econometric Strategy}

In order to estimate the causal effect of enrollment in managed care on healthcare utilization and health outcomes, we exploit two main sources of variation in the implementation of California's program. Our main specification is a differences-in-differences analysis that leverages the fact that individuals were mandated to enroll in MMC based on their birth month. Specifically, we estimate:

$$
y_{i t}=\beta_{0}+\beta_{1} \text { mandate }_{i t}+\gamma_{t}+\alpha_{i}+\varepsilon_{i t}
$$

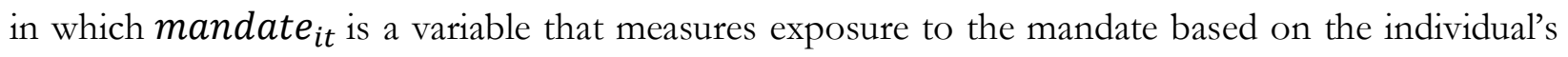
birth month and quarter of observation, $\gamma_{t}$ are quarter fixed effects, $\alpha_{i}$ are individual fixed effects, and $\varepsilon_{i t}$ is an idiosyncratic error term. Standard errors are clustered at the individual level. The variable mandate $_{i t}$ codes whether individuals are affected by the mandate given their birth month and the current year-quarter. ${ }^{25}$

\footnotetext{
${ }^{24}$ The mandate allows some groups such as dual-eligibles (i.e. individuals eligible for both Medicare and Medicaid) and those in longterm care to remain in FFS.

25 This mandate $_{i t}$ variable is coded as either $0,1 / 3,2 / 3$ or 1 based on what fraction of the quarter of observation an individual was exposed to an MMC mandate. For example, an individual born in August was required to enroll in August of 2011. For those individuals, during the third quarter of 2011 mandate $_{i t}$ is coded as 2/3 reflecting the individual was required to enroll in MMC for 2 of the 3 months of that quarter. Similarly, an individual born in September would be coded as $1 / 3$ during that quarter. In each subsequent

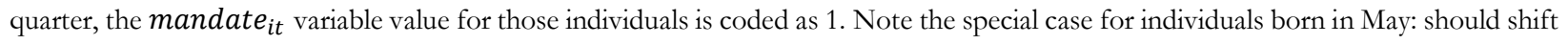


When considering the outcome of mortality, we are obviously unable to include individual fixed effects. Therefore, our mortality analysis involves the following steps. First, we exclude individuals without any hospital discharges between the second quarter of 2009 and the fourth quarter of 2013 from the analysis sample, since we can only track deaths outside hospitals for those with discharge records. We then run linear regressions of our death indicator variable on mandate indicator(s), county FEs, quarter FEs, age FEs, and gender indicator with standard errors clustered at the county level.

Our main identifying assumption is that the timing of MMC enrollment is orthogonal to other factors that might affect an enrollee's utilization of healthcare services and health outcomes. This assumption is reasonable since enrollment is based on the calendar month of birth across all ages. Of course, there could still be two concerns about identifying the effect of MMC in this way. The first is that there is an underlying relationship between month of birth and the use of healthcare services. While we are unaware of any such factor, we attempt to address this concern by estimating eventstudy specifications that allow us to examine the time path of outcomes before and after the reforminduced shift to managed care. This allows us to more clearly examine both the pre-trends in our outcomes of interest and the time path of the estimated changes after mandatory enrollment. Specifically, we estimate the following specification:

$$
y_{i t}=\sum_{r \leq-3}^{r \geq 4} \theta_{r} \mathbb{I}\left(t=\text { mandate quarter } r_{i t}+r\right)+\gamma_{t}+\alpha_{i}+\epsilon_{i t}
$$

We include a full set of pre (up to 3 quarters prior to) and post (up to 4 quarters post) mandate indicator variables (with the quarter before indicator excluded) for each individual that depends on

to MMC in May 2012 but shown to have shifted to MMC in May 2011; coding the mandate indicator according to the data pattern for the beneficiaries born in May. 
his/her birth month, county of residence, and the quarter observed. ${ }^{26,27}$ When considering the outcome of mortality, we estimate a specification of equation (2) that is modified in the same manner as our discussion of equation (1) above.

There could also be a second concern about broader changes in the provision of healthcare services that occur at the same time as the mandate. These could include changes in the supply of healthcare in response to the reform that could occur for all enrollees regardless of their birth month. To address this concern, we estimate a second specification in which we include data from enrollees that live in the COHS counties. These individuals were enrolled in MMC programs prior to the reform and therefore their experiences can control for these secular trends. For these individuals, mandate $_{i t}$ is always coded as zero as they are unaffected by the mandate.

Furthermore, in light of the recent and growing literature on potential concerns with common two-way fixed effects difference-in-differences analyses, we run additional robustness checks using stacked event study (Goodman-Bacon 2020; Callaway and Sant'Anna 2020; Sun and Abraham 2020; Baker et al 2021). These specifications are similar to those in Cengiz et al 2019; Deshpande and Li 2019). We provide more detail on these robustness checks in Appendix A. In nearly all cases, the results from these exercises concur with our main estimates. Where there are meaningful differences that would impact the interpretation of our main estimates (e.g. when examining heterogeneity in the effect on mortality based on health status defined using prior utilization) we discuss those differences in more detail.

\footnotetext{
${ }^{26}$ Note that in the event study specification without COHS control groups, we only include indicator for T-3 instead of T-3+ to address the collinearity concern of time FE, relative time FE, and individual FE.

${ }^{27}$ Note that the indicator for quarter of mandate implementation $(\mathrm{r}=0)$ is scaled by the fraction of the quarter $(1 / 3,2 / 3$, or 1$)$ exposed to an MMC mandate. For example, for an individual in the treatment group born in August, T-3+ indicator is coded as 1 in 2010Q2, 2010Q3, and 2010Q4 and 0 in all other quarters27, T-2 indicator is coded as 1 in 2011Q1 and 0 in all other quarters, T-1 indicator is coded as 1 in 2011Q2 (but excluded in actual regression with coefficient normalized to 0 ), $\mathrm{T}$ indicator is coded as 2/3 in 2011Q3, T+1 indicator is coded as 1 in 2011Q4, T+2 indicator is coded as 1 in 2012Q1, T+3 indicator is coded as 1 in 2012Q2, and T+4+ indicator is coded as 1 in 2012Q3 - 2013Q4.
} 
Our primary outcomes of interest are inpatient hospitalizations, ED Visits, and mortality. For inpatient hospitalizations, we are interested in both the total number of visits and the source of admission. For mortality, we have a person-quarter level indicator for mortality (both in and out of the hospital) and we drop all observations for individuals after their death.

As discussed above, we use data from the second quarter of 2009 through the first quarter of 2010 to select our sample and to construct the baseline characteristics for our heterogeneity analysis. We then estimate the effect of mandatory MMC enrollment using data from the second quarter of 2010 through the fourth quarter of 2013 (i.e. we do not use data from the sample selection period in our analysis). This allows us to have a meaningful length of time after the reform while avoiding the primary impact of the 2014 ACA insurance expansions, which could have effects on both the operation of Medi-Cal but also on the operations of providers. Starting the analysis period in the second quarter of 2010 also limits the impact of mean reversion from our sample selection process.

Given our interest in heterogeneity in the effect of MMC, we then estimate models that allow the effect of the mandate to vary based on the beneficiary's health status. We measure health status based on the pre-reform health of individuals. We begin by classifying individuals based on their prereform use of healthcare services. Specifically, we group patients based on whether they had an above or below median number of inpatient hospitalizations and ER visits from the second quarter of 2009 to the first quarter of 2010. Our second measure of health status is based on an enrollee's underlying condition. This is measured using an Elixhauser score which is a count of the chronic conditions that are indicated by a patient's principal diagnosis or co-diagnosis in either the inpatient discharge data or the ED visit data. ${ }^{28}$

\footnotetext{
${ }_{28}$ These Elixhauser scores are unweighted, i.e. all conditions count equally to the score. An alternative measure of sickness would by a Charlson Comorbidity Index, which weights conditions based on their contribution to an individual's ten-year mortality. Appendix Tables A10 and A11 replicated our Elixhauser score results using the Charlson index as the measure of morbidity. These results are remarkably similar to our main estimates.
} 
Finally, we examine the effect of market structure on our outcomes by estimating models that allow the effect to vary based on whether enrollees are in markets with a large local initiative plan (i.e. a two-plan county) or in a market with a large number of private commercial competitors (i.e. a GMC county).

\section{The Effect of Medicaid Managed Care on the Use of Healthcare Services}

We begin by looking at the effect of the reform on MMC enrollment. After confirming that the reform suddenly shifted a large portion of our sample from FFS to MMC, in section VI.B we estimate the change in the use of hospital services for those who moved into MMC and in VI.C we examine heterogeneity in the magnitude of these changes. In Section VI.D we examine the mortality effects of mandatory enrollment in MMC and then in VI.E we estimate whether our estimates vary based on the structure of the Medicaid managed care market.

\section{VI.A. Effect of Reform on the Share of SPD Patients Enrolled in MMC}

Our analysis hinges on the assumption that the requirement that SPD beneficiaries in the reform counties enroll in MMC based on their birth month beginning in June 2011 actually impacted the insurance status of the patients in our sample. Panel A of Figure 3 shows the share of total discharges $^{29}$ in reform counties covered by Medicaid MMC and FFS over time. Prior to June 2011, MMC discharges are largely stable at approximately 5 percent of all discharges. Similarly, FFS discharges were a relatively flat 14 percent of total discharges. Beginning in June 2011, the share of MMC swiftly increases over the next year until it stabilizes at approximately 10 percent of all hospital discharges. Over the same time period, the FFS discharge share declines until it stabilizes at approximately 10 percent of all discharges.

\footnotetext{
${ }^{29}$ Including discharges for all ages (i.e., not just the cohorts included in our analysis sample).
} 
Panel B of Figure 3 shows the share of MMC discharges by age cohort. As would be expected, the pre-existing carve-out for older and disabled Medicaid recipients caused the share of pre-reform discharges covered by MMC to be decreasing in age. For example, in January 2011 the share of MMC discharges was approximately 4\% for the cohort born 1950-1955 and 9\% for the cohort born between 1971 and 1985. However, after the reform there was far less variation in the enrollment share by beneficiary age - with the gap in discharges between the oldest and youngest cohort shrinking from 5 to just -0.2 percentage points in January 2013.

Table 3 contains our estimated effects of the change in MMC discharges in our sample caused by the reform. Panel A displays estimates from our main specification. The first two columns contain estimates from the hospital inpatient discharge data and the data are intended to directly measure MMC status, albeit with some degree of measurement error. The first column confirms the mandate increased the number of discharges in the sample covered by the Medicaid MMC system. As a result of the reform, there was an increase of 0.023 discharges per person/quarter covered by MMC. The second column shows a corresponding decrease of 0.026 in the number of per person/quarter discharges covered by Medicaid FFS. These changes are similar in magnitude, which demonstrates that the reform largely moved people from FFS to MMC. As shown in the third column, we also find a modest increase in the number of privately insured hospital discharges, which could reflect classification errors if hospital officials mistakenly code some commercial MMC patients as privately insured. ${ }^{30}$

Figure 4(a) contains the event study estimates for our main specification that leverages only the month of birth of the beneficiary. Coefficients prior to the mandate are generally flat and close to zero - supporting our identifying assumptions. After the mandate, there is a swift increase in MMC enrollment and a decline in the number of discharges in our sample covered by the FFS system.

${ }^{30}$ It could also conceivably represent individuals moving from Medicaid into private insurance as a result of the mandate. 
Our second specification relies on COHS counties serving as an additional control group. Figure 5(a) shows the share of MMC discharges across different county groups. Prior to the reform, all counties have a broadly flat trend. Beginning in June 2011, the share of MMC escalates quickly in the reform counties and remains high in the COHS counties. After the reform is fully implemented, the share of discharges in reform counties is flat. In the COHS counties there is a modest one-time decline in the share of $\mathrm{MMC}$, which is otherwise stable during our study period. Figure 5(b) contains the share of Medicaid visits that are covered by MMC. Starting shortly after the reform there is a discrete drop in this share. We are unaware of any reason for this one-time change but note that it does happen in all COHS counties.

Panel B of Table 3 contains estimates of the change in insurance states for discharges from our second specification that includes beneficiaries in the COHS counties as an additional control group. Broadly speaking, these estimates are quite similar to those in Panel A of the same Table. For inpatient discharges, we estimate that the mandate substantially increased the number of discharges covered by MMC. This is accompanied by a similarly large decline in the number of Medicaid FFS discharges (and increase in privately insured discharges) - which would be expected given our policy reform. Similarly, Figure 4(b) contains the event study coefficients for the change in insurance status for this specification. These are largely similar to those in Panel A.

As the fifth column of this same table shows, there is a substantial decline in the number of Medicaid FFS visits to the emergency department. As discussed above, in contrast to the hospital discharge data, MMC ED visits are apparently coded as "private" in the ED data. The sixth column shows an even larger increase in this measure.

\section{VI.B Effect of Medicaid Managed Care on the Use of Hospital Services}

We next examine the impact of mandatory MMC enrollment on the use of hospital services. Panel A of Table 4 contains our primary estimates of the impact of this shift in insurance coverage 
using only variation in the birth month for beneficiaries in the reform counties. As shown in the second column of Table 4, we do not find that MMC enrollment changed the overall number of inpatient discharges. We do, however, find that it caused a 2.4 percent increase in the number of ED visits compared to what would have occurred if the SPD beneficiaries had remained in the FFS system. Panel B contains the estimates for our specification that also uses beneficiaries in COHS counties as a set of controls for changes in the provision of medical care in the absence of the reform. For this specification, the pattern of estimates is largely the same.

Figures 6(a) and 6(b) contain the event study estimates of the change in ED use for both specifications. In both figures, the pre-trends prior to the mandate are relatively flat and close to zero. This provides support for our identifying assumption that the imposition of the reform was unrelated to trends in the pre-reform use of the ED. For both specifications, the increase in ED visits occurs in the quarter immediately after an individual's birth month required them to enroll in MMC.

For our main specification, the pattern of estimates suggests the increase in ED visits is largely transitory as the estimated effect is trending back towards zero over time. This could be evidence that the change in ED visits is temporary and is perhaps the result of individuals moving into new and more restrictive insurance networks for the first time. However, the specification using COHS counties as a comparison group shows a more persistent increase in the use of the ED because of enrollment in MMC. This suggests some of the transitory nature of the change in ED visits in the main specification may be the result of the either: (1) the lack of a comparison group in the first specification to control for the evolution of healthcare services after the reform is fully implemented; or (2) the fact our earliest treated observations are effectively in the control group for later observations (particularly for the specification without COHS counties). To address the second concern, Appendix Figure A1(a) contains results from the stacked event study - as specification that 
should not be impacted by the staggered nature of adoption. These estimates demonstrate a far less transitory effect on the use of the ED for individuals who are moved into MMC.

To further understand the nature of the increase in $\mathrm{ED}$ visits we also examine the underlying reason for the visit. An increase in the ED could reflect many things. First, the visits could reflect a difficulty in receiving non-emergent medical services in an outpatient setting or physician's office. Second, it could reflect poor primary care management resulting in emergency services that should have been avoidable. Finally, it could reflect certain types of medical services that may be difficult to access in a more restricted network. In Appendix Table $\mathrm{A} 1^{31}$ we find evidence that suggests the increase in ED visits reflects all of these channels. Across both specifications we find an increase in visits that required the ED but were preventable, were non-emergent and were for psychiatric conditions. ${ }^{32}$ Taken together, this analysis of visit types suggests that at least part of the increase in ED visits is the result of reduced access to healthcare services outside of the hospital.

We also find that MMC enrollment is associated with a large and statistically significant increase in the number of inpatient admissions that began as transfers from other hospitals. Figure 7(a) suggests that this increase is largely transitory. However, similar to the results pertaining to ED visits above, the stacked event study in Appendix Figure A1(b) provides evidence that the effect is more persistent. In considering a potential mechanism for these transfers, we note that many of these transfers could have begun in the emergency room of the initial hospital. If that hospital were out of network for the private MMC plan the patient would be transferred to an in-network hospital after being stabilized for their inpatient admission. Supporting this point, Appendix Table A2 contains estimates based on the initial hospital admission that demonstrates that most of these transfers are

\footnotetext{
31 We classify the types of ED visits according to the ICD-9 code groups developed by the NYU Center for Health and Public Service Research (https://wagner.nyu.edu/faculty/billings/nyued-background).

32 In our specification that includes COHS counties we also found an increase in visits for conditions that were non-preventable and emergent, however we did not find evidence of this in our main specification.
} 
actually from individuals that entered the hospital through the ED of the transferring hospital. ${ }^{33}$ In this way these estimates provide evidence of some both an increased use of the ED and the role of hospital networks in the implementation of MMC.

Looking at other types of hospital visits, we find little evidence of other changes in the use of the inpatient hospital or the ED. For example, we estimate negative but not statistically significant coefficients for non-transfer non-ED hospitalizations and scheduled hospitalizations. If MMC firms were expending efforts to reduce "unnecessary" hospitalizations, these are categories of visits where we might expect to see a reduction. This provides some evidence of the limits in how much of a change in the use of hospital services the MMC firms achieved in the SPD population. We also find no evidence that the shift to MMC increased the number of inpatient visits admitted from each hospital's own ED.

It is possible that rather than decreasing the quantity of visits, MMC firms implement selective networks to steer patients to lower price or higher value facilities. To examine this possibility, we next examine changes in discharges at various types of hospitals. These estimates are contained in Appendix Table A3 and Appendix Figures A2 - A9. We observe an increase in discharges at for-profit hospitals and a decline in discharges at non-profit and government hospitals, which may reflect the characteristics of providers in the MMC networks. While we observe an increase in ED visits at most types of facilities, the increase in most pronounced at non-profit and government hospitals. We also see a decline in discharges from teaching hospitals. Given that these hospitals tend to be more expensive, these estimates are indicative of cost-reducing measures of the MMC plans. That said, we do not find precise estimates across both specifications.

\footnotetext{
33 We can identify the original admission for approximately 60 percent of the transfers.
} 


\section{VI.C Effect of Medicaid Managed Care on Mortality}

If the increase in ED visits and hospital transfers simply represents a learning or transaction cost for new MMC enrollees, it might not be particularly concerning. After all, every policy has some degree of transition cost during implementation. However, particularly sick individuals could suffer meaningful adverse health consequences from even relatively minor disruptions in access to care (Buchmueller, Jacobson and Wold 2006; Baum et al. 2019). Notably, this includes difficulty in accessing not just the hospital visits we observe but also primary care physicians, specialists, and other non-ED outpatient facilities that would also be affected by a more restrictive managed care network. In addition, MMC firms can impact the use of pharmaceuticals which could impact the health of enrollees (Layton et al. 2019).

These very concerns about differential adverse consequences drove the initial decision of California (and other states) to exempt the SPD population from mandatory MMC enrollment in the first place. Obviously, the most consequential health outcome an enrollee could experience is death, which we observe through our linked mortality files. Table 5 contains estimates of the effect of the reform on mortality. Panel A contains the estimate from our main specification, which shows that the MMC mandate increases mortality by a statistically significant 0.09 percentage points. This is a nearly 12 percent increase over baseline mortality. Panel B contains the estimate from our specification including COHS counties. This estimate suggests a slightly smaller, but still statistically significant, 11 percent increase in mortality.

Figures $8(\mathrm{a})$ and $8(\mathrm{~b})$ contain the event study coefficients for the outcome of mortality for the two specifications. Prior to the mandate, the estimated coefficients are generally small and not statistically distinguishable from zero. There are also no demonstrable pre-trends in these estimates. However, after the reform the estimates are uniformly positive and larger. While the estimates are not 
always statistically significant, the pattern of coefficients suggests our estimate of increased mortality in Table 5 is not simply a statistical artifact.

To further investigate whether the estimated mortality increase is caused by mandating MMC enrollment, we next present a series of exercises intended to explore both the robustness and the plausibility of our estimates. First, Appendix Figure A10 includes the stacked event study specification for mortality. The pattern and magnitude of estimates is largely similar to those from our main specification - supporting the finding that transitioning the SPD population into MMC increased mortality.

Second, we note that there could be a concern that since mortality is a relatively infrequent outcome, the linear probability model is an inappropriate choice for estimating the effect of MMC on this outcome. To address this concern, we estimated a logit model and plotted the average marginal effects in Appendix Figure A11. Reassuringly, the average marginal effects from the logit model follow an almost identical pattern as the OLS event study estimates.

Third, there could be an additional concern that our estimated mortality increase is simply reflecting an unrelated change in a particular locality rather than a widespread response to mandatory MMC enrollment. To examine this possibility, Appendix Table A4 contains the estimates from a leave one out analysis at the county level. Each coefficient in the table is the estimate from a specification that leaves out the respective county. For comparison purposes, the overall estimate is included in the first row. These estimates provide no compelling evidence that the change in mortality is a statistical artifact driven by just one county.

Finally, to examine the plausibility of our estimated mortality increase, we consider whether the mortality increases were concentrated in individuals with medical conditions where temporary disruptions in care could plausibly result in such adverse health consequences. Table 6 contains the estimated change in mortality rates for samples based on whether an individual had an inpatient 
hospital visit for a particular medical condition (defined at the level of ICD-9 codes). The estimates in this table are from our main specification (in Appendix Table A5 we provide similar estimates for the specification including beneficiaries in COHS counties).

In Panel A of Table 6, we find the largest and most consistently estimated effects for individuals suffering from circulatory conditions. These conditions include hypertension, ischemic heart disease, heart failure, and other cardiac conditions. It is plausible that for individuals suffering from these conditions even limited disruptions in care could cause an increased risk of death. For these individuals, mandatory enrollment in MMC causes an approximately 27 percent increase in mortality. The magnitude of this effect is broadly consistent across our two specifications.

In Panel A of Table 6 and Appendix Table A5 we also estimate statistically significant increases in mortality for a number of other conditions. However, the estimates for these other conditions are generally smaller and are not consistently estimated across the specifications. These estimates also include the effect of individuals with comorbidities of cardiac conditions and these other outcomes. In Panel B of Table 6 and Appendix Table A5, we provide estimates for these medical conditions after removing all individuals with circulatory conditions. After removing those individuals, the estimated effect for individuals with infectious and parasitic diseases is far less precisely estimated. The estimated effect for individuals with Diseases of the Blood and Blood-forming Organs is still large and consistently estimated across the specifications. These conditions make up a relatively small part of the overall sample and also are conditions where individuals could be quite medically frail and disruptions to care could have severe health consequences.

\section{VI.D Heterogeneity in the Effect of Privatization by Patient Health}

Compared to the existing literature, our estimates provide initial evidence that the consequence of privatization varies across patients. We next look for additional evidence of such heterogeneity within our sample of SPD beneficiaries, which was itself not homogenous in health status. To that 
end, we split our sample based on two measures of health status. Our first measure is based on whether an individual had an above or below median use of inpatient and ED hospital services prior to the reform. ${ }^{34}$ Our assumption is that those with a greater use of hospital services prior to the reform represent the type of sicker population that might suffer more adverse consequences from mandatory MMC enrollment. There could be a concern that the use of hospital services provides an incomplete measure of health. Therefore, our second measure of health status relies on the underlying conditions that caused individuals to seek treatment at the hospital. The severity measure is based on whether an individual had an above or below median ${ }^{35}$ number of baseline chronic conditions (the Elixhauser score), calculated from the principal and co-diagnoses of all their inpatient hospitalizations and ED visits in 2009Q2 - 2010Q1.

Table 7 contains estimates where the effect of mandatory enrollment in MMC is allowed to vary by these measures of health status. We find that the overall change in ED visits discussed above is almost entirely driven by less healthy SPD enrollees. For example, we find that the population with an above-median use of hospital services prior to the reform had a 4 percent increase in ED visits as a result of the reform. This estimate is statistically distinct from the below median utilizers, who had a change in ED visits that was negative and not statistically distinguishable from zero. This was also true for our specification including COHS counties. Moreover, Appendix Table A6 shows almost identical patterns of MMC effect heterogeneity, using the severity measure based on baseline Elixhauser scores. Figure 9 and Appendix Figure A13 contain the event study coefficients from both specifications, using the utilization measure and severity measure. These event studies provide compelling evidence of a casual effect for the sicker patients and no meaningful change in ED visits

\footnotetext{
${ }^{34}$ We classify an individual as heavy utilizer if the total number of hospital discharge and ER visits in 2009Q2 - 2010Q1 is greater than or equal to the median, which is 2 in our sample.

35 The median baseline Elixhauser score is 1 . Thus an individual is classified as high severity patient if baseline Elixhauser score is greater than or equal to 2 .
} 
for those with lower baseline utilization or severity across both specifications. Appendix Figures A12(a) and A14(a) contain the stacked event study figures for ED visits and they are largely consistent with these main estimates.

Looking at non-ED transfer hospitalizations, we also see this is primarily driven by less healthy enrollees. Similarly, in Appendix Tables A7 and A8, we see that the changes in discharges and ED visits by facility types are mainly driven by the high utilizers.

Finally, to further analyze the causal role of mandatory MMC enrollment on mortality, we next examine heterogeneity based on health status. Recall that the estimated change in ED visits and hospital transfers are concentrated among those who had either an above median use of hospital and ED services or an above median co-morbidity prior to enrollment in MMC (i.e. those who we assume are the sicker members of the sample). If the estimated mortality increase was driven by mandatory MMC enrollment, then it would be reasonable to expect this change in mortality is also driven by these potentially sicker individuals.

To examine this question, Column (2) of Table 5 contains estimates that allow the effect of MMC on mortality to vary by the pre-reform use of hospital services and the severity of medical conditions. These estimates demonstrate that the increase in mortality is driven almost entirely by patients with decreased health status. As can be seen in the event study estimates in Figures 10 and 11 , the evidence of this heterogeneity for mortality is most consistent when health status is measured by the Elixhauser score rather than by the previous utilization of medical services. The estimated effect for mortality for the low utilization sample does increase in the quarters after implementation and is eventually the same magnitude as for those with high utilization. The same is not true when health status is defined by the Elixhauser score. The same pattern is seen in the stacked event study estimates in Appendix Figures A12(b) and A14(b). This may demonstrate that utilization of medical care in 
previous years is not as good of a measure of medical frailty as a definition based on the specific conditions afflicting patients.

Overall, we find a pattern of estimates where our main mortality effects were broadly driven by the same groups that experienced changes in the use of the hospital services. This provides further evidence that the effect is caused by mandatory MMC enrollment for this population rather than another unobserved confounder. It also demonstrates the importance of considering such heterogeneity when considering the effects of MMC across different patient populations.

\section{VI.E. Heterogeneity in the Effect by Market Structure}

The results above demonstrate that the concerns about the adverse consequences of the incentives to reduce costs have some basis. However, it is also possible that a more competitive environment among MMC firms could ameliorate some of these outcomes by changing the firms' incentives. In order to examine this point, we next take advantage of the variation in the structure of California's Medicaid program.

As described above, within the reform counties in our sample there are two dominant market structures: GMC and two-plan counties. Enrollees in a two-plan county had two choices for insurers: a quasi-public local-initiative plan run by the county or a commercial plan. The majority of enrollees in these counties enrolled in the local-initiative plan - thus while they are in the MMC program they are not typically served by a private firm who is the residual claimant on the capitated payment. However, two counties were organized as GMC counties where enrollees could pick between several privately run MMC plans but did not have an option for a government run plan.

If the competition between privately run plans changes the incentives and actions of the private firms, we should observe differences in the use of hospital services by enrollees that were mandated to enroll in MMC in GMC counties compared to Two-Plan counties. Table 8 contains 
estimates of the effect of the reform where the estimates are allowed to vary by county type. Results are presented for both the use hospital services and health outcomes.

Overall, we estimate little difference in the effect by the type of Medicaid managed care. The only meaningful difference is that enrollees in GMC counties had a greater reduction in scheduled inpatient hospital services. These types of visits are a category where we might expect a managed care firm to implement utilization management techniques to decrease the use of low value care. This provides some limited evidence that market structure may affect the actions of Medicaid managed care firms - though the identifiable scope of this impact in our setting is quite small.

\section{Conclusion}

Our estimates provide new evidence about the effects of requiring more complicated patients to enroll in privately operated managed care plans. On the whole, these estimates demonstrate heterogeneity in the effects of MMC and show that the sickest patients suffer adverse consequences from the requirement to enroll in MMC. Specifically, we find that individuals who were sicker (as indicated by a higher use of hospital services while in the FFS system or by a greater disease burden) experienced an increase in the use of ED services, hospitals transfers, and mortality. We found limited evidence of an overall reduction in the use of hospital services or other indications of reduced spending from the hospital sector. This suggests states may want to exhibit caution before broadly expanding the set of patients required to enroll in MMC. It also may also cast doubt on the desirability of requiring mandatory managed care enrollment in other programs such as Medicare Advantage.

Our results demonstrate that the effects of insurance extend beyond simply the extensive margin of coverage. Changes in the form of the insurance contract can impact both the use of healthcare and mortality. In that way, this study contributes to an emerging literature about the mortality consequences of health insurance coverage. For example, both Miller et al. (2019) and Goldin, Lurie and McCubbin (2019) find that the increases in insurance coverage caused by the ACA 
decreased mortality among affected populations. Similarly, Abaluck, Bravo, Hull, and Starc (2021) estimate mortality increases across MA plans.

Our results stand in marked contrast to those of Layton et al. (2019) which also examines the question of MMC for older and sicker populations in other states. Examining managed care in Texas, these authors found MMC allowed for an increase in the use of prescription drugs and a reduction in inpatient use. The types of inpatient use where they see a reduction are visits that are likely responsive to an increased use of prescription drugs. Looking at New York they found a large reduction in the use of inpatient services. They posit that this reduction is likely the result of stinting by the private firms that are residual claimants on healthcare spending. While we find no reduction in the use of inpatient services overall, if we examine the markets where commercial firms are competing for business we do find suggestive evidence of limited declines in inpatient admissions. For some outcomes these declines are statistically significant and overall we cannot rule out fairly large declines in admissions that are either scheduled or did not begin in the ED.

Rather than viewing the difference in results across the two studies as a point of contention, we believe it demonstrates the important local nature of state Medicaid systems. Examining our results in combination with those of Layton et al. (2019) serves to reinforce the oft-stated maxim, "if you've seen one Medicaid program, you've seen one Medicaid program” (Adams, 2013). As a result, policymakers and economists should exhibit meaningful caution in attempting to generalize results across both states and types of patients.

At a minimum, the generosity and structure of the FFS program is important. For example, the largely positive effects for Texas appear to be driven by a rather stringent cap on pharmaceuticals in the FFS program - restrictions which do not exist in our setting. In addition, the lack of large negative health effects (such as the mortality effects we find) could be driven by the exclusion of 
inpatient spending in the MMC program for disabled residents in Texas, which is again not a feature of the California expansion.

We also would caution anyone from drawing any broad conclusions from our estimates about the overall welfare implications of California moving complicated patients into MMC. We show that for the most complicated patients, MMC appears to have adverse consequences in terms of both an interruption in the usual source of care and an increase in mortality. However, there were many less complicated patients that were included in the SPD population and appear to have been largely unaffected by the policy change. It is possible that there were great savings or benefits for these individuals from the move to MMC that could offset the costs to the more complicated patients. At a minimum, our results demonstrate that the potential costs of such a move are meaningful and cannot be predicted by the experiences of either younger or healthier patients in California or of similar patient populations in other states. 


\section{Bibliography}

Abaluck, J., Bravo, M., Hull, P., \& Starc, A. (2021). Mortality Effects and Choice Across Private Health Insurance Plans, forthcoming Quarterly Journal of Economics.

Adams, R. (2013, April 19). State Medicaid Officials Consider Multi-Tiered Benefits, Cost-Shareing Under Overbaul. Retrieved April 12, 2020, from The Commonwealth Fund:

https://www.commonwealthfund.org/publications/newsletter-article/state-medicaidofficials-consider-multi-tiered-benefits-cost

Aizer, A., Currie, J., \& Moretti, E. (2007, August). Does Managed Care Hurt Health? Evidence from Medicaid Mothers. The Review of Economics and Statistics, 89(3), 385-399.

Baker, A.C., Larcker D.F., \& Wang C.C.Y. (2021). How Much Should We Trust Staggered Difference-In-Difference Estimates? ECGI Working Paper Series in Finance, Working Paper N $736 / 2021$.

Baum, A., Barnett, M., Wisnivesky, J., \& Schwartz, M. (2019). Association Between a Temporary Reduction in Access to Health Care and Long-term Changes in Hypertension Control Among Veterans After a Natural Disaster. JAMA Network Open, e1915111.

Brown, J., Duggan,M., I. Kuziemko, \& W. Woolston. (2014) How Does Risk Selection Respond to Risk Adjustment? New Evidence from the Medicare Advantage Program. American Economic Review, 104(10), 3335-3364.

Buchmueller, T., Jacobson, M., \& Wold, C. (2006). How Far to the Hospital? The Effect of Hospital Closures on Access to Care. Journal of Health Economics, 740-761.

Callaway, B., \& Sant'Anna, P.H.C. (2020). Difference-in-Difference with Multiple Time Periods. Journal of Econometrics, https://doi.org/10.1016/j.jeconom.2020.12.001.

Cengiz, D., Dube, A., Lindner, A. \& Zipperer, B. (2019). The Effect of Minimum Wages on LowWage Jobs. The Quarterly Journal of Econometrics, 134(3): 1405-1454.

Chandra, A., \& Garthwaite, C. (2019). Economic Principles for Medicare Reform. The Annals of the American Academy, 63-92.

CMS. (1999). Medicaid Financial Management Report - Net Services (CMS-64) FY1999.

CMS. (2014). Medicaid Financial Management Report - Net Services (CMS-64) FY 2013.

CMS. (2015). Medicaid Managed Care Enrollment and Program Characteristics, 2013. Mathematica Policy Research. 
CMS. (2018a). Medicaid Financial Management Report - Net Services (CMS-64) FY 2016.

CMS. (2018b). Medicaid Managed Care Enrollment and Program Characteristics, 2016. Mathematica Policy Research.

CMS. (2019, December 17). National Health Expenditure Data. Retrieved April 11, 2020, from CMS.gov: https://www.cms.gov/Research-Statistics-Data-and-Systems/Statistics-Trendsand-Reports/NationalHealthExpendData/NationalHealthAccountsHistorical

Currie, J., \& Fahr, J. (2005). Medicaid Managed Care: Effects on Children's Medicaid Coverage and Utilization. Journal of Public Economics, 89, 85-108.

Curto, V., Einav, L., Finkelstein, A., Levin, J., \& Bhattacharya, J. (2019). Health Care Spending and Utilizaton in Public and Private Medicare. American Economic Journal: Applied Economics, 302332.

Deshpande, M. \& Li, Y. (2019). Who is Screened Out? Application Costs and the Targeting of Disability Programs. American Economic Journal: Economic Policy, 11(4): 213-248.

Duggan, M. (2004). Does Contracting out Increase the Efficiency of Government Programs? Evidence from Medicaid HMOs. Journal of Public Economics, 88, 2549-2572.

Duggan, M., \& Hayford, T. (2013). Has the Shift to Managed Care Reduced Medicaid Expenditures? Evidence from State and Local-Level Mandates. Journal of Policy Analysis and Management, 505535.

Duggan, M., Gruber, J., \& Vabson, B. (2018). The Consequences of Health Care Privatization: Evidence from Medicare Advantage Exits. American Economic Journal: Economic Policy, 153-186.

Finkelstein, A., \& McKnight R. (2008). What did Medicare Do? The Initial Impact of Medicare on Mortality and Out of Pocket Medical Spending. Journal of Public Economics, 92:1644-1668.

Finkelstein, A., Taubman, S., Wright, B., Bernstein, M., Gruber, J., Newhouse, J., Allen, H., Baicker, K., \& Oregon Health Study Group. (2012). The Oregon Health Insurance Experiment: Evidence from The First Year. The Quarterly Journal of Economics, 127(3): 1057-1106.

Garthwaite, C., Graves, J., Gross, T., Karaca, Z., Marone, V., \& Notowidigdo, M. (2019). All Medicaid Expansions Are Not Created Equal: The Geography and Targeting of the Affordable Care Act. Brookings Papers on Economic Activity.

Garthwaite, C. \& Notowidigdo, M. (2020). Plan Value-Added: Evaluating Medicaid Managed Care Plans Using Random Assignment, working paper.

Geruso, M., Layton, T. \& Prinz, D. (2019) Screening in Contract Design: Evidence from the ACA Health Insurance Exchanges. American Economic Journal: Economic Policy, 11(2): 64-107. 
Geruso, M., \& Layton, T. (2020). Upcoding or Selection? Evidence from Medicare on Squishy Risk Adjustment. Journal of Political Economy, 128(3): 984-1026.

Geruso, M., Layton, T., \& Wallace J. (2020). Are all Managed Care Plans Created Equal? Evidence from Random Plan Assignment in Medicaid, working paper.

Goldin, J., Lurie, I., \& McCubbin, J. (2019). Health Insurance and Mortality: Experimental Evidence from Taxpaer Outreach. NBER Working Paper 26533.

Goodman-Bacon, A. (2020). Difference-in-Difference with Variation in Treatment Timing, working paper.

Harbage, P., \& King, M. (2012). A Bridge to Reform: California's Medicaid Section 1115 Waiver. California HealthCare Foundation.

Hart, O., Shleifer, A., \& Vishny, R. (1997). The Proper Scope of Government: Theory and An Application to Prisons. The Quarterly Journal of Economics, 1127-1161.

Kaiser Family Foundation. (2014a). Medicaid Enrollees by Enrollment Group. Retrieved April 11, 2020, from https://www.kff.org/medicaid/state-indicator/distribution-of-medicaid-enrollees-byenrollment-

group $/$ ?currentTimeframe $=0 \&$ sortModel $=\% 7 \mathrm{~B} \% 22$ colId $\% 22: \% 22$ Location $\% 22, \% 22$ sort $\%$ 22: $\% 22$ asc $\% 22 \% 7 \mathrm{D}$

Kaiser Family Foundation. (2014b). Medicaid Spending per Enrollee (Full or Partial Benefit). Retrieved April 11, 2020, from https://www.kff.org/medicaid/state-indicator/medicaid-spending-perenrollee/?currentTimeframe $=0 \&$ sortModel $=\% 7 \mathrm{~B} \% 22$ colld $\% 22: \% 22$ Location $\% 22, \% 22$ sort $\% 22: \% 22$ asc $\% 22 \% 7 \mathrm{D}$

Kuziemko, I., Meckel, K., \& Rossin-Slater, M. (2018). Does Managed Care Widen Infant Health Disparities? Evidence from Texas Medicaid. American Economic Journal: Economic Policy, 10(3), 255-283.

Layton, T., Maestas, N., Prinz, D., \& Vabson, B. (2019). Private vs. Public Provision of Social Insurance: Evidence from Medicaid. NBER Working Paper 26042.

Lee, A. (2020). How Do Hospitals Respond to Managed Care? Evidence From At-Risk Newborns. Journal of Public Economics.

Levy, H., \& Meltzer, D. (2008) The Impact of Health Insurance on Health. Annual Review of Public Health, 29: 399-409.

MACPAC. (2019). MACStats: Medicaid and CHIP Data Book.

Marton, J., Yelowitz, A., \& Talbert, J. (2014). A Tale of Two Cities? The Heterogeneous Impact of Medicaid Managed Care. Journal of Health Economics, 47-68. 
Miller, S., Altekruse, S., Johnson, N., \& Wherry, L. (2019). Medicaid and Mortality: New Evidence from Linked Survey and Administrative Data. NBER Working Paper 26081.

NYU Center for Health and Public Service Research. Accessed May 29 , 2020. https://wagner.nyu.edu/faculty/billings/nyued-background

Sommers, B., Baicker, K., \& Epstein, A. (2012). Mortality and Access to Care among Adults after State Medicaid Expansions. The New England Journal of Medicine, 367(11): 1025-1034.

Sommers, B., Long, S., \& Baicker, K. (2014). Changes in Mortality After Massachusetts Health Care Reform. Annals of Internal Medicine, 160(9): 585-593.

Sun, L. \& Abraham, S. (2020). Estimating Dynamic Treatment Effects in Event Studies with Heterogeneous Treatment Effects. Journal of Econometrics, https://doi.org/10.1016/j.jeconom.2020.09.006.

Tater, M., Paradise, J., \& Garfield, R. (2016). Medi-Cal Managed Care: An Overview and Key Issues. The Kaiser Commission on Medicaid and the Uninsured. 


\section{Appendix A: Difference-in-Differences with Two Way Fixed Effects Robustness Checks}

There has been a recent and growing literature on potential bias in common two-way fixed effect DiD analysis with staggered treatment timing (Goodman-Bacon 2020; Callaway and Sant'Anna 2020; Sun and Abraham 2020; Baker et al 2021). In this appendix, we discuss how our main specifications may be affected by such concerns, and describe how we check the robustness of our main analysis using the stacked event study method (similar to specifications in Cengiz et al (2019) and Deshpande and Li (2019)).

In our main analysis, we estimate the effect of the MMC mandate using the following DiD specification, regressing outcome variables on an indicator of mandate status and controlling for time and individual fixed effects:

$$
y_{i t}=\beta_{0}+\beta_{1} \text { mandate }_{i t}+\gamma_{t}+\alpha_{i}+\varepsilon_{i t}
$$

In our setting of the staggered implementation of the MMC mandate, $\beta_{1}$ it is a weighted average of DiD estimators of all 2-by-2 pairs of different treatment and timing groups (Goodman-Bacon 2020). While the Goodman-Bacon DiD decomposition can be used to illustrate the weight of each group, it is not applicable in our case since we do not have a balanced panel. In general, Goodman-Bacon (2020) shows that the weights are proportional to group size and variance of the treatment indicator in the pair, and suggests that $\beta_{1}$ may be biased towards the treatment effects of groups treated in the middle of the panel.

Hence for robustness, we turn to an event study version of the analysis using the following specification, regressing outcome variables on a vector of indicators for time relative to mandate implementation and controlling for time and individual fixed effects:

$$
y_{i t}=\sum_{r \leq-3}^{r \geq 4} \theta_{r} \mathbb{I}\left(t=\text { mandate quarter }_{i t}+r\right)+\gamma_{t}+\alpha_{i}+\epsilon_{i t}
$$

While this specification overcomes the weighting issue discussed in Goodman-Bacon (2020), it can still be problematic due to heterogeneous treatment effects. As illustrated in Callaway and Sant'Anna (2020), Sun and Abraham (2020), Baker et al (2021), already-treated units can be part of the control group just like units that are not yet treated, and thus the estimations from common event study specification can still be biased when treatment effects are heterogeneous. The aforementioned papers propose and discuss various alternative methods to restrict control group to not-yet-treated units and reduce bias in estimation.

In light of these discussions, we check the robustness of our results using the stacked event study method, following similar analysis in Cengiz et al (2019) and Deshpande and Li (2019).

We first create separate (sub)datasets for different treatment-control pairs. Since the MMC mandate is implemented month by month according to the birth month of beneficiaries, in each (sub)dataset, the treatment group include individuals of a particular birth month in treatment (Two-Plan/GMC) counties, and the control group include all individuals in the COHS counties. Thus, we ensure that already-treated individuals never enter the control group, which consists only of never-treated individuals. Note that this method has an additional benefit of balancing the number of observations in treatment and control groups, as there are approximately ten times as many beneficiaries in TwoPlan/GMC counties than in COHS counties in our sample. 
We then stack these (sub)datasets together to form the sample for robustness analysis, labeling each of the treatment-control pair with treatment cohort indicators.

With this stacked sample, we estimate treatment effects of the MMC mandate that are averaged across these treatment cohorts, by running the event study specification in our main analysis, except interacting individual/county fixed effect, time fixed effect, and any time-varying control variables with the cohort indicators. The estimated coefficients are plotted in Figures A1, A10, A12, and A14 and discussed in the main text. Reassuringly, the estimations are similar to what we find using our main specifications. 


\section{Tables}

Table I: Summary Statistics

\begin{tabular}{|c|c|c|c|c|}
\hline \multicolumn{5}{|l|}{ Panel A: Treatment Counties } \\
\hline Time Period & $\begin{array}{l}\text { Sample Selection } \\
\text { 2009Q2-2010Q } \mathrm{I}\end{array}$ & $\begin{array}{l}\text { Pre-Implementation } \\
\text { 20IOQ2-20IIQI }\end{array}$ & $\begin{array}{l}\text { Implementation } \\
\text { 20IIQ2-20I2 } Q_{2}\end{array}$ & $\begin{array}{l}\text { Post-Implementation } \\
{ }_{2012} \mathrm{Q}_{3-2013} \mathrm{Q}_{4}\end{array}$ \\
\hline Number of patients & 132,635 & 132,635 & 130,325 & $\mathrm{I} 28,245$ \\
\hline Number of obs & 530,540 & 526,859 & 647,4 II & 763,812 \\
\hline \multicolumn{5}{|l|}{ Demographics } \\
\hline Average age & 49.28 & 50.25 & 51.36 & 52.58 \\
\hline Share female & 0.63 & 0.64 & 0.64 & 0.64 \\
\hline Share black & $0.2 \mathrm{I}$ & $0.2 \mathrm{I}$ & $0.2 \mathrm{I}$ & $0.2 \mathrm{I}$ \\
\hline Share hispanic & 0.34 & 0.35 & 0.35 & 0.35 \\
\hline \multicolumn{5}{|l|}{ Average Utilization } \\
\hline Number of discharge/qtr & 0.17 & O.II & 0.09 & 0.08 \\
\hline Number of ER/qtr & 0.46 & $0.3 \mathrm{I}$ & 0.29 & 0.28 \\
\hline \multicolumn{5}{|l|}{ Discharge Payer Share } \\
\hline MMC & 0.24 & 0.22 & 0.38 & 0.55 \\
\hline MCDFFS & 0.66 & 0.64 & 0.40 & 0.19 \\
\hline Medicare & 0.00 & 0.05 & O.II & 0.14 \\
\hline Private & 0.03 & 0.04 & 0.05 & 0.06 \\
\hline Self & 0.03 & 0.02 & 0.02 & 0.02 \\
\hline Other & 0.03 & 0.03 & 0.03 & 0.04 \\
\hline \multicolumn{5}{|l|}{ ER Payer Share } \\
\hline MCD & 0.85 & 0.79 & $0.7 \mathrm{I}$ & 0.65 \\
\hline Medicare & 0.00 & 0.03 & 0.06 & 0.08 \\
\hline Private & 0.05 & 0.07 & O.II & 0.14 \\
\hline Self & 0.07 & 0.08 & 0.07 & 0.07 \\
\hline Other & 0.03 & 0.03 & 0.04 & 0.06 \\
\hline
\end{tabular}




\begin{tabular}{|c|c|c|c|c|}
\hline \multicolumn{5}{|l|}{ Panel B: Control Counties } \\
\hline Time Period & $\begin{array}{l}\text { Sample Selection } \\
\text { 2009Q2-2010Q }\end{array}$ & $\begin{array}{l}\text { Pre-Implementation } \\
\text { 20I0Q2-20II } Q_{1}\end{array}$ & $\begin{array}{l}\text { Implementation } \\
{ }_{20 \mathrm{II}} \mathrm{Q}_{2-2 \mathrm{O} 2} \mathrm{Q}_{2}\end{array}$ & $\begin{array}{c}\text { Post-Implementation } \\
2 \mathrm{OI}_{2} \mathrm{Q}_{3}-2 \mathrm{O}_{3} \mathrm{Q}_{4}\end{array}$ \\
\hline Number of patients & 18,756 & 18,756 & I 8,475 & $\mathrm{I} 8,2 \mathrm{I} 8$ \\
\hline Number of obs & 75,024 & 74,573 & $9 \mathrm{I}, 8 \mathrm{I} 8$ & 108,687 \\
\hline \multicolumn{5}{|l|}{ Demographics } \\
\hline Average age & 48.84 & 49.82 & 50.93 & 52.16 \\
\hline Share female & 0.63 & 0.63 & 0.63 & 0.63 \\
\hline Share black & O.IO & O.IO & o.IO & O.IO \\
\hline Share hispanic & 0.35 & 0.36 & 0.36 & 0.36 \\
\hline \multicolumn{5}{|l|}{ Average Utilization } \\
\hline Number of discharge/qtr & O.I4 & 0.08 & 0.07 & 0.06 \\
\hline Number of ER/qtr & $0.5 \mathrm{I}$ & 0.32 & 0.30 & 0.28 \\
\hline \multicolumn{5}{|l|}{ Discharge Payer Share } \\
\hline $\mathrm{MMC}$ & $0.7 \mathrm{I}$ & 0.69 & 0.66 & $0.6 \mathrm{I}$ \\
\hline MCDFFS & 0.15 & O.IO & 0.07 & 0.07 \\
\hline Medicare & 0.00 & 0.06 & 0.13 & 0.19 \\
\hline Private & 0.03 & 0.05 & 0.05 & 0.03 \\
\hline Self & 0.02 & 0.02 & 0.02 & 0.02 \\
\hline Other & O.IO & 0.09 & 0.08 & 0.08 \\
\hline \multicolumn{5}{|l|}{ ER Payer Share } \\
\hline MCD & 0.83 & 0.74 & 0.70 & 0.66 \\
\hline Medicare & 0.00 & 0.03 & 0.07 & O.IO \\
\hline Private & 0.08 & O.II & 0.12 & O.II \\
\hline Self & 0.06 & 0.09 & 0.08 & 0.08 \\
\hline Other & 0.03 & 0.03 & 0.04 & 0.05 \\
\hline
\end{tabular}

Notes: This table shows summary statistics of the analysis sample in different time periods. Panel A contains data for only individuals living in treatment countries while Panel B contains data on those living in COHS counties. Demographics and average utilization are computed by taking average over personquarter level observations (unit of regression analysis). Payer shares are computed from total number of discharges and ER visits of different payers across all individuals in respective time periods of the analysis sample. 
Table 2: Distribution by MMC Status

\begin{tabular}{lccc}
\hline Panel A: Age & MMC Always & MMC Switch & MCDFFS Always \\
\hline $\begin{array}{l}\text { Average } \\
\text { Share by Group }\end{array}$ & 49.45 & $5 \mathrm{I} .72$ & $50.8 \mathrm{I}$ \\
$39-45$ & & & \\
$45-50$ & 0.24 & 0.13 & 0.18 \\
$50-55$ & 0.29 & 0.22 & 0.25 \\
$55-6 \mathrm{I}$ & 0.27 & $0.3 \mathrm{I}$ & 0.27 \\
& $0.2 \mathrm{I}$ & 0.35 & $0.3 \mathrm{I}$
\end{tabular}

Panel B: Length of Stay MMC Always MMC Switch MCDFFS Always

\begin{tabular}{|c|c|c|c|}
\hline Average & 5.01 & 6.74 & 15.35 \\
\hline \multicolumn{4}{|l|}{ Share by Group } \\
\hline I-4 days & 0.44 & 0.35 & 0.27 \\
\hline 4-7 days & 0.39 & 0.39 & 0.36 \\
\hline 7-Io days & O.IO & 0.13 & 0.16 \\
\hline IO-I3 days & 0.03 & 0.05 & 0.06 \\
\hline I3-I6 days & 0.02 & 0.03 & 0.04 \\
\hline I6-2I days & O.OI & 0.02 & 0.03 \\
\hline 2I-5I days & O.OI & 0.02 & 0.05 \\
\hline ५I+ days & 0.00 & O.OI & 0.03 \\
\hline Panel C: Charge & MMC Always & MMC Switch & MCDFFS Always \\
\hline Average & 50502.90 & 56422.35 & 75086.33 \\
\hline \multicolumn{4}{|l|}{ Share by Group } \\
\hline \$o-Iok & 0.04 & 0.05 & 0.07 \\
\hline \$IO-3ok & 0.36 & 0.37 & 0.36 \\
\hline$\$ 30-50 k$ & 0.25 & 0.25 & $0.2 \mathrm{I}$ \\
\hline \$5O-Iook & $0.2 \mathrm{I}$ & $0.2 \mathrm{I}$ & 0.20 \\
\hline \$IOO-20ok & 0.07 & 0.09 & O.IO \\
\hline \$200-5ook & 0.02 & 0.03 & 0.05 \\
\hline \$5ook+ & 0.00 & O.OI & 0.02 \\
\hline missing & 0.06 & O.OI & 0.00 \\
\hline
\end{tabular}

Notes: Based on universe of hospital discharges in California from 2009q2 to 2oriqi that are non-birth related for individuals residing in the same reform county in 2009q2 - 201394, born in 1950-69, with valid RLN, and having at least one Medi-Cal covered hospital discharge in both $2009 \mathrm{q} 2-2011 \mathrm{qI}$ and $2012 \mathrm{q} 3$ - 201394. Each observation is the average outcome for the individual across all dischrges in 2009q2 - 201rqI. Table displays the distribution by MMC status before and after the SPD mandate, which was implemented from $2011 \mathrm{q} 2$ to $2012 \mathrm{q} 2$. 
Table 3: First Stage

\begin{tabular}{|c|c|c|c|c|c|c|c|}
\hline & (I) & $(2)$ & (3) & (4) & (5) & (6) & (7) \\
\hline $\begin{array}{l}\text { Panel A: } \\
\text { No Control Group }\end{array}$ & $\begin{array}{c}\text { Inpatient } \\
\text { Medicaid } \\
\text { Managed Care }\end{array}$ & $\begin{array}{c}\text { Inpatient } \\
\text { Medicaid } \\
\text { Fee for Service }\end{array}$ & $\begin{array}{l}\text { Inpatient } \\
\text { Private }\end{array}$ & $\begin{array}{l}\text { Inpatient } \\
\text { Medicare }\end{array}$ & $\begin{array}{c}\text { Emergency Room } \\
\text { Medicaid }\end{array}$ & $\begin{array}{l}\text { Emergency Room } \\
\text { Private }\end{array}$ & $\begin{array}{c}\text { Emergency Room } \\
\text { Medicare }\end{array}$ \\
\hline mandate & $\begin{array}{c}2.274^{* * *} \\
\text { (o.IOI) }\end{array}$ & $\begin{array}{c}-2.585^{* * *} \\
\text { (o.IIO) }\end{array}$ & $\begin{array}{l}0.237^{* * *} \\
(0.0344)\end{array}$ & $\begin{array}{c}0.0534 \\
(0.0573)\end{array}$ & $\begin{array}{c}-\mathrm{I} .027^{* * *} \\
(0.278)\end{array}$ & $\begin{array}{l}\text { I. } 463^{* * *} \\
\text { (o.Io8) }\end{array}$ & $\begin{array}{c}0.0657 \\
(0.0767)\end{array}$ \\
\hline Time FE & $\mathrm{Y}$ & $\mathrm{Y}$ & $\mathrm{Y}$ & Y & $\mathrm{Y}$ & $\mathrm{Y}$ & $\mathrm{Y}$ \\
\hline Individual FE & $\mathrm{Y}$ & $\mathrm{Y}$ & $\mathrm{Y}$ & $\mathrm{Y}$ & $\mathrm{Y}$ & $\mathrm{Y}$ & $\mathrm{Y}$ \\
\hline Pre-Reform Mean (y) & 2.397 & 6.914 & 0.383 & 0.570 & 24.125 & 2.208 & 0.864 \\
\hline Observations & 1938082 & 1938082 & 1938082 & 1938082 & 1938082 & 1938082 & 1938082 \\
\hline $\begin{array}{l}\text { Panel B: } \\
\text { COHS Control Group }\end{array}$ & $\begin{array}{c}\text { Inpatient } \\
\text { Medicaid } \\
\text { Managed Care }\end{array}$ & $\begin{array}{c}\text { Inpatient } \\
\text { Medicaid } \\
\text { Fee for Service }\end{array}$ & $\begin{array}{l}\text { Inpatient } \\
\text { Private }\end{array}$ & $\begin{array}{l}\text { Inpatient } \\
\text { Medicare }\end{array}$ & $\begin{array}{c}\text { Emergency Room } \\
\text { Medicaid }\end{array}$ & $\begin{array}{c}\text { Emergency Room } \\
\text { Private }\end{array}$ & $\begin{array}{l}\text { Emergency Room } \\
\text { Medicare }\end{array}$ \\
\hline mandate & $\begin{array}{c}2.6 \mathrm{II}^{* * *} \\
(0.0900)\end{array}$ & $\begin{array}{l}-3.029^{* * *} \\
(0.072 \mathrm{I})\end{array}$ & $\begin{array}{l}0.277^{* * *} \\
(0.0299)\end{array}$ & $\begin{array}{l}0.00787 \\
(0.0465)\end{array}$ & $\begin{array}{c}-0.747^{* * *} \\
(0.255)\end{array}$ & $\begin{array}{l}\mathrm{I} .8 \mathrm{I} 3^{* * *} \\
\text { (o.IOI) }\end{array}$ & $\begin{array}{l}-0.180^{* *} \\
(0.0852)\end{array}$ \\
\hline Time FE & Y & $\mathrm{Y}$ & $\mathrm{Y}$ & Y & $\mathrm{Y}$ & $\mathrm{Y}$ & $\mathrm{Y}$ \\
\hline Individual FE & $\mathrm{Y}$ & $\mathrm{Y}$ & $\mathrm{Y}$ & $\mathrm{Y}$ & $\mathrm{Y}$ & $\mathrm{Y}$ & $\mathrm{Y}$ \\
\hline Pre-Reform Mean (y) & 2.786 & 6.152 & 0.380 & 0.556 & 24.129 & 2.382 & $0.87 \mathrm{I}$ \\
\hline Observations & 2213160 & 2213160 & 2213160 & 2213160 & 2213160 & 2213160 & 2213160 \\
\hline
\end{tabular}

Notes: Panel A based on analysis sample in $2 \mathrm{OIO}_{2}$ - 2013 $\mathrm{Q}_{4}$, excluding observations of the control group. Panel B based on all observations in the analysis sample in $20 \mathrm{Io}_{2}$ - 20I3 $\mathrm{Q}_{4}$. Outcome variables are multiplied by roo at each person-quarter cell for presentation purpose. The coefficients are from regressions of outcome variables on mandate indicator, quarter FEs, and individual FEs, with standard errors clustered at individual level. ${ }^{*} p<0.10,{ }^{* *} p<0.05,{ }^{* * *} p<0.01$ 
Table 4: Effect of MMC on Hospital Services

\begin{tabular}{|c|c|c|c|c|c|c|}
\hline & (I) & (2) & (3) & (4) & (s) & (6) \\
\hline $\begin{array}{l}\text { Panel A: } \\
\text { No Control Group }\end{array}$ & ER Visit & Discharge & $\begin{array}{l}\text { Non-ER } \\
\text { Transfer }\end{array}$ & $\begin{array}{l}\text { Non-ER } \\
\text { Non-transfer }\end{array}$ & $\begin{array}{l}\text { Admitted from } \\
\text { Own ER }\end{array}$ & Scheduled \\
\hline mandate & $\begin{array}{l}0.727^{* *} \\
(0.32 \mathrm{I})\end{array}$ & $\begin{array}{l}0.0258 \\
(0.158)\end{array}$ & $\begin{array}{l}0.0724^{* *} \\
(0.0296)\end{array}$ & $\begin{array}{l}-0.0996 \\
(0.0648)\end{array}$ & $\begin{array}{l}0.0531 \\
(0.132)\end{array}$ & $\begin{array}{l}-0.0643 \\
(0.0476)\end{array}$ \\
\hline Time FE & $\mathrm{Y}$ & $\mathrm{Y}$ & $\mathrm{Y}$ & $\mathrm{Y}$ & $\mathrm{Y}$ & $\mathrm{Y}$ \\
\hline Individual FE & $\mathrm{Y}$ & $\mathrm{Y}$ & $\mathrm{Y}$ & $\mathrm{Y}$ & $\mathrm{Y}$ & $\mathrm{Y}$ \\
\hline Pre-Reform Mean (y) & 30.582 & Io.829 & 0.424 & 2.332 & 8.073 & 1.269 \\
\hline Observations & 1938082 & 1938082 & 1938082 & 1938082 & 1938082 & 1938082 \\
\hline $\begin{array}{l}\text { Panel B: } \\
\text { COHS Control Group }\end{array}$ & ER Visit & Discharge & $\begin{array}{l}\text { Non-ER } \\
\text { Transfer }\end{array}$ & $\begin{array}{c}\text { Non-ER } \\
\text { Non-transfer }\end{array}$ & $\begin{array}{l}\text { Admitted from } \\
\text { Own ER }\end{array}$ & Scheduled \\
\hline mandate & $\begin{array}{l}\text { I.I79 } \\
(0.289)\end{array}$ & $\begin{array}{l}-0.0367 \\
(0.121)\end{array}$ & $\begin{array}{l}0.0628^{* * *} \\
(0.0223)\end{array}$ & $\begin{array}{l}-0.0463 \\
(0.047 \mathrm{I})\end{array}$ & $\begin{array}{l}-0.0532 \\
(0.10 I)\end{array}$ & $\begin{array}{r}-0.00949 \\
(0.0348)\end{array}$ \\
\hline Time FE & $\mathrm{Y}$ & $\mathrm{Y}$ & $\mathrm{Y}$ & $\mathrm{Y}$ & $\mathrm{Y}$ & $\mathrm{Y}$ \\
\hline Individual FE & $\mathrm{Y}$ & $\mathrm{Y}$ & $\mathrm{Y}$ & $\mathrm{Y}$ & $\mathrm{Y}$ & $\mathrm{Y}$ \\
\hline Pre-Reform Mean (y) & 30.810 & I0.475 & 0.419 & 2.273 & $7 \cdot 78 \mathrm{I}$ & I.250 \\
\hline Observations & 2213160 & 2213160 & 2213160 & 2213160 & 2213160 & 2213160 \\
\hline
\end{tabular}

Notes: Panel A based on analysis sample in $2 \mathrm{OIOQ}_{2}-{ }_{2} \mathrm{OI}_{3} \mathrm{Q}_{4}$, excluding observations of the control group. Panel B based on all observations in the analysis sample in $2010 \mathrm{Q}_{2}-\mathrm{2}_{3} \mathrm{Q}_{4}$. Outcome variables are multiplied by 100 at each person-quarter cell for presentation purpose. The coefficients are from regressions of outcome variables on mandate indicator, quarter FEs, and individual FEs, with standard errors clustered at individual level. ${ }^{*} p<0.10,{ }^{* *} p<0.05$, *** $p<0.01$. 
Table 5: Effect of MMC on Mortality

\begin{tabular}{|c|c|c|c|c|c|}
\hline Panel A: No Control Group & (I) & $(2)$ & (3) & $(4)$ & (5) \\
\hline & & \multicolumn{2}{|c|}{ By Utilization } & \multicolumn{2}{|c|}{ By Elixhauser Score } \\
\hline mandate & $\begin{array}{c}0.000884^{* * *} \\
(0.000257)\end{array}$ & & & & \\
\hline mandate (low severity) & & $\begin{array}{l}0.0000965 \\
(0.000427)\end{array}$ & & $\begin{array}{c}0.000190 \\
(0.000313)\end{array}$ & \\
\hline mandate (high severity) & & $\begin{array}{l}0.00136^{* * *} \\
(0.000309)\end{array}$ & $\begin{array}{c}0.00127^{* *} \\
(0.000505)\end{array}$ & $\begin{array}{l}0.00134^{* * *} \\
(0.000297)\end{array}$ & $\begin{array}{l}0.00115^{* * *} \\
(0.000325)\end{array}$ \\
\hline Time FE & $\mathrm{Y}$ & $\mathrm{Y}$ & & $\mathrm{Y}$ & \\
\hline County FE & $\mathrm{Y}$ & $\mathrm{Y}$ & & $\mathrm{Y}$ & \\
\hline Pre-Reform Mean (y) & $0.0075 \mathrm{I}$ & & & & \\
\hline Pre-Reform Mean (y) (low severity) & & 0.00370 & & 0.00237 & \\
\hline Pre-Reform Mean (y) (high severity) & & 0.00986 & & 0.0106 & \\
\hline $\mathrm{N}$ & 1095446 & & & & \\
\hline N (low severity) & & 422560 & & 419534 & \\
\hline $\mathrm{N}$ (high severity) & & 672886 & & 675912 & \\
\hline \multicolumn{6}{|l|}{ Panel B: COHS Control Group } \\
\hline & & \multicolumn{2}{|c|}{ By Utilization } & \multicolumn{2}{|c|}{ By Elixhauser Score } \\
\hline mandate & $\begin{array}{c}0.000798^{* * *} \\
(0.000172)\end{array}$ & & & & \\
\hline mandate (low severity) & & $\begin{array}{c}0.00046 \mathrm{I} \\
(0.00033 \mathrm{I})\end{array}$ & & $\begin{array}{c}0.0003 \mathrm{II} \\
(0.00025 \mathrm{I})\end{array}$ & \\
\hline mandate (high severity) & & $\begin{array}{c}0.000940^{* * *} \\
(0.000254)\end{array}$ & $\begin{array}{c}0.000479 \\
(0.000465)\end{array}$ & $\begin{array}{l}0.00121^{* * *} \\
(0.000230)\end{array}$ & $\begin{array}{l}0.000903^{* *} \\
(0.000329)\end{array}$ \\
\hline Time FE & $\mathrm{Y}$ & $\mathrm{Y}$ & & $\mathrm{Y}$ & \\
\hline County FE & $\mathrm{Y}$ & $\mathrm{Y}$ & & $\mathrm{Y}$ & \\
\hline Pre-Reform Mean (y) & 0.00748 & & & & \\
\hline Pre-Reform Mean (y) (low severity) & & 0.00372 & & 0.00235 & \\
\hline Pre-Reform Mean (y) (high severity) & & 0.00977 & & 0.0106 & \\
\hline $\mathrm{N}$ & I232288 & & & & \\
\hline N (low severity) & & 472062 & & 476601 & \\
\hline $\mathrm{N}$ (high severity) & & 760226 & & 755687 & \\
\hline
\end{tabular}

Notes: Panel A based on analysis sample in $2 \mathrm{OIOQ}_{2}-{ }_{2} \mathrm{OI}_{3} \mathrm{Q}_{4}$, excluding observations of the control group and individuals without any hospital discharge in $2009 \mathrm{Q}_{2}-{ }_{2} \mathrm{OI}_{3} \mathrm{Q}_{4}$. Panel B based on all observations in the analysis sample in $2010 \mathrm{Q}_{2}-2013 \mathrm{Q}_{4}$, excluding individuals without any hospital discharge in ${ }_{2009} \mathrm{Q}_{2}-20 \mathrm{I}_{3} \mathrm{Q}_{4}$. The coefficients are from linear regression of outcome variable ( $\mathrm{o} / \mathrm{I}$ death indicator) on mandate indicators (shown in tables), quarter $\mathrm{FEs}$, county FEs, age FEs, and gender indicator, with standard errors clustered at county level. Column i shows the results from full sample. Column 2 shows the coefficients for high and low baseline utilizers separately by interacting all RHS variables with high utilizer indicator, which is equivalent to running the regressions separately for the two groups. Column 3 tests for statistical significance of the differences between high vs. low utilizer coefficients, by regressing outcome variables on mandate indicator and mandate indicator interacted with high utilizer indicator. High utilizer is defined as individuals whose total number of inpatient hospital discharge $+\mathrm{ER}$ visit is higher than or equal to the median (which equals 2 in the analysis sample). Column 4 shows the coefficients for those with high and low baseline Elixhauser scores separately. Column 5 tests for statistical significance of differences between the coefficients for those with high and low baseline Elixhauser scores. High severity patient is defined as individuals whose total unweighted number of chronic conditions (Elixhauser score) based on principal and co-diagnoses of all inpatient hospital discharges and ER visits at baseline is higher than the median (which equals $\mathrm{I}$ in the analysis sample). ${ }^{*} p<0.10,{ }^{* *} p<0.05,{ }^{* * *} p<0.01$. 
Table 6: Effect of MMC on Mortality by Baseline Health Condition (No Control Group)

\begin{tabular}{|c|c|c|c|c|c|c|c|c|}
\hline Panel A: & $\begin{array}{l}\text { Infectious and } \\
\text { Parasitic Diseases }\end{array}$ & Neoplasms & $\begin{array}{l}\text { Endocrine, Nutritional and } \\
\text { Metabolic Diseases, and } \\
\text { Immunity Disorders }\end{array}$ & $\begin{array}{l}\text { Diseases of } \\
\text { Blood and Blood- } \\
\text { forming Organs }\end{array}$ & Mental Disorders & $\begin{array}{l}\text { Diseases of the } \\
\text { Nervous System }\end{array}$ & $\begin{array}{l}\text { Diseases of the } \\
\text { Circulatory System }\end{array}$ & $\begin{array}{l}\text { Diseases of the } \\
\text { Respiratory System }\end{array}$ \\
\hline mandate & $\begin{array}{l}0.00278^{*} \\
(0.00131)\end{array}$ & $\begin{array}{l}-0.00105 \\
(0.00210)\end{array}$ & $\begin{array}{c}0.00103 \\
(0.00149)\end{array}$ & $\begin{array}{l}0.0109^{* * *} \\
(0.00345)\end{array}$ & $\begin{array}{l}-0.000130 \\
(0.00226)\end{array}$ & $\begin{array}{l}-0.000629 \\
(0.000568)\end{array}$ & $\begin{array}{l}0.00302^{* *} \\
(0.00118)\end{array}$ & $\begin{array}{c}0.00135 \\
(0.00106)\end{array}$ \\
\hline Time FE & $\mathrm{Y}$ & $\mathrm{Y}$ & $\mathrm{Y}$ & $\mathrm{Y}$ & $\mathrm{Y}$ & $\mathrm{Y}$ & Y & Y \\
\hline County FE & $\mathrm{Y}$ & $\mathrm{Y}$ & $\mathrm{Y}$ & $\mathrm{Y}$ & $\mathrm{Y}$ & $\mathrm{Y}$ & $\mathrm{Y}$ & $\mathrm{Y}$ \\
\hline Pre-Reform Mean(y) & 0.0172 & 0.0267 & 0.0129 & 0.0205 & 0.00608 & 0.00904 & 0.0113 & 0.0108 \\
\hline Observations & 69336 & 65524 & 88586 & 23000 & $\mathrm{I} 25082$ & пाо88г & 164503 & 198564 \\
\hline & $\begin{array}{l}\text { Diseases of the } \\
\text { Digestive System }\end{array}$ & $\begin{array}{l}\text { Diseases of the } \\
\text { Genitourinary System }\end{array}$ & $\begin{array}{l}\text { Diseases of the } \\
\text { Skin and Subcutaneous Tissue }\end{array}$ & $\begin{array}{l}\text { Diseases of the } \\
\text { Musculoskeletal System } \\
\text { and Connective Tissue }\end{array}$ & Congenital Anomalies & $\begin{array}{l}\text { Symptoms, Signs, } \\
\text { and Ill-defined Conditions }\end{array}$ & Injury and Poisoning & Supplementary Classification \\
\hline mandate & $\begin{array}{c}0.00110 \\
(0.000636)\end{array}$ & $\begin{array}{l}0.000753 \\
(0.00121)\end{array}$ & $\begin{array}{l}0.000284 \\
(0.000888)\end{array}$ & $\begin{array}{c}0.00103 \\
(0.000979)\end{array}$ & $\begin{array}{l}0.00247 \\
(0.00426)\end{array}$ & $\begin{array}{c}0.000777 \\
(0.000604)\end{array}$ & $\begin{array}{l}0.000768 \\
(0.000509)\end{array}$ & $\begin{array}{c}-0.0000590 \\
(0.00154)\end{array}$ \\
\hline Time FE & Y & $\mathrm{Y}$ & Y & Y & Y & Y & $\mathrm{Y}$ & Y \\
\hline County FE & $\mathrm{Y}$ & $\mathrm{Y}$ & $\mathrm{Y}$ & $\mathrm{Y}$ & $\mathrm{Y}$ & $\mathrm{Y}$ & $\mathrm{Y}$ & $\mathrm{Y}$ \\
\hline Pre-Reform Mean(y) & 0.0113 & 0.00893 & 0.00945 & 0.00719 & 0.00693 & 0.00913 & 0.00835 & 0.0122 \\
\hline Observations & 191540 & 134046 & 95931 & 171536 & $2 \mathrm{IIS}$ & 367479 & 260683 & 94268 \\
\hline & \multicolumn{8}{|c|}{ Excluding Individuals with Circulatory Conditions } \\
\hline Panel B: & $\begin{array}{l}\text { Infectious and } \\
\text { Parasitic Diseases }\end{array}$ & Neoplasms & $\begin{array}{l}\text { Endocrine, Nutritional and } \\
\text { Metabolic Diseases, and } \\
\text { Immunity Disorders }\end{array}$ & $\begin{array}{c}\text { Diseases of } \\
\text { Blood and Blood- } \\
\text { forming Organs }\end{array}$ & Mental Disorders & $\begin{array}{l}\text { Diseases of the } \\
\text { Nervous System }\end{array}$ & $\begin{array}{l}\text { Diseases of the } \\
\text { Circulatory System }\end{array}$ & $\begin{array}{l}\text { Diseases of the } \\
\text { Respiratory System }\end{array}$ \\
\hline mandate & $\begin{array}{c}0.00221 \\
(0.00193)\end{array}$ & $\begin{array}{l}-0.00202 \\
(0.00187)\end{array}$ & $\begin{array}{l}-0.000128 \\
(0.00151)\end{array}$ & $\begin{array}{l}0.00969^{*} \\
(0.00467)\end{array}$ & $\begin{array}{l}0.000578 \\
(0.00217)\end{array}$ & $\begin{array}{l}-0.000979 \\
(0.000910)\end{array}$ & & $\begin{array}{c}0.00161 \\
(0.00135)\end{array}$ \\
\hline Time FE & Y & $\mathrm{Y}$ & Y & Y & Y & Y & & Y \\
\hline County FE & $\mathrm{Y}$ & $\mathrm{Y}$ & $\mathrm{Y}$ & $\mathrm{Y}$ & Y & $\mathrm{Y}$ & & $\mathrm{Y}$ \\
\hline Pre-Reform Mean(y) & 0.0143 & 0.0257 & $0.0099 \mathrm{I}$ & 0.0202 & 0.00534 & 0.00814 & & 0.00878 \\
\hline \multirow[t]{2}{*}{ Observations } & 61315 & 61546 & 74492 & 20310 & II 4250 & 97171 & & 173222 \\
\hline & $\begin{array}{l}\text { Diseases of the } \\
\text { Digestive System }\end{array}$ & $\begin{array}{l}\text { Diseases of the } \\
\text { Genitourinary System }\end{array}$ & $\begin{array}{l}\text { Diseases of the } \\
\text { Skin and Subcutaneous Tissue }\end{array}$ & $\begin{array}{l}\text { Diseases of the } \\
\text { Musculoskeletal System } \\
\text { and Connective Tissue }\end{array}$ & Congenital Anomalies & $\begin{array}{l}\text { Symptoms, Signs, } \\
\text { and Ill-defined Conditions }\end{array}$ & Injury and Poisoning & Supplementary Classification \\
\hline mandate & $\begin{array}{l}0.000944 \\
(0.000883)\end{array}$ & $\begin{array}{l}0.000521 \\
(0.00119)\end{array}$ & $\begin{array}{l}-0.000749 \\
(0.000992)\end{array}$ & $\begin{array}{l}0.000282 \\
(0.00106)\end{array}$ & $\begin{array}{l}0.00487 \\
(0.00712)\end{array}$ & $\begin{array}{l}0.000582 \\
(0.00055 \mathrm{I})\end{array}$ & $\begin{array}{l}0.000854 \\
(0.000589)\end{array}$ & $\begin{array}{l}-0.00124 \\
(0.00164)\end{array}$ \\
\hline Time FE & Y & Y & Y & Y & $\mathrm{Y}$ & Y & Y & Y \\
\hline County FE & $\mathrm{Y}$ & Y & $\mathrm{Y}$ & $\mathrm{Y}$ & Y & $\mathrm{Y}$ & Y & $\mathrm{Y}$ \\
\hline Pre-Reform Mean(y) & 0.0103 & 0.00758 & 0.00856 & 0.00604 & 0.00607 & $0.0080 \mathrm{I}$ & 0.00709 & 0.0112 \\
\hline Observations & 172785 & 119460 & 85233 & I51339 & 1812 & 310640 & 230907 & 77335 \\
\hline
\end{tabular}

Notes: Panel A based on analysis sample in $2010 \mathrm{Q}_{2}-2 \mathrm{O}_{3} \mathrm{Q}_{4}$, excluding observations of the control group and individuals without any hospital discharge in $2009 \mathrm{Q}_{2}$ - 2013 $\mathrm{Q}_{4}$. Panel $\mathrm{B}$ based on same sample while excluding all individuals with any discharge/ER visit for circulatory conditions at baseline. The coefficients are from linear regression of outcome variable (o/I death indicator) on mandate indicator (shown in tables), quarter FEs, county FEs, age FEs, and gender indicator, with standard errors clustered at county level. ${ }^{*} p<0.10,{ }^{* *} p<0.05,{ }^{* * *} p<0.01$. 
Table 7: Heterogeneity in the use of Hospital Services

\begin{tabular}{|c|c|c|c|c|c|c|c|c|c|c|c|c|}
\hline & (I) & $(2)$ & $(3)$ & $(4)$ & (5) & (6) & (7) & (8) & (9) & (го) & (II) & (I2) \\
\hline $\begin{array}{l}\text { Panel A: } \\
\text { No Control Group }\end{array}$ & \multicolumn{2}{|c|}{ ER Visit } & \multicolumn{2}{|c|}{ Discharge } & \multicolumn{2}{|c|}{$\begin{array}{l}\text { Non-ER } \\
\text { Transfer }\end{array}$} & \multicolumn{2}{|c|}{$\begin{array}{c}\text { Non-ER } \\
\text { Non-transfer }\end{array}$} & \multicolumn{2}{|c|}{$\begin{array}{l}\text { Admitted from } \\
\text { Own ER }\end{array}$} & \multicolumn{2}{|c|}{ Scheduled } \\
\hline mandate (high util) & $\begin{array}{l}\mathrm{I} .837^{* * *} \\
(0.563)\end{array}$ & $\begin{array}{l}2.250^{* * *} \\
(0.636)\end{array}$ & $\begin{array}{c}0.1 \mathrm{II} \\
(0.270)\end{array}$ & $\begin{array}{c}0.179 \\
(0.314)\end{array}$ & $\begin{array}{l}0.133^{* * *} \\
(0.05 \mathrm{II})\end{array}$ & $\begin{array}{l}0.124^{* *} \\
(0.0586)\end{array}$ & $\begin{array}{c}-0.0746 \\
(0.108)\end{array}$ & $\begin{array}{l}0.0504 \\
(0.129)\end{array}$ & $\begin{array}{l}0.0549 \\
(0.226)\end{array}$ & $\begin{array}{c}0.00442 \\
(0.26 \mathrm{I})\end{array}$ & $\begin{array}{l}-0.016 \mathrm{I} \\
(0.078 \mathrm{I})\end{array}$ & $\begin{array}{c}0.0979 \\
(0.0947)\end{array}$ \\
\hline
\end{tabular}

Time FE

Individual FE

Y $\quad \mathrm{Y}$

I4.479

Pre-Reform Mean (y) (high util) $\quad 45.803$

$\mathrm{N}$ (low util)

$\mathrm{N}$ (high util)

45.803
950686

987396

$\begin{array}{cc}\mathrm{Y} & \mathrm{Y} \\ \mathrm{Y} & \mathrm{Y} \\ 4.985 & 0.199 \\ \mathrm{I} 6.353 & 0.637 \\ 950686 & 950686 \\ 987396 & 987396\end{array}$

$\mathrm{Y}$
$\mathrm{Y}$
$\mathrm{I} .25 \mathrm{I}$
3.353
950686
987396

$\begin{array}{cc}\mathrm{Y} & \mathrm{Y} \\ \mathrm{Y} & \mathrm{Y} \\ 3.534 & 0.753 \\ \mathrm{I} 2.363 & \mathrm{I} .756 \\ 950686 & 950686 \\ 987396 & 987396\end{array}$

\begin{tabular}{|c|c|c|c|c|c|c|}
\hline $\begin{array}{l}\text { Panel B: } \\
\text { COHS Control Group }\end{array}$ & ER Visit & Discharge & $\begin{array}{l}\text { Non-ER } \\
\text { Transfer }\end{array}$ & $\begin{array}{c}\text { Non-ER } \\
\text { Non-transfer }\end{array}$ & $\begin{array}{l}\text { Admitted from } \\
\text { Own ER }\end{array}$ & Scheduled \\
\hline mandate (low util) & $\begin{array}{c}0.162 \\
(0.242)\end{array}$ & $\begin{array}{c}0.0444 \\
(0.12 \mathrm{I})\end{array}$ & $\begin{array}{c}0.0205 \\
(0.0220)\end{array}$ & $\begin{array}{l}-0.0245 \\
(0.0516)\end{array}$ & $\begin{array}{c}0.0484 \\
(0.0970)\end{array}$ & $\begin{array}{l}-0.0224 \\
(0.0393)\end{array}$ \\
\hline mandate (high util) & $\begin{array}{l}2.123^{* * *} \\
(0.516)\end{array}$ & $\begin{array}{cc}-0.124 & -0.168 \\
(0.208) & (0.240)\end{array}$ & $\begin{array}{l}0.0836^{*} \\
(0.0442)\end{array}$ & $\begin{array}{cc}-0.0708 & -0.0463 \\
(0.0778) & (0.0934)\end{array}$ & $\begin{array}{l}-0.157 \\
(0.174)\end{array}$ & $\begin{array}{l}0.00177 \\
(0.0567)\end{array}$ \\
\hline
\end{tabular}

Time FE

Individual FE

Y

Pre-Reform Mean (y) (low util) I4.595

Pre-Reform Mean (y) (high util) $\quad 46.095$

$\mathrm{N}$ (low util)

46.095
1083760

II 29400

$\begin{array}{cc}\mathrm{Y} & \mathrm{Y} \\ \mathrm{Y} & \mathrm{Y} \\ 4.827 & 0.198 \\ 15.798 & 0.627 \\ 1083760 & \mathrm{I083760} \\ \mathrm{II} 29400 & \mathrm{II} 29400\end{array}$

$\mathrm{Y}$
$\mathrm{Y}$
$\mathrm{I} .226$
$3.26 \mathrm{I}$
$\mathrm{I} 83760$
$\mathrm{II} 29400$

$\begin{array}{cc}\mathrm{Y} & \mathrm{Y} \\ \mathrm{Y} & \mathrm{Y} \\ 3.4 \mathrm{O} 2 & 0.745 \\ \mathrm{II} .91 \mathrm{O} & \mathrm{I} .725 \\ \mathrm{I0} 83760 & \mathrm{I0} 83760 \\ \mathrm{II} 29400 & \mathrm{II} 29400\end{array}$

Notes: Panel A based on analysis sample in $2 \mathrm{OIOQ}_{2}-2 \mathrm{O}_{3} \mathrm{Q}_{4}$, excluding observations of the control group. Panel B based on all observations in the analysis sample in $20 \mathrm{OIO}_{2}$ - 20I3 $\mathrm{Q}_{4}$. Outcome variables are multiplied by 100 at each person-quarter cell for presentation purpose. The coefficients are from regressions of outcome variables on mandate indicators (shown in tables), quarter FEs, and individual FEs, with standard errors clustered at individual level. The odd-numbered columns show the coefficients for high and low baseline utilizers separately by interacting all RHS variables with high utilizer indicator, which is equivalent to running the regressions separately for the two groups. The even-numbered columns test for statistical significance of the differences between high vs. low utilizer coefficients, by regressing outcome variables on mandate indicator and mandate indicator interacted with high utilizer indicator. High utilizer is defined as individuals whose total number of inpatient hospital discharge + ER visit is higher than or equal to the median (which equals 2 in the analysis sample). ${ }^{*} p<0.10,{ }^{* *} p<0.05,{ }^{* * *} p<0.01$. 
Table 8: Heterogeneity by GMC vs. Two-Plan

\begin{tabular}{|c|c|c|c|c|c|c|c|c|c|c|c|c|}
\hline & (I) & $(2)$ & (3) & $(4)$ & $(5)$ & (6) & (7) & $(8)$ & (9) & (г) & (II) & (12) \\
\hline $\begin{array}{l}\text { Panel A: } \\
\text { No Control Group }\end{array}$ & \multicolumn{2}{|c|}{ ER Visit } & \multicolumn{2}{|c|}{ Discharge } & \multicolumn{2}{|c|}{$\begin{array}{l}\text { Non-ER } \\
\text { Transfer }\end{array}$} & \multicolumn{2}{|c|}{$\begin{array}{c}\text { Non-ER } \\
\text { Non-transfer }\end{array}$} & \multicolumn{2}{|c|}{$\begin{array}{l}\text { Admitted from } \\
\text { Own ER }\end{array}$} & \multicolumn{2}{|c|}{ Scheduled } \\
\hline mandate (Two-Plan) & $\begin{array}{l}0.727^{* *} \\
(0.35 \mathrm{I})\end{array}$ & & $\begin{array}{l}0.126 \\
(0.174)\end{array}$ & & $\begin{array}{l}0.0733^{* *} \\
(0.0327)\end{array}$ & & $\begin{array}{l}-0.0765 \\
(0.0708)\end{array}$ & & $\begin{array}{l}0.129 \\
(0.145)\end{array}$ & & $\begin{array}{l}-0.0280 \\
(0.0520)\end{array}$ & \\
\hline mandate (GMC) & $\begin{array}{l}0.720 \\
(0.791)\end{array}$ & $\begin{array}{c}-0.00662 \\
(0.865)\end{array}$ & $\begin{array}{l}-0.486 \\
(0.382)\end{array}$ & $\begin{array}{l}-0.6 \mathrm{II} \\
(0.419)\end{array}$ & $\begin{array}{c}0.0688 \\
(0.0687)\end{array}$ & $\begin{array}{l}-0.00453 \\
(0.076 \mathrm{I})\end{array}$ & $\begin{array}{l}-0.223 \\
(0.160)\end{array}$ & $\begin{array}{l}-0.147 \\
(0.175)\end{array}$ & $\begin{array}{l}-0.331 \\
(0.314)\end{array}$ & $\begin{array}{l}-0.460 \\
(0.346)\end{array}$ & $\begin{array}{l}-0.250^{* *} \\
(0.118)\end{array}$ & $\begin{array}{l}-0.222^{*} \\
(0.129)\end{array}$ \\
\hline Time FE & $\mathrm{Y}$ & & $\mathrm{Y}$ & & $\mathrm{Y}$ & & $\mathrm{Y}$ & & $\mathrm{Y}$ & & $\mathrm{Y}$ & \\
\hline Pre-Reform Mean(y) (Two-Plan) & $30.48 \mathrm{I}$ & & 10.869 & & 0.418 & & 2.370 & & $8.08 \mathrm{I}$ & & I.274 & \\
\hline Pre-Reform Mean(y) (GMC) & 31.095 & & 10.625 & & 0.458 & & 2.136 & & 8.030 & & $\mathrm{I} .244$ & \\
\hline N (Two-Plan) & 1620786 & & 1620786 & & 1620786 & & 1620786 & & 1620786 & & 1620786 & \\
\hline $\mathrm{N}(\mathrm{GMC})$ & 317296 & & 317296 & & 317296 & & 317296 & & 317296 & & 317296 & \\
\hline $\begin{array}{l}\text { Panel B: } \\
\text { COHS Control Group }\end{array}$ & \multicolumn{2}{|c|}{ ER Visit } & \multicolumn{2}{|c|}{ Discharge } & \multicolumn{2}{|c|}{$\begin{array}{l}\text { Non-ER } \\
\text { Transfer }\end{array}$} & \multicolumn{2}{|c|}{$\begin{array}{c}\text { Non-ER } \\
\text { Non-transfer }\end{array}$} & \multicolumn{2}{|c|}{$\begin{array}{l}\text { Admitted from } \\
\text { Own ER }\end{array}$} & \multicolumn{2}{|c|}{ Scheduled } \\
\hline Time FE & $\mathrm{Y}$ & $\mathrm{Y}$ & $\mathrm{Y}$ & $\mathrm{Y}$ & $\mathrm{Y}$ & $\mathrm{Y}$ & $\mathrm{Y}$ & $\mathrm{Y}$ & $\mathrm{Y}$ & $\mathrm{Y}$ & $\mathrm{Y}$ & $\mathrm{Y}$ \\
\hline Individual FE & $\mathrm{Y}$ & $\mathrm{Y}$ & $\mathrm{Y}$ & $\mathrm{Y}$ & $\mathrm{Y}$ & $\mathrm{Y}$ & $\mathrm{Y}$ & $\mathrm{Y}$ & $\mathrm{Y}$ & Y & $\mathrm{Y}$ & $\mathrm{Y}$ \\
\hline Pre-Reform Mean(y) (Two-Plan and COHS) & 30.763 & & I0.449 & & 0.413 & & 2.296 & & $7 \cdot 740$ & & I.25I & \\
\hline $\begin{array}{l}\text { Pre-Reform Mean(y) (GMC and COHS) } \\
\text { N (Two-Plan and COHS) }\end{array}$ & I895864 & 31.712 & I895864 & $9 \cdot 394$ & 1895864 & 0.423 & 1895864 & 2.009 & I895864 & 6.960 & I895864 & $\mathrm{I} . \mathrm{I} 84$ \\
\hline $\mathrm{N}(\mathrm{GMC}$ and $\mathrm{COHS})$ & & 592374 & & 592374 & & 592374 & & 592374 & & 592374 & & 592374 \\
\hline
\end{tabular}

Notes: Panel A based on analysis sample in $2 \mathrm{OIOQ}_{2}-2 \mathrm{O}_{3} \mathrm{Q}_{4}$, excluding observations of the control group. Panel B based on all observations in the analysis sample in $2010 \mathrm{Q}_{2}-2 \mathrm{O}_{3} \mathrm{Q}_{4}$. Outcome variables are multiplied by 100 at each person-quarter cell for presentation purpose. The coefficients are from regressions of outcome variables on mandate indicators (shown in tables), quarter FEs, and individual FEs, with standard errors clustered at individual level. In panel A, the odd-numbered columns show the coefficients for GMC and Two-Plan counties separately by interacting all RHS variables with GMC indicator, which is equivalent to running the regressions separately for the two groups. The even-numbered columns test for statistical significance of the differences between GMC vs. Two-Plan county coefficients, by regressing outcome variables on relative event time indicators and relative event time indicators interacted with GMC indicator. In panel B, the odd-numbered columns show the coefficients from regressions with sample that includes both Two-Plan and COHS control counties, and the even-numbered columns show the coefficint from regressions with sample that includes both GMC and COHS control counties. GMC counties include San Diego and Sacramento. ${ }^{*} p<0.10,{ }^{* *} p<0.05,{ }^{* * *} p<0.01$. 


\section{Figures}

Figure I: Medicaid Manged Care Enrollment and Expenditure in the US
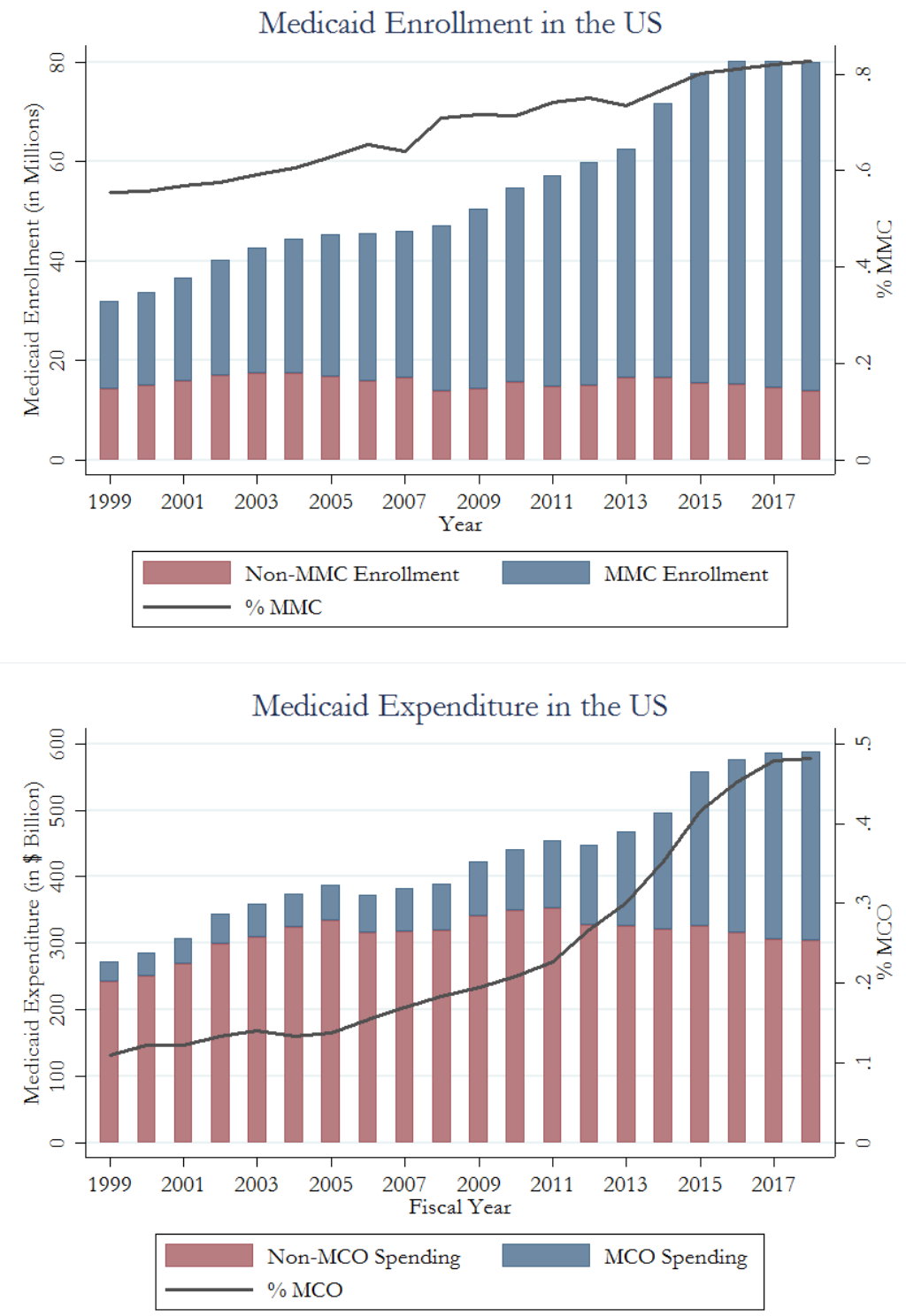

Notes: Medicaid expenditure data from CMS Medicaid Financial Management Report - Net Services (CMS-64) 1999 - 2018. Medicaid expenditure is based on total net expenditure on medical services reported in $\mathrm{CMS}_{4}$ forms, excluding CHIP spending and administrative spending. MCO spending does not include expenditures on MCO evaluation and management, prepaid ambulatory health plan, and prepaid inpatient health plan. Expenditure data are inflation adjusted (reported in \$2018). Medicaid enrollment data from CMS Medicaid Managed Care Enrollment Reports 2005, 2011, 2013, 2014, 2015, 2016, 2017,2018 and CMS Medicaid Managed Care Trends and Snapshots 2000 - 2013. Table reports Medicaid enrollment as of June $30 t h$ for 1999 - 2009 and July Ist for 2010 - 2018. The unduplicated managed care enrollment figures include enrollees receiving comprehensive benefits and limited benefits. 
Figure 2: MMC Enrollment by Birth Month

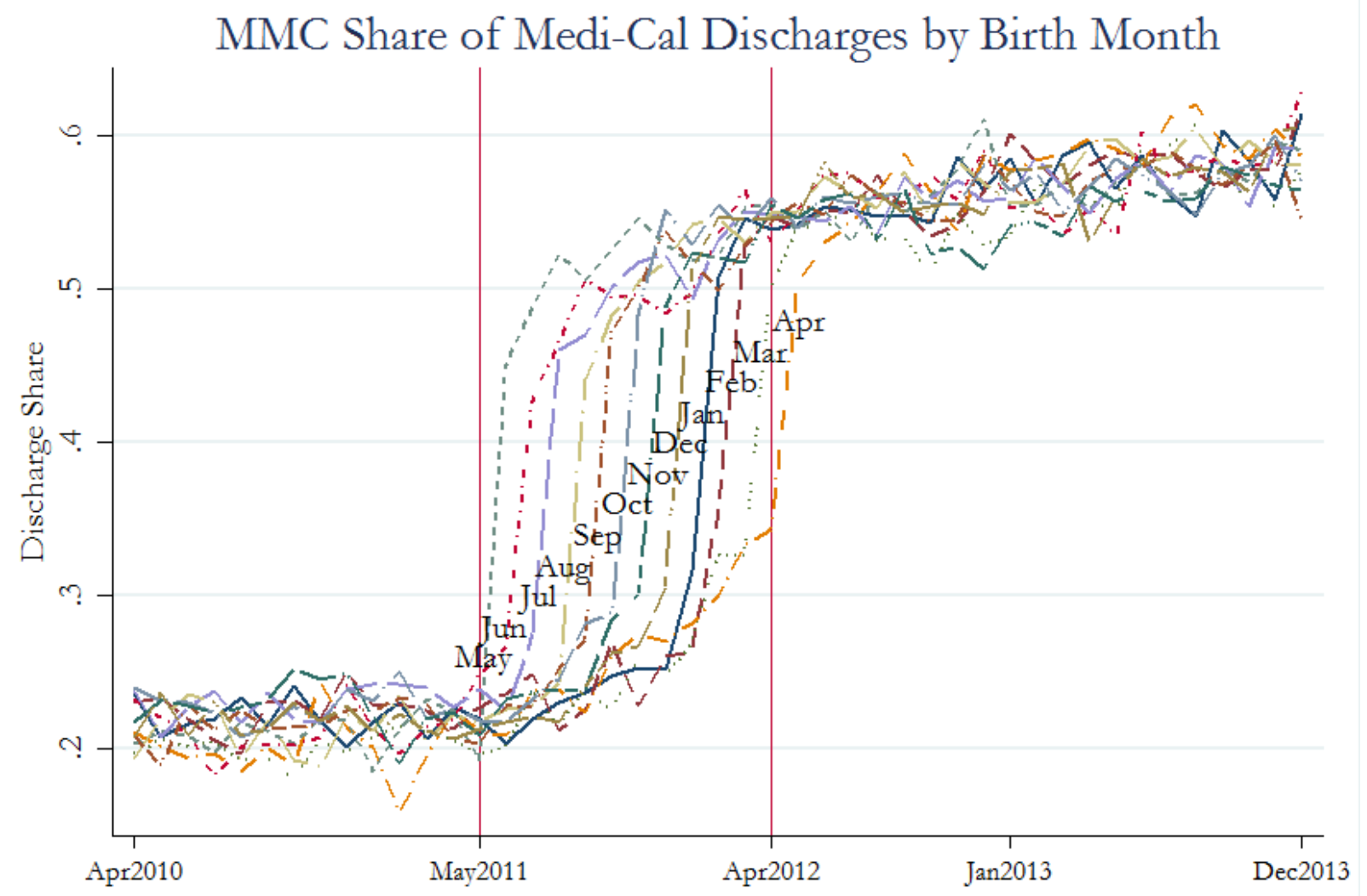

Notes: Based on universe of hospital discharges in California from 2010q2 to 201394 that are non-birth related for individuals residing in reform counties and born in 1950-69. Figure plots MMC discharges as share of Medicaid discharges in each month for each birth month. Policy implementation period is from $2011 \mathrm{q} 2$ to $2012 \mathrm{q} 2$. 
Figure 3: MMC Share of Hospital Discharge

(a) MMC and MCDFFS Share of Total Discharge in Reform Counties

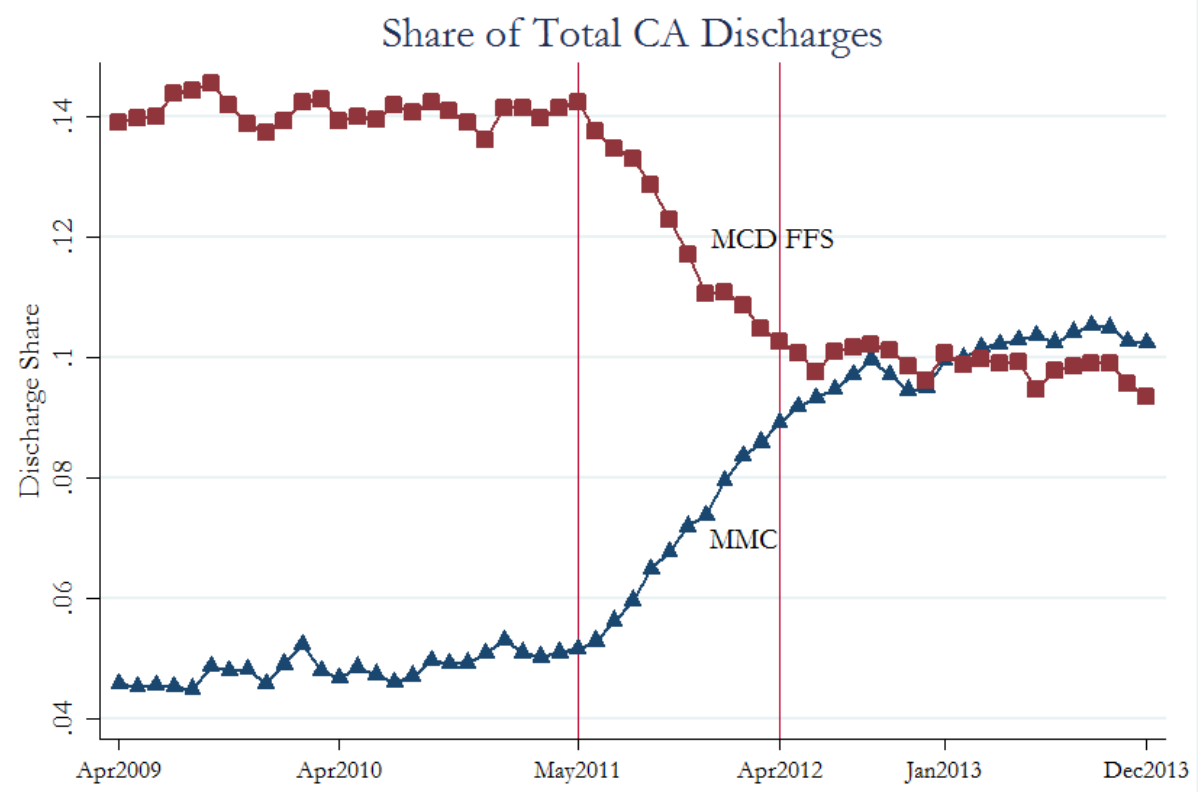

(b) MMC Share of Total Discharge in Reform Counties by Birth Cohort

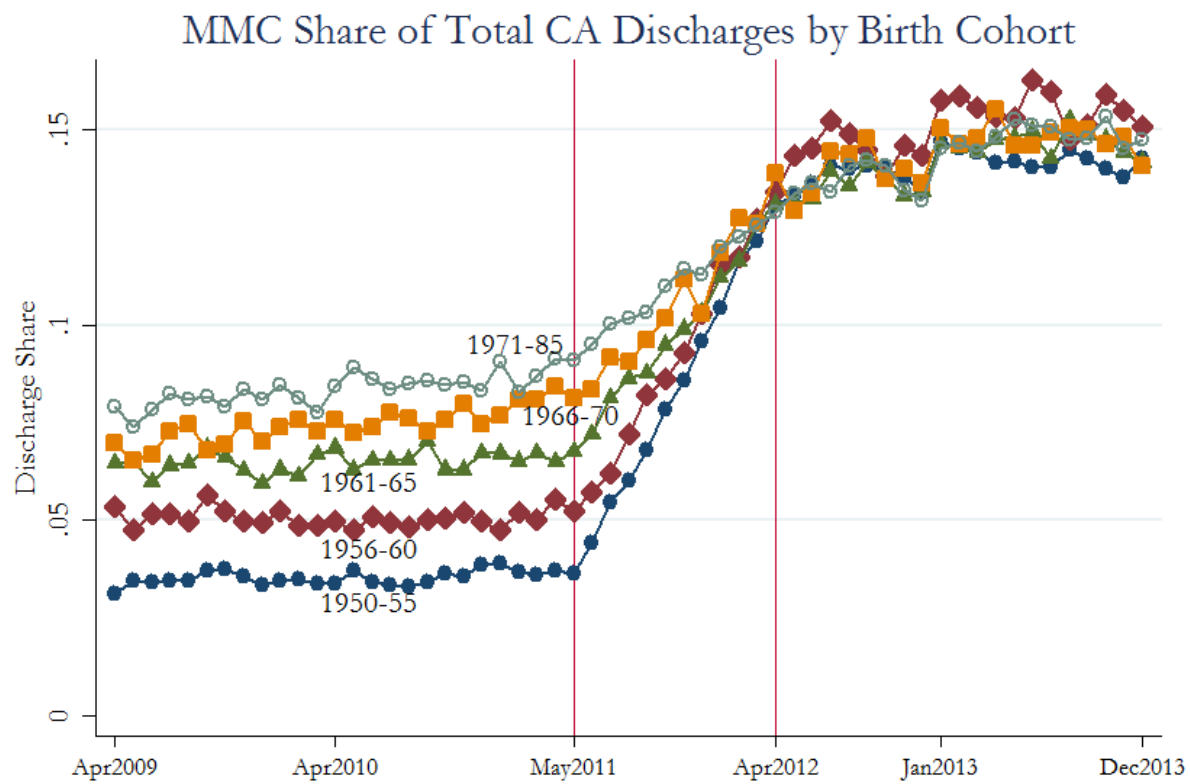

Notes: Based on universe of hospital discharges in California from $2009 \mathrm{q} 2$ to $2013 \mathrm{q} 4$ that are non-birth related for individuals residing in reform counties, not restricting year of birth in panel A and restricting to those born in $1950-85$ in panel B. Figure plots MMC and MCDFFS discharges as share of all hospital discharges in each month. Policy implementation period is from $2011 \mathrm{q} 2$ to $2012 \mathrm{q} 2$. 


\section{Figure 4: MMC Enrollment Event Study}

\section{(a) Main Specification}

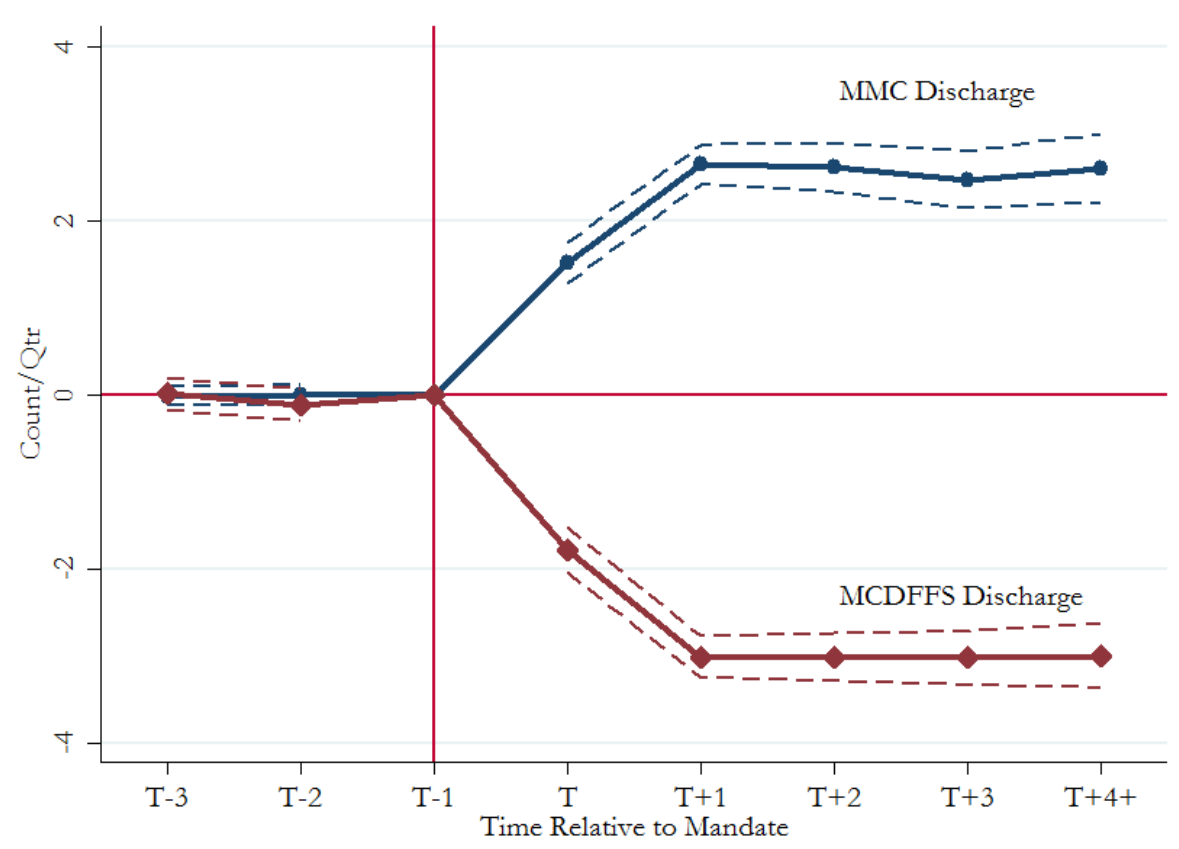

(b) COHS Specification

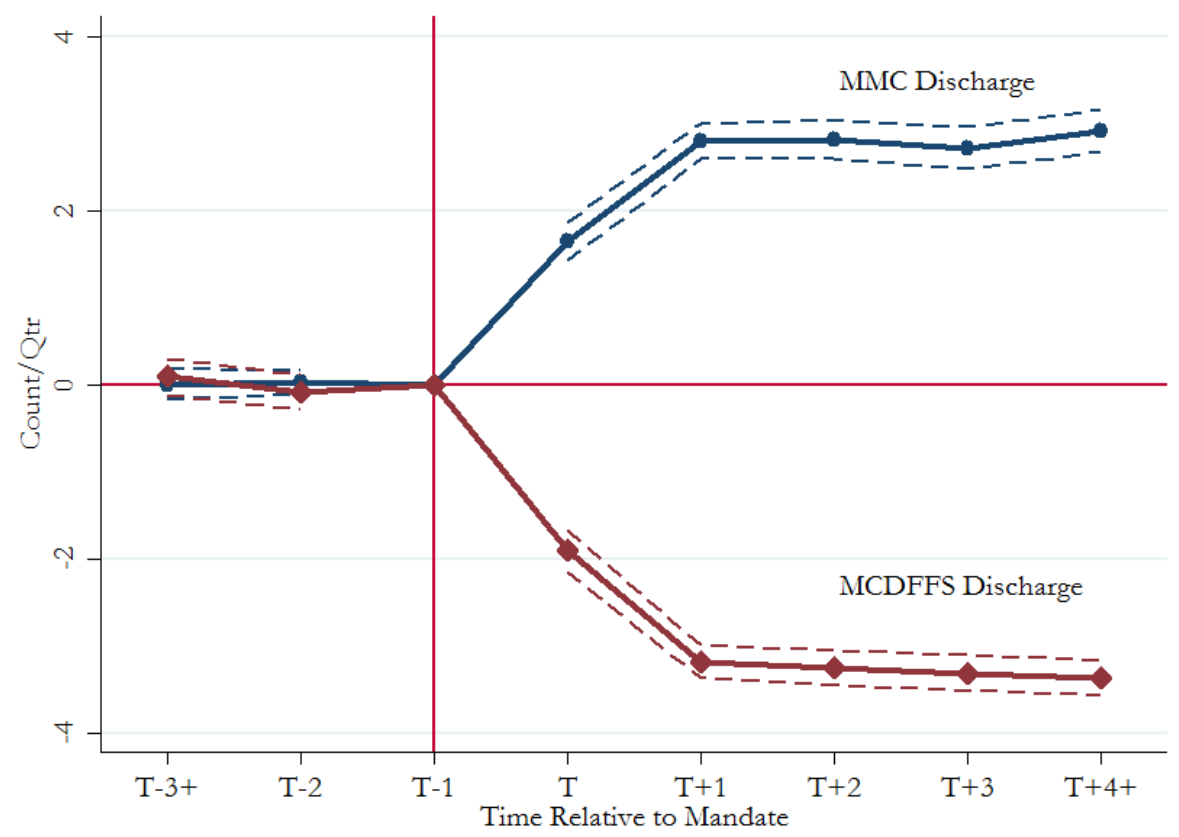

Notes: Panel A based on analysis sample in ${ }_{2} \mathrm{OI}_{2} \mathrm{Q}_{2}-{ }_{2} \mathrm{O}_{3} \mathrm{Q}_{4}$, excluding observations of the control group. Panel B based on all observations in the analysis sample in $2010 Q_{2}-2013 Q_{4}$. Outcome variables are multiplied by 100 at each person-quarter cell for presentation purpose. The coefficients are from regressions of outcome variables on mandate indicators, quarter FEs, and individual FEs, with standard errors clustered at individual level. 
Figure 5: MMC Share of Hospital Discharge by COHS vs. Reform Counties

(a) MMC Share of Total Discharge

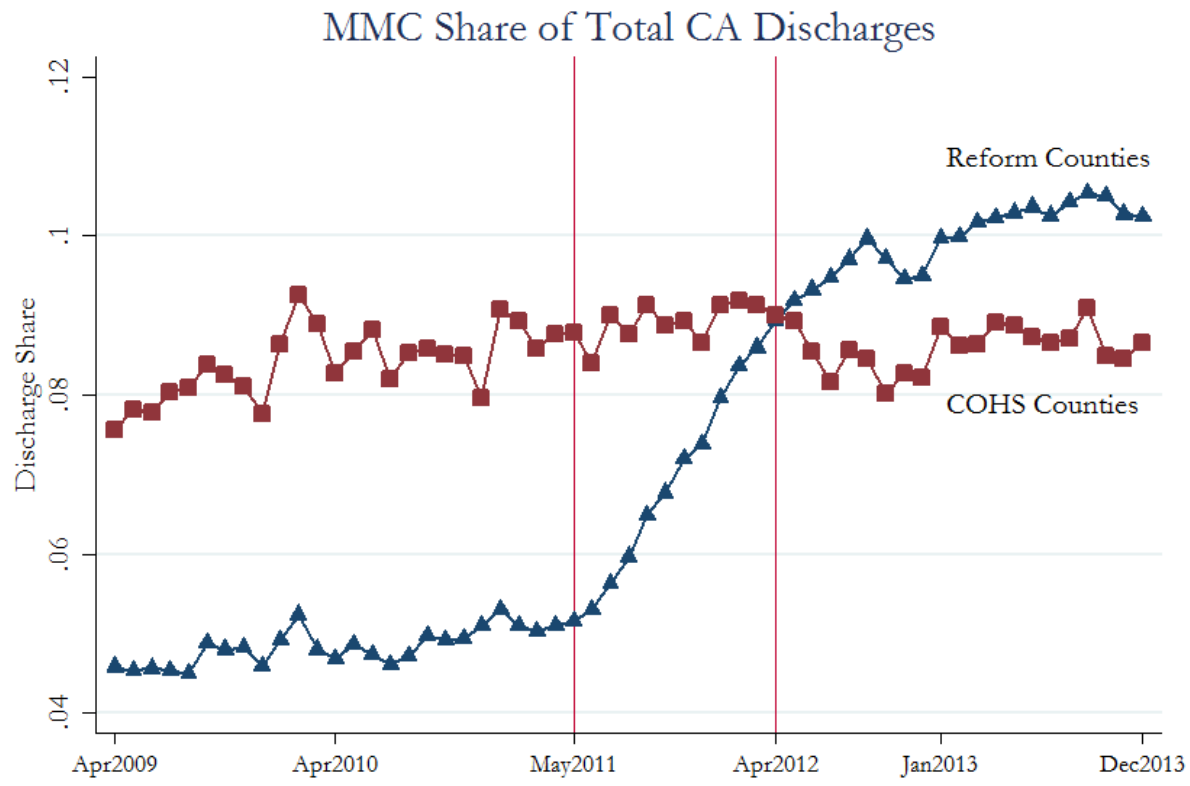

(b) MMC Share of Medicaid Discharge

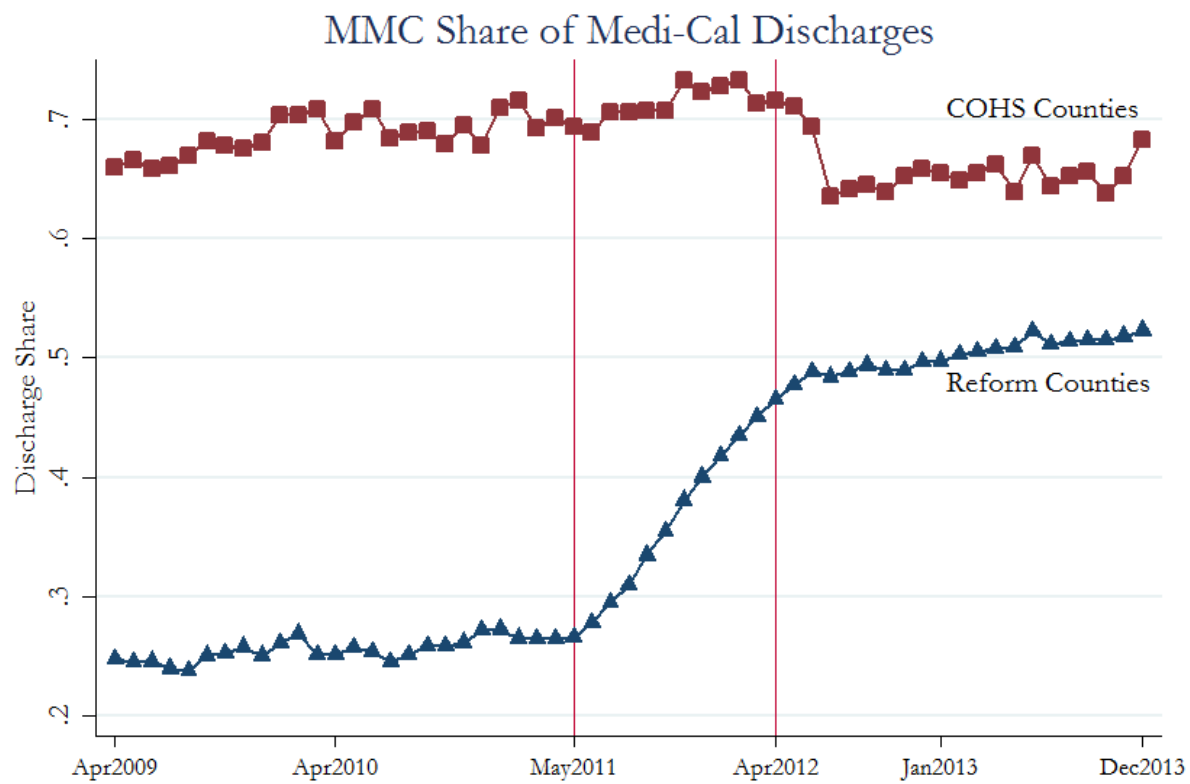

Notes: Based on universe of hospital discharges in California from 2009q2 to 2013q4 that are non-birth related for individuals residing in reform and COHS counties. Figure plots MMC discharges as share of all hospital discharges in each month in panel A and as share of Medi-Cal discharges in panel B. Policy implementation period is from $2011 \mathrm{q} 2$ to $2012 \mathrm{q} 2$. 
Figure 6: ER Visit Event Study

(a) Main Specification

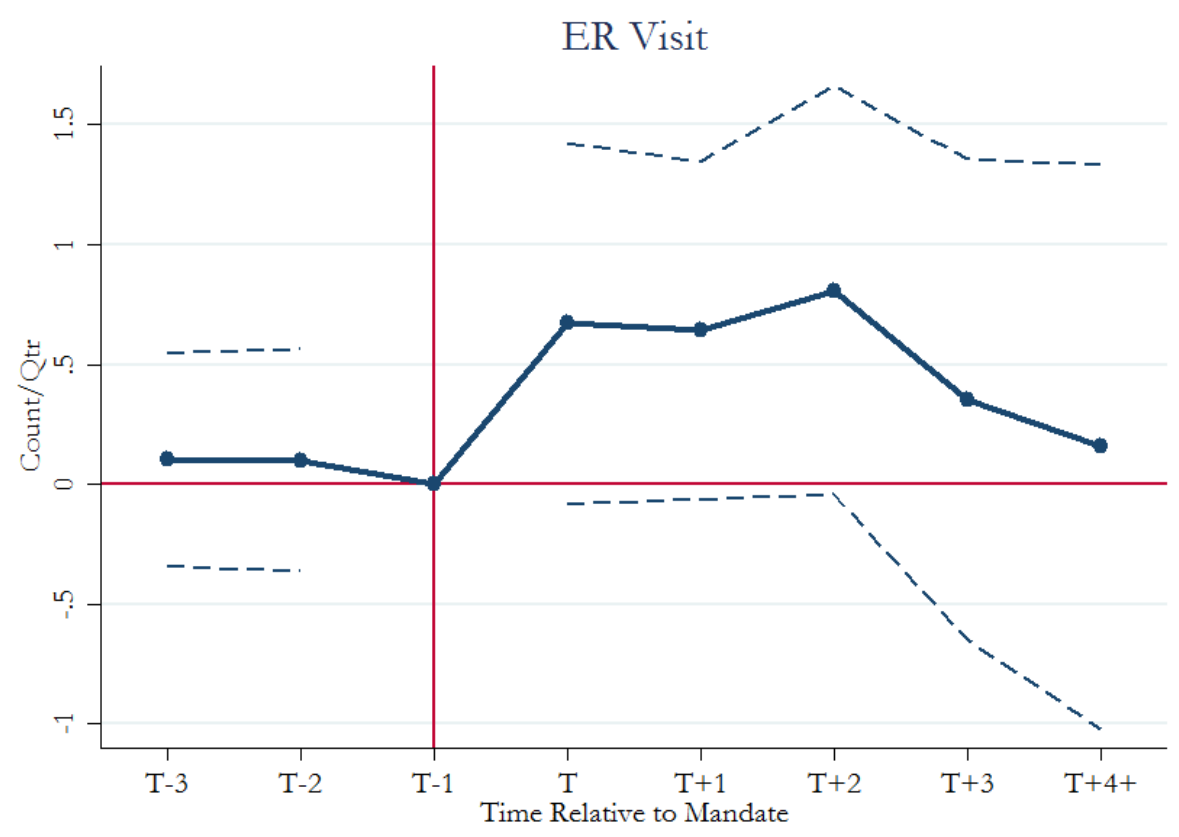

(b) COHS Specification

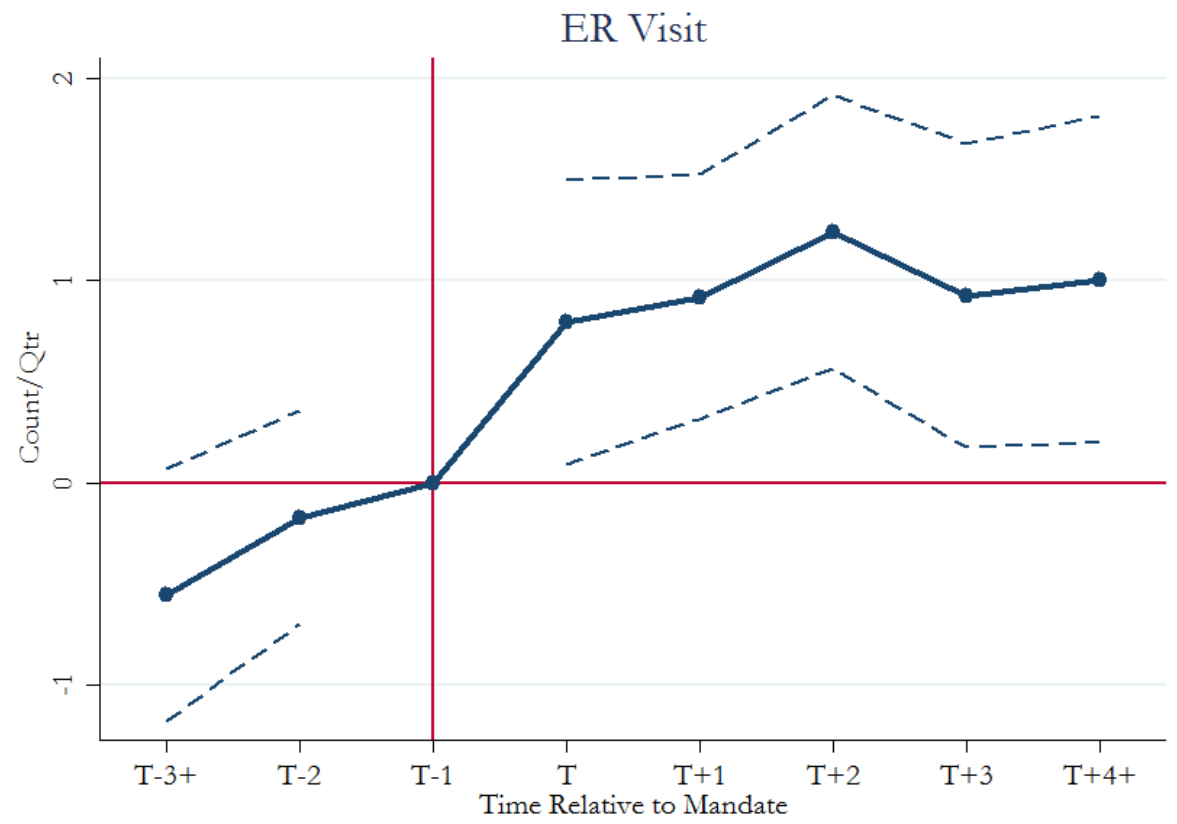

Notes: Panel A based on analysis sample in $2 \mathrm{OIOQ}_{2}-2 \mathrm{O}_{3} \mathrm{Q}_{4}$, excluding observations of the control group. Panel B based on all observations in the analysis sample in $2010 Q_{2}-2013 Q_{4}$. Outcome variables are multiplied by 100 at each person-quarter cell for presentation purpose. The coefficients are from regressions of outcome variables on mandate indicators, quarter FEs, and individual FEs, with standard errors clustered at individual level. 


\title{
Figure 7: Non-ER-Transfer Hospitalization Event Study
}

\author{
(a) Main Specification
}

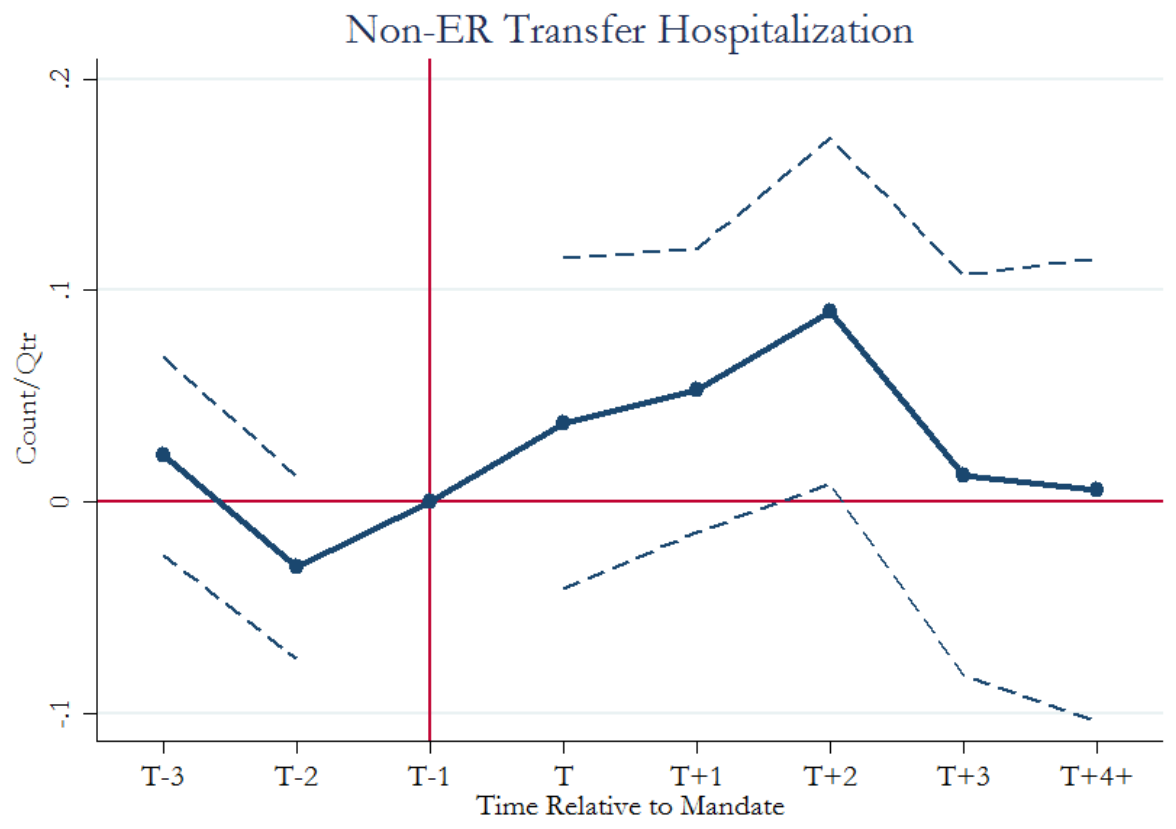

(b) COHS Specification

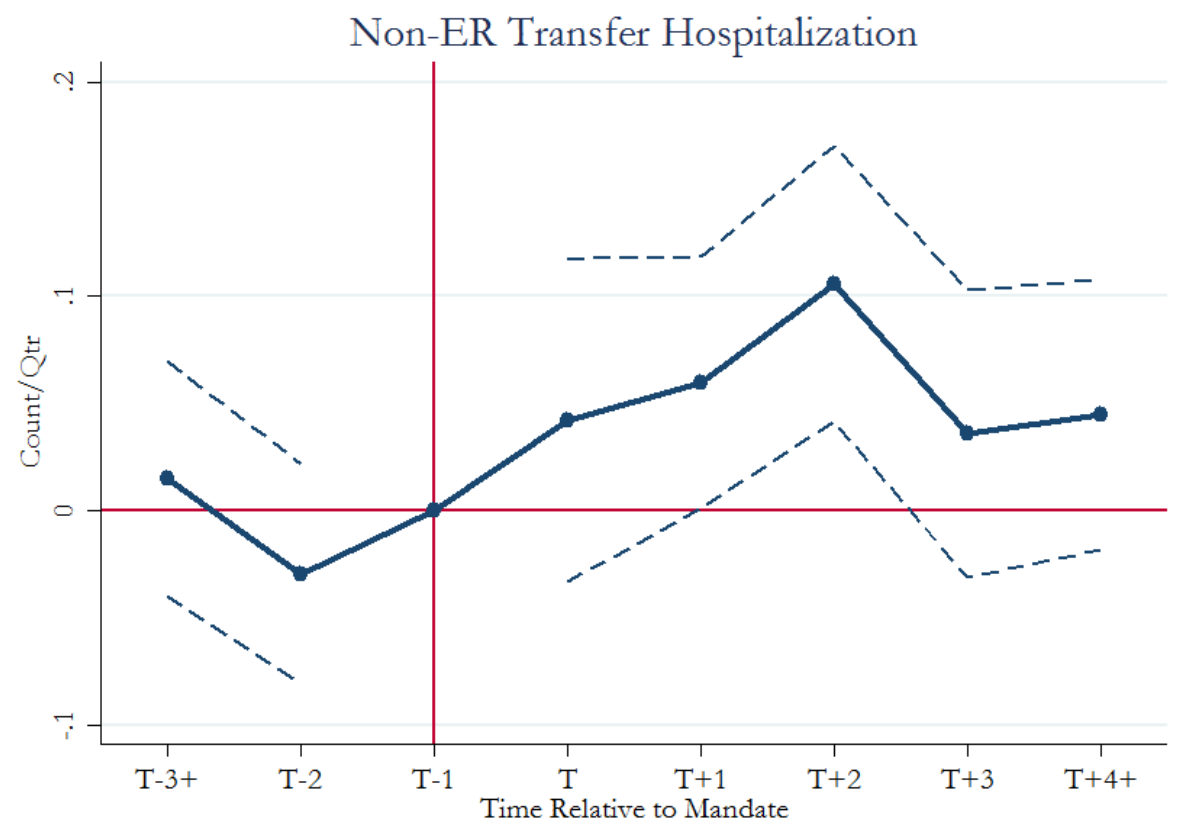

Notes: Panel A based on analysis sample in $2 \mathrm{OIOQ}_{2}-2 \mathrm{O}_{3} \mathrm{Q}_{4}$, excluding observations of the control group. Panel B based on all observations in the analysis sample in $2010 Q_{2}-2013 Q_{4}$. Outcome variables are multiplied by 100 at each person-quarter cell for presentation purpose. The coefficients are from regressions of outcome variables on mandate indicators, quarter FEs, and individual FEs, with standard errors clustered at individual level. 
Figure 8: Mortality Event Study

(a) Main Specification

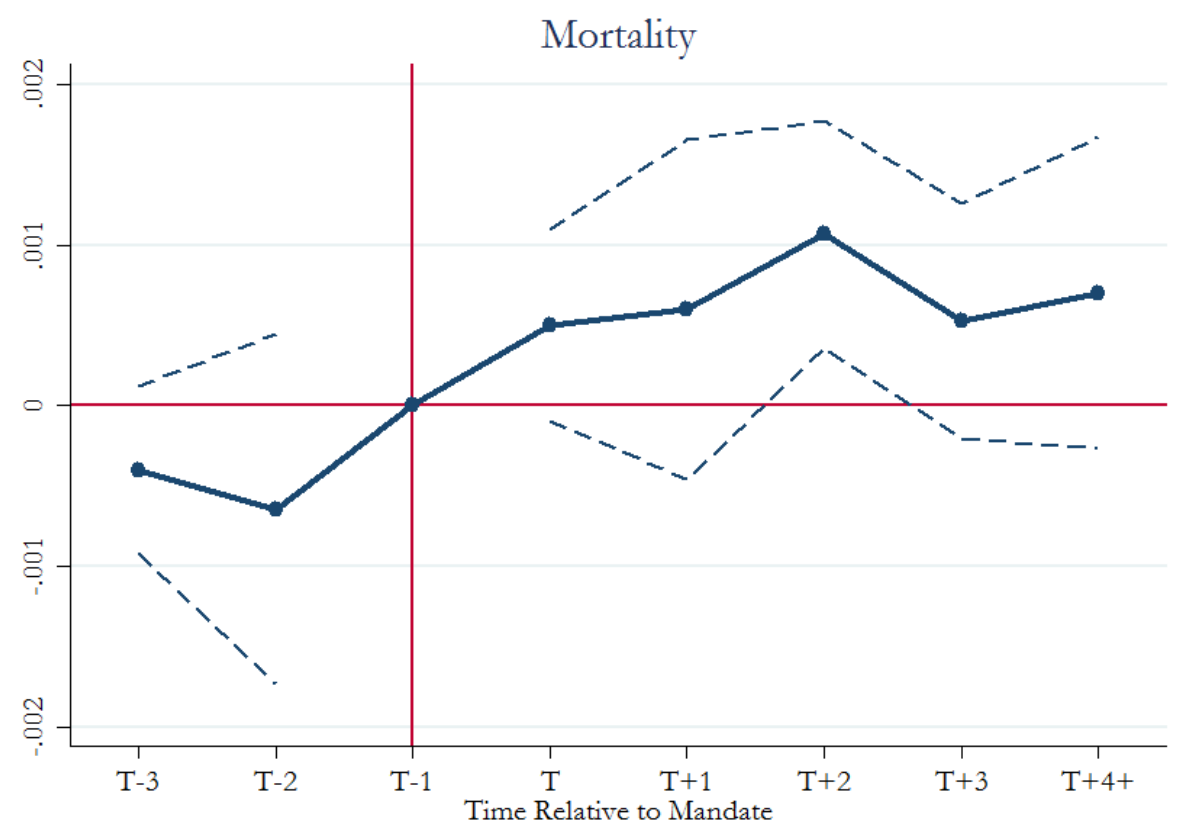

(b) COHS Specification

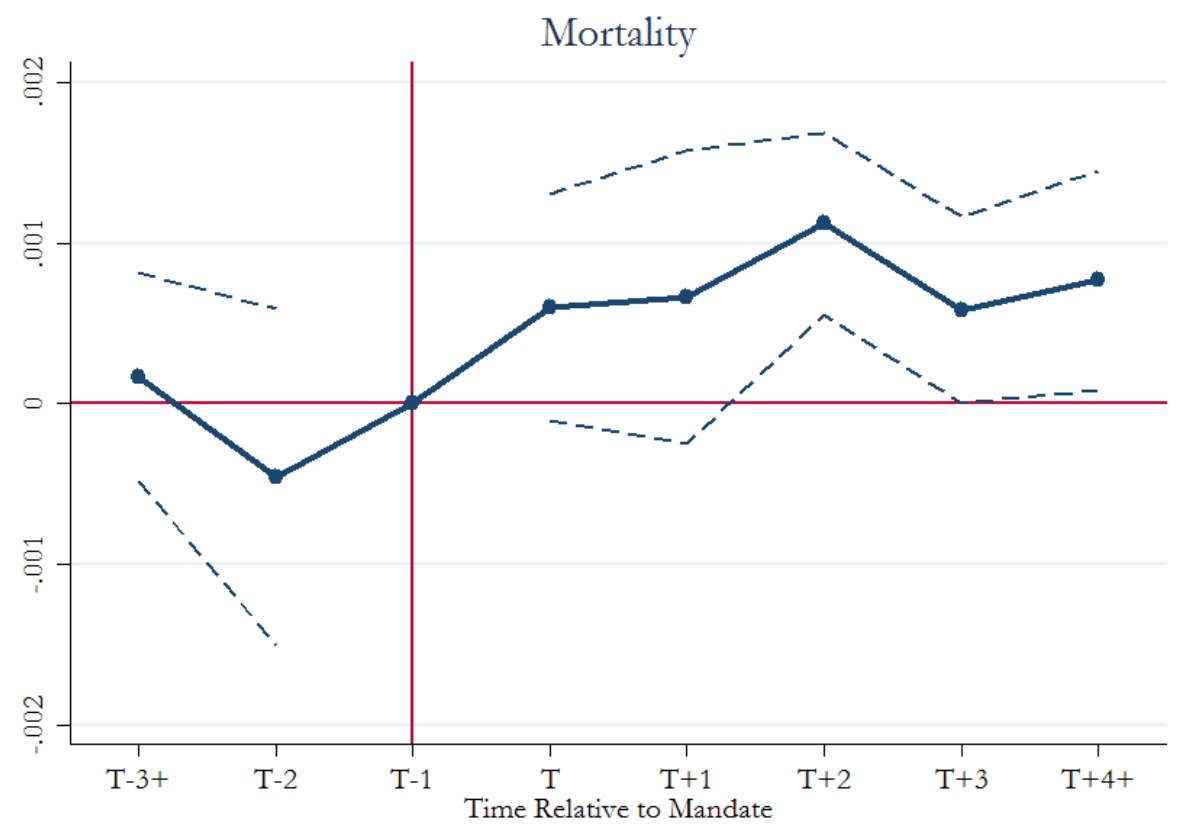

Notes: Panel A based on analysis sample in $2 \mathrm{O}_{20} \mathrm{Q}_{2}-2 \mathrm{O}_{3} \mathrm{Q}_{4}$, excluding observations of the control group and individuals without any hospital discharge in ${ }_{2009} \mathrm{Q}_{2}-{ }_{2} \mathrm{O}_{3} \mathrm{Q}_{4}$. Panel B based on all observations in the analysis sample in $2010 \mathrm{Q}_{2}-20{ }_{3} \mathrm{Q}_{4}$, excluding individuals without any hospital discharge in ${ }_{2009} \mathrm{Q}_{2}-{ }_{2} \mathrm{Ol}_{3} \mathrm{Q}_{4}$. The coefficients are from linear regression of outcome variable (o/I death indicator) on mandate indicators, quarter FEs, county FEs, age FEs, and gender indicator, with standard errors clustered at county level. 


\section{Figure 9: ER Visit Event Study by High vs. Low Baseline Utilization}

\section{(a) Main Specification}

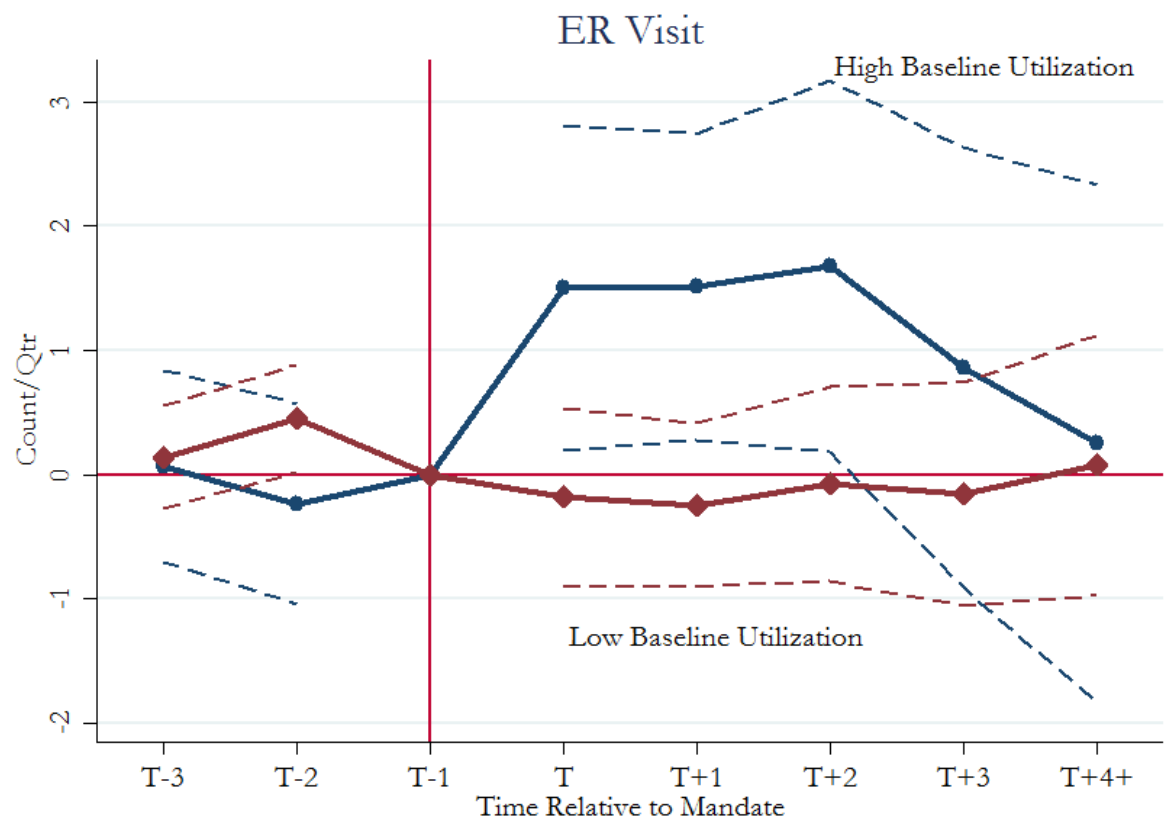

(b) COHS Specification

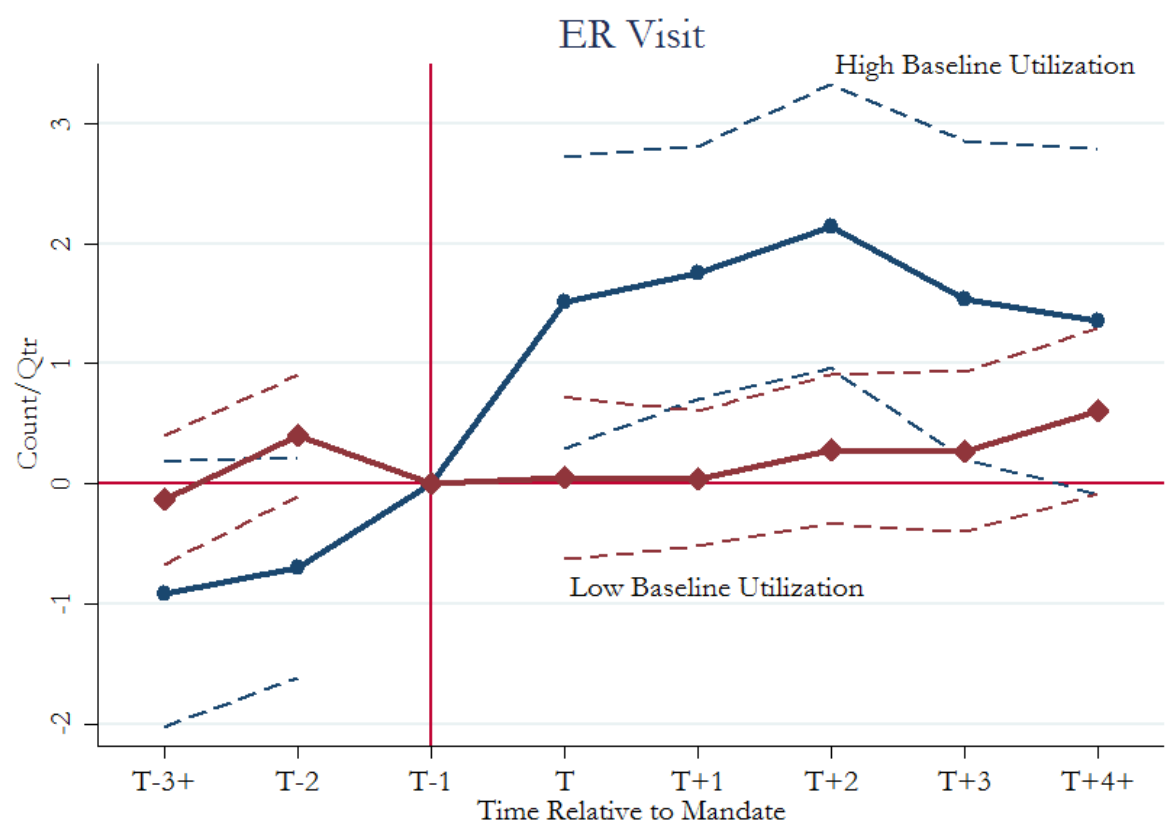

Notes: Panel A based on analysis sample in $2010 \mathrm{Q}_{2}-2 \mathrm{O}_{3} \mathrm{Q}_{4}$, excluding observations of the control group. Panel B based on all observations in the analysis sample in $2010 \mathrm{Q}_{2}-\mathrm{2OI}_{3} \mathrm{Q}_{4}$. Outcome variables are multiplied by 100 at each person-quarter cell for presentation purpose. The coefficients are from separate regressions by baseline utilization of outcome variables on mandate indicators, quarter FEs, and individual FEs, with standard errors clustered at individual level. High utilizer is defined as individuals whose total number of inpatient hospital discharge + ER visit is higher than or equal to the median (which equals 2 in the analysis sample). 
Figure ro: Mortality Event Study by High vs. Low Baseline Utilization

(a) Main Specification

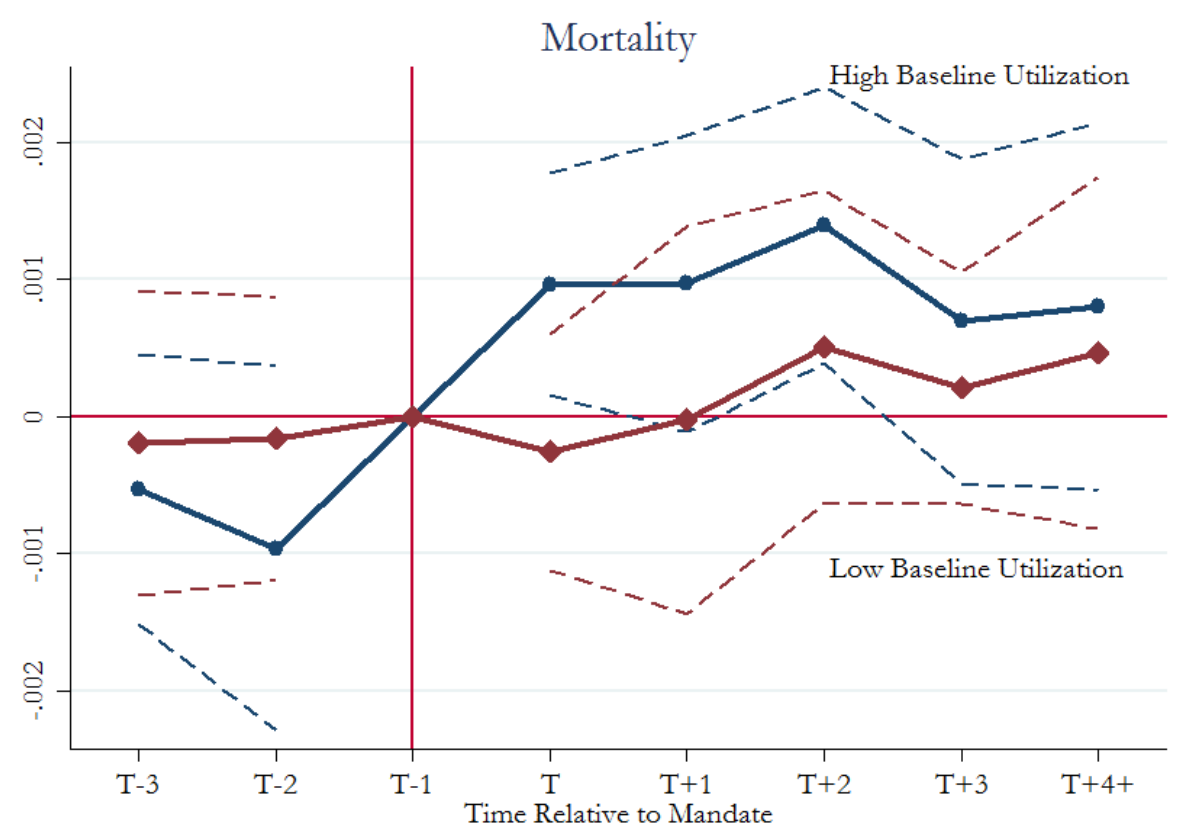

(b) COHS Specification

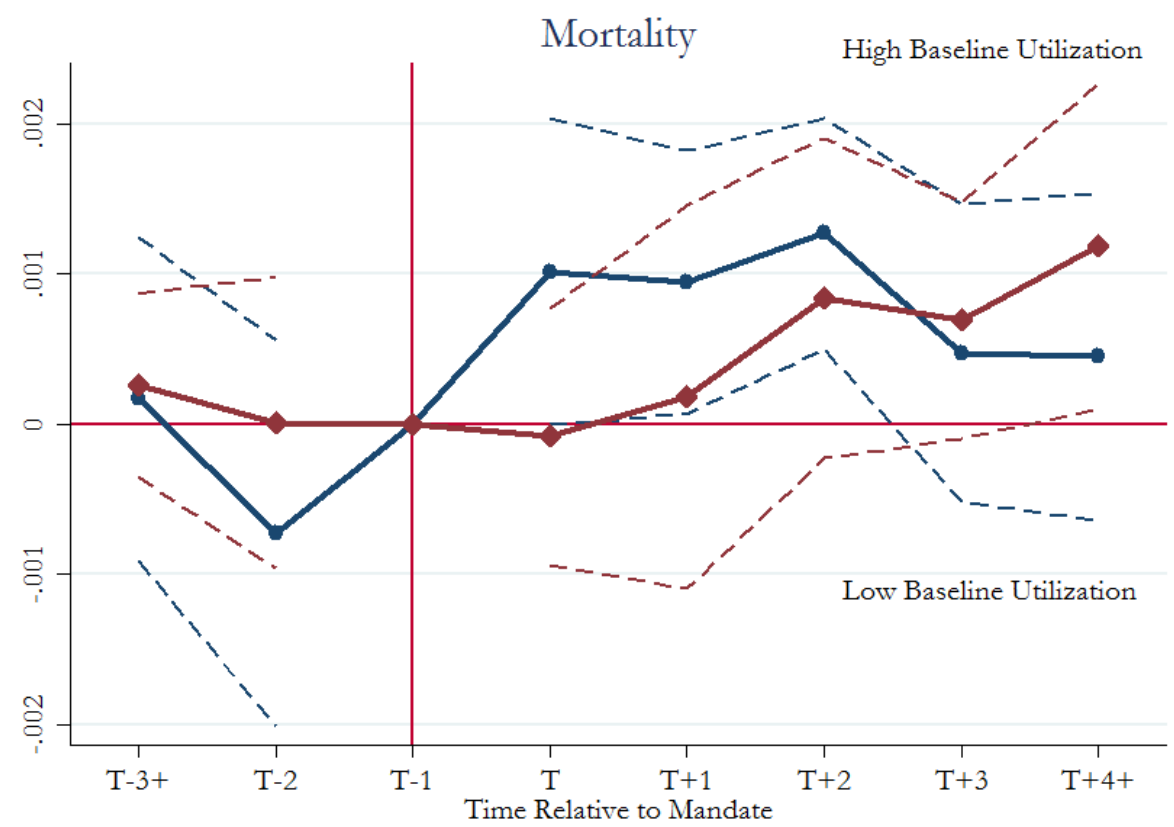

Notes: Panel A based on analysis sample in $2010 \mathrm{Q}_{2}-{ }_{2} \mathrm{O}_{3} \mathrm{Q}_{4}$, excluding observations of the control group and individuals without any hospital discharge in $2009 \mathrm{Q}_{2}-2 \mathrm{OI}_{3} \mathrm{Q}_{4}$. Panel B based on all observations in the analysis sample in $2010 \mathrm{Q}_{2}-20 \mathrm{O}_{3}$, excluding individuals without any hospital discharge in $2009 Q_{2}-2013 Q_{4}$. The coefficients are from separate linear regression by baseline utilization of outcome variable ( $\mathrm{o} / \mathrm{I}$ death indicator) on mandate indicators, quarter FEs, county FEs, age FEs, and gender indicator, with standard errors clustered at county level. High utilizer is defined as individuals whose total number of inpatient hospital discharge + ER visit is higher than or equal to the median (which equals 2 in the analysis sample). 
Figure II: Mortality Event Study by High vs. Low Baseline Elixhauser Score

(a) Main Specification

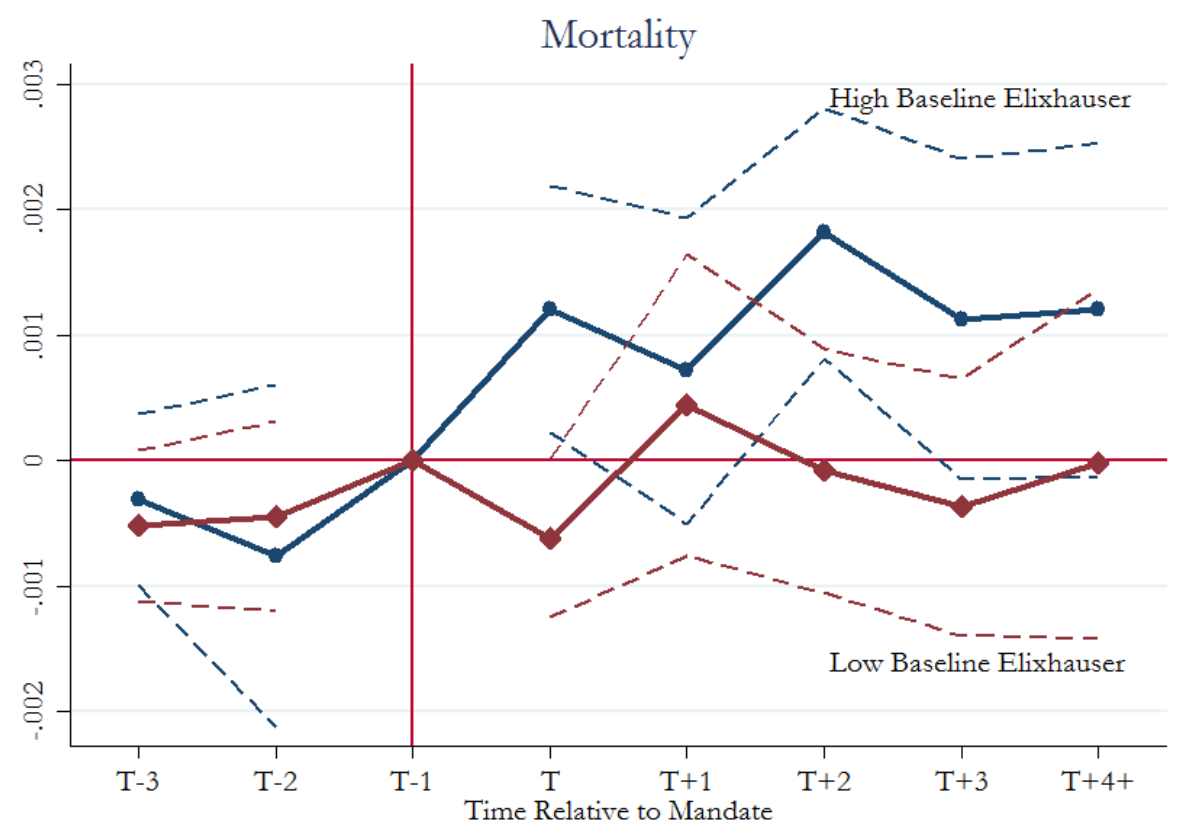

(b) COHS Specification

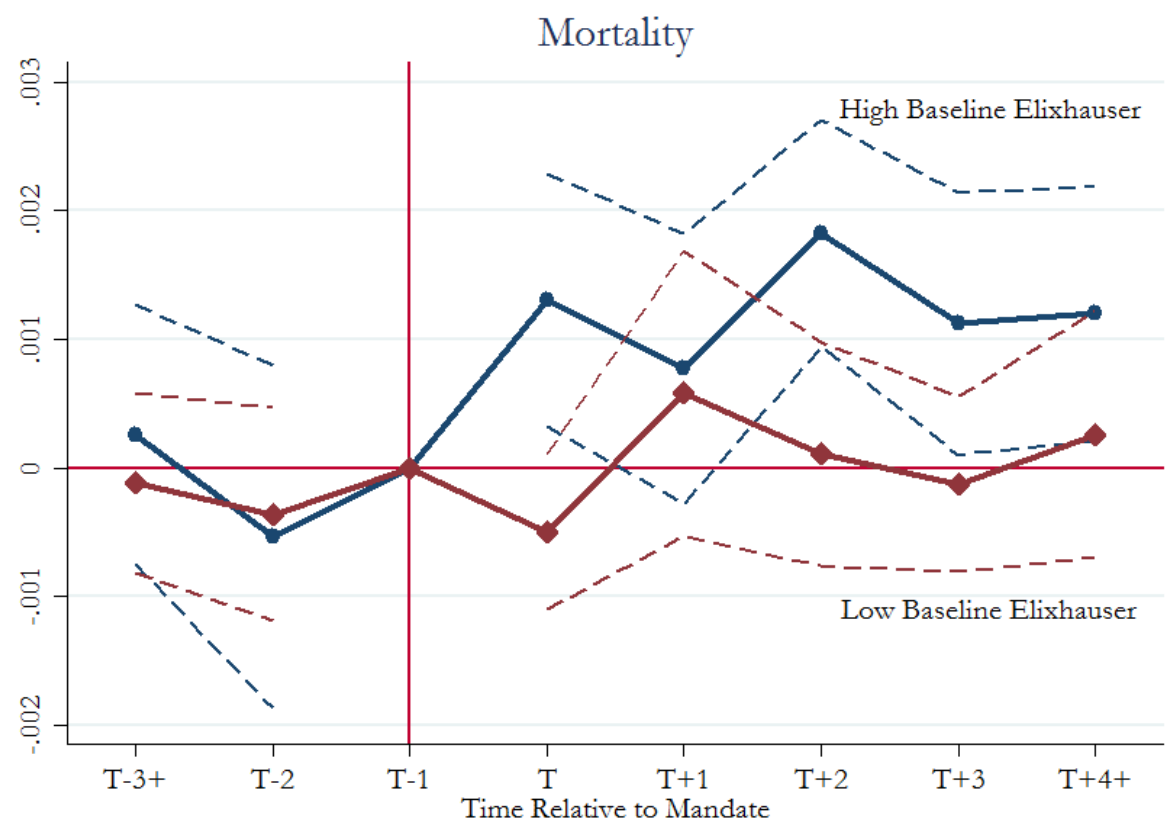

Notes: Panel A based on analysis sample in $2 \mathrm{OIOQ}_{2}-2 \mathrm{O}_{3} \mathrm{Q}_{4}$, excluding observations of the control group and individuals without any hospital discharge in ${ }_{2009} \mathrm{Q}_{2}-2013 \mathrm{Q}_{4}$. Panel $\mathrm{B}$ based on all observations in the analysis sample in $2010 \mathrm{Q}_{2}-20 \mathrm{I}_{3} \mathrm{Q}_{4}$, excluding individuals without any hospital discharge in $2009 \mathrm{Q}_{2}$ $-{ }_{2} \mathrm{O}_{3} \mathrm{Q}_{4}$. The coefficients are from separate linear regression by baseline Elixhauser score of outcome variable $(\mathrm{o} / \mathrm{I}$ death indicator) on mandate indicators, quarter FEs, county FEs, age FEs, and gender indicator, with standard errors clustered at county level. High severity patient is defined as individuals whose total unweighted number of chronic conditions (Elixhauser score) based on principal and co-diagnoses of all inpatient hospital discharges and ER visits at baseline is higher than the median (which equals $\mathrm{I}$ in the analysis sample). 


\section{Appendix}

Table Ar: Effect of MMC on ER Visit by Types

\begin{tabular}{|c|c|c|c|c|c|c|c|c|c|c|}
\hline & (I) & (2) & (3) & (4) & (s) & (6) & (7) & $(8)$ & (9) & (Iо) \\
\hline Panel A: No Control Group & ER (All) & $\begin{array}{c}\text { ED Needed } \\
\text { Not Preventable }\end{array}$ & $\begin{array}{l}\text { ED Needed } \\
\text { Preventable }\end{array}$ & $\begin{array}{c}\text { Emergent } \\
\text { PC Treatable }\end{array}$ & Non Emergent & Alcohol & Drug & Injury & Psych & Unclassified \\
\hline Time FE & Y & $\mathrm{Y}$ & Y & Y & Y & Y & Y & Y & Y & Y \\
\hline Individual FE & $\mathrm{Y}$ & $\mathrm{Y}$ & $\mathrm{Y}$ & $\mathrm{Y}$ & $\mathrm{Y}$ & $\mathrm{Y}$ & $\mathrm{Y}$ & $\mathrm{Y}$ & $\mathrm{Y}$ & $\mathrm{Y}$ \\
\hline Pre-Reform Mean (y) & 30.58 & 3.828 & 2.408 & 7.023 & 7.138 & 0.372 & 0.123 & 4.244 & 0.960 & 4.486 \\
\hline Observations & 1938082 & 1938082 & 1938082 & 1938082 & 1938082 & 1938082 & 1938082 & 1938082 & 1938082 & 1938082 \\
\hline Panel B: COHS Control Group & ER (All) & $\begin{array}{c}\text { ED Needed } \\
\text { Not Preventable }\end{array}$ & $\begin{array}{l}\text { ED Needed } \\
\text { Preventable }\end{array}$ & $\begin{array}{c}\text { Emergent } \\
\text { PC Treatable }\end{array}$ & Non Emergent & Alcohol & Drug & Injury & Psych & Unclassified \\
\hline mandate & $\begin{array}{l}\text { I.I79 } \\
(0.289)\end{array}$ & $\begin{array}{l}0.192^{* * *} \\
(0.0607)\end{array}$ & $\begin{array}{l}0.0880^{*} \\
(0.0487)\end{array}$ & $\begin{array}{l}0.232^{* * *} \\
(0.086 \mathrm{I})\end{array}$ & $\begin{array}{l}0.524^{* * *} \\
(0.105)\end{array}$ & $\begin{array}{c}-0.0201 \\
(0.0299)\end{array}$ & $\begin{array}{c}0.0132 \\
(0.0160)\end{array}$ & $\begin{array}{c}-0.0403 \\
(0.074 \mathrm{I})\end{array}$ & $\begin{array}{l}0.120^{* * *} \\
(0.0406)\end{array}$ & $\begin{array}{c}0.0702 \\
(0.0872)\end{array}$ \\
\hline
\end{tabular}

Time FE

Individual FE

Pre-Reform Mean (y)

$\begin{array}{cc}\mathrm{Y} & \mathrm{Y} \\ \mathrm{Y} & \mathrm{Y} \\ 30.8 \mathrm{I} & 3.8\end{array}$

Y

Observations

2213160

$\begin{array}{cc}\mathrm{Y} & \mathrm{Y} \\ \mathrm{Y} & \mathrm{Y} \\ 2.392 & 7.062\end{array}$

Y

Notes: Panel A based on analysis sample in $20 \mathrm{IOQ}_{2}-2 \mathrm{O}_{3} \mathrm{Q}_{4}$, excluding observations of the control group. Panel $\mathrm{B}$ based on all observations in the analysis sample in $2010 \mathrm{Q}_{2}-2 \mathrm{O}_{3} \mathrm{Q}_{4}$. Outcome variables ar multiplied by 100 at each person-quarter cell for presentation purpose. The coefficients are from regressions of outcome variables on mandate indicator, quarter FEs, and individual FEs, with standard errors clustered at individual level. The outcome variable in column $\mathrm{I}$ is the total number of ER visits in each person-quarter cell (same as column I in Table 4 , included here for comparison). The outcome variables in columns 2 - Io are the numbers of ER visits by types, classified according to the ICD-9 groups developed by NYU Center for Health and Public Service Research (https://wagner.nyu.edu/faculty/billings/nyuedbackground). ${ }^{*} p<0.10,{ }^{* *} p<0.05,{ }^{* * *} p<0.01$. 
Table A2: Effect of MMC on Non-ER Transfer by Source

\begin{tabular}{|c|c|c|c|c|}
\hline & (I) & (2) & (3) & (4) \\
\hline Panel A: No Control Group & $\begin{array}{l}\text { Non-ER } \\
\text { Transfer }\end{array}$ & $\begin{array}{c}\text { From } \\
\text { ER Admission }\end{array}$ & $\begin{array}{c}\text { From } \\
\text { Non-ER Admission }\end{array}$ & $\begin{array}{l}\text { Source } \\
\text { Unknown }\end{array}$ \\
\hline mandate & $\begin{array}{l}0.0724^{* *} \\
(0.0296)\end{array}$ & $\begin{array}{l}0.0430^{* *} \\
(0.0193)\end{array}$ & $\begin{array}{c}0.0184 \\
(0.0116)\end{array}$ & $\begin{array}{c}0.0110 \\
(0.0164)\end{array}$ \\
\hline Time FE & Y & Y & $\mathrm{Y}$ & Y \\
\hline Individual FE & $\mathrm{Y}$ & $\mathrm{Y}$ & $\mathrm{Y}$ & $\mathrm{Y}$ \\
\hline Pre-Reform Mean (y) & 0.424 & 0.213 & 0.0740 & 0.137 \\
\hline Observations & 1938082 & 1938082 & 1938082 & 1938082 \\
\hline Panel B: COHS Control Group & $\begin{array}{l}\text { Non-ER } \\
\text { Transfer }\end{array}$ & $\begin{array}{c}\text { From } \\
\text { ER Admission }\end{array}$ & $\begin{array}{c}\text { From } \\
\text { Non-ER Admission }\end{array}$ & $\begin{array}{c}\text { Source } \\
\text { Unknown } \\
\end{array}$ \\
\hline mandate & $\begin{array}{l}0.0628^{* * *} \\
(0.0223)\end{array}$ & $\begin{array}{l}0.038 \mathrm{I}^{* * *} \\
(0.0144)\end{array}$ & $\begin{array}{c}0.012 \mathrm{I} \\
(0.0085 \mathrm{I})\end{array}$ & $\begin{array}{c}0.0126 \\
(0.0123)\end{array}$ \\
\hline Time FE & $\mathrm{Y}$ & Y & Y & Y \\
\hline Individual FE & $\mathrm{Y}$ & $\mathrm{Y}$ & $\mathrm{Y}$ & $\mathrm{Y}$ \\
\hline Pre-Reform Mean (y) & 0.419 & $0.2 \mathrm{II}$ & 0.0720 & 0.136 \\
\hline Observations & 2213160 & 2213160 & 2213160 & 2213160 \\
\hline
\end{tabular}

Notes: Panel A based on analysis sample in $2010 Q_{2}-2 \mathrm{O}_{3} \mathrm{Q}_{4}$, excluding observations of the control group. Panel B based on all observations in the analysis sample in $2010 \mathrm{Q}_{2}-{ }_{2} \mathrm{OI}_{3} \mathrm{Q}_{4}$. Outcome variables are multiplied by 100 at each person-quarter cell for presentation purpose. The coefficients are from regressions of outcome variables on mandate indicator, quarter FEs, and individual FEs, with standard errors clustered at individual level. The outcome variable in column $\mathrm{I}$ is the number of inpatient hospitalizations that are transfers from other hospitals (same as column 3 in Table 4 , included here for comparison). The outcome variables in columns $2-4$ are the numbers of these hospitalizations by the initial source of admission at the transferring hospital. ${ }^{*} p<0.10$, ${ }^{* *} p<0.05$, *** $p<0.01$. 
Table A3: Effect of MMC on Hospital Services by Facility Type

\begin{tabular}{|c|c|c|c|c|c|c|c|c|c|c|}
\hline & (I) & $(2)$ & (3) & (4) & (5) & (6) & (7) & $(8)$ & (9) & (го) \\
\hline \multirow[t]{2}{*}{ Panel A: No Control Group } & \multicolumn{2}{|l|}{ All } & \multicolumn{2}{|c|}{ For-Profit } & \multicolumn{2}{|c|}{ Non-Profit } & \multicolumn{2}{|c|}{ Government } & \multicolumn{2}{|c|}{ Teaching } \\
\hline & Discharge & ER & Discharge & ER & Discharge & ER & Discharge & ER & Discharge & ER \\
\hline mandate & $\begin{array}{l}0.0258 \\
(0.158)\end{array}$ & $\begin{array}{l}0.727^{* *} \\
(0.321)\end{array}$ & $\begin{array}{c}0.177^{* *} \\
(0.0746)\end{array}$ & $\begin{array}{l}0.0845 \\
(0.126)\end{array}$ & $\begin{array}{c}-0.0705 \\
(0.114)\end{array}$ & $\begin{array}{c}0.213 \\
(0.24 \mathrm{I})\end{array}$ & $\begin{array}{l}-0.0703 \\
(0.0695)\end{array}$ & $\begin{array}{l}0.344^{* *} \\
(0.148)\end{array}$ & $\begin{array}{l}-0.00368 \\
(0.0783)\end{array}$ & $\begin{array}{c}0.106 \\
(0.135)\end{array}$ \\
\hline
\end{tabular}

Time FE

Individual FE

Pre-Reform Mean (y)

$\begin{array}{cccccccccc}\mathrm{Y} & \mathrm{Y} & \mathrm{Y} & \mathrm{Y} & \mathrm{Y} & \mathrm{Y} & \mathrm{Y} & \mathrm{Y} & \mathrm{Y} & \mathrm{Y} \\ \mathrm{Y} & \mathrm{Y} & \mathrm{Y} & \mathrm{Y} & \mathrm{Y} & \mathrm{Y} & \mathrm{Y} & \mathrm{Y} & \mathrm{Y} & \mathrm{Y} \\ 10.83 & 30.58 & 2.283 & 4.849 & 5.884 & 17.98 & 2.416 & 7.285 & 2.926 & 6.315 \\ 1938082 & 1938082 & 1938082 & 1938082 & 1938082 & 1938082 & 1938082 & 1938082 & 1938082 & 1938082\end{array}$

Observations

$\begin{array}{lll}1938082 & 1938082 & 1938082\end{array}$

\begin{tabular}{|c|c|c|c|c|c|c|c|c|c|c|}
\hline \multirow[t]{2}{*}{ Panel B: COHS Control Group } & \multicolumn{2}{|c|}{ All } & \multicolumn{2}{|c|}{ For-Profit } & \multicolumn{2}{|c|}{ Non-Profit } & \multicolumn{2}{|c|}{ Government } & \multicolumn{2}{|c|}{ Teaching } \\
\hline & Discharge & ER & Discharge & ER & Discharge & ER & Discharge & ER & Discharge & ER \\
\hline mandate & $\begin{array}{c}-0.0367 \\
(0.12 I)\end{array}$ & $\begin{array}{l}\mathrm{I} .179^{* * *} \\
(0.289)\end{array}$ & $\begin{array}{l}0.185^{* * *} \\
(0.0595)\end{array}$ & $\begin{array}{c}0.42^{* * *} \\
(0.117)\end{array}$ & $\begin{array}{c}-0.0797 \\
(0.0897)\end{array}$ & $\begin{array}{c}0.608^{* * *} \\
(0.224)\end{array}$ & $\begin{array}{l}-0.146^{* * *} \\
(0.0463)\end{array}$ & $\begin{array}{l}0.0293 \\
(0.114)\end{array}$ & $\begin{array}{l}-0.104^{* *} \\
(0.0528)\end{array}$ & $\begin{array}{c}-0.278^{* * *} \\
(0.0902)\end{array}$ \\
\hline
\end{tabular}

Time FE

Individual FE

Pre-Reform Mean (y)

$\begin{array}{cccccccccc}\mathrm{Y} & \mathrm{Y} & \mathrm{Y} & \mathrm{Y} & \mathrm{Y} & \mathrm{Y} & \mathrm{Y} & \mathrm{Y} & \mathrm{Y} & \mathrm{Y} \\ \mathrm{Y} & \mathrm{Y} & \mathrm{Y} & \mathrm{Y} & \mathrm{Y} & \mathrm{Y} & \mathrm{Y} & \mathrm{Y} & \mathrm{Y} & \mathrm{Y} \\ 10.47 & 30.8 \mathrm{I} & 2.274 & 4.974 & 5.772 & 18.47 & 2.203 & 6.900 & 2.694 & 5.76 \mathrm{I} \\ 221316 \mathrm{O} & 2213160 & 2213160 & 2213160 & 2213160 & 2213160 & 2213160 & 2213160 & 2213160 & 2213160\end{array}$

Notes: Panel A based on analysis sample in $20 \mathrm{IOQ}_{2}$ - 2013 $\mathrm{Q}_{4}$, excluding observations of the control group. Panel B based on all observations in the analysis sample in 2010 2 - 2013 $\mathrm{Q}_{4}$. Outcome variables are multiplied by roo at each person-quarter cell for presentation purpose. The coefficients are from regressions of outcome variables on mandate indicator, quarter FEs, and individual FEs, with standard errors clustered at individual level. ${ }^{*} p<0.10,{ }^{* *} p<0.05,{ }^{* * *} p<0.01$. 
Table A4: Leave-one-out Mortality Analysis at County Level

\begin{tabular}{|c|c|c|c|c|c|c|c|}
\hline Panel A: No Control Group & All Counties & Alameda & Contra Costa & Kern & LA & Riverside & Sacramento (GMC) \\
\hline mandate & $\begin{array}{c}0.000884^{* * *} \\
(0.000257)\end{array}$ & $\begin{array}{l}0.000856^{* * *} \\
(0.000274)\end{array}$ & $\begin{array}{c}0.000950^{* * *} \\
(0.00025 \mathrm{I})\end{array}$ & $\begin{array}{l}0.000830^{* *} \\
(0.000272)\end{array}$ & $\begin{array}{l}0.000739^{*} \\
(0.000393)\end{array}$ & $\begin{array}{c}0.000894^{* * *} \\
(0.000274)\end{array}$ & $\begin{array}{l}0.000938^{* * *} \\
(0.000264)\end{array}$ \\
\hline Time FE & $\mathrm{Y}$ & $\mathrm{Y}$ & $\mathrm{Y}$ & $\mathrm{Y}$ & $\mathrm{Y}$ & $\mathrm{Y}$ & $\mathrm{Y}$ \\
\hline County FE & $\mathrm{Y}$ & $\mathrm{Y}$ & $\mathrm{Y}$ & $\mathrm{Y}$ & $\mathrm{Y}$ & $\mathrm{Y}$ & $\mathrm{Y}$ \\
\hline Pre-Reform Mean(y) & $0.0075 \mathrm{I}$ & 0.00756 & $0.0075 \mathrm{I}$ & 0.00759 & 0.00759 & 0.00750 & 0.00753 \\
\hline \multirow[t]{2}{*}{ Observations } & 1095446 & 1038826 & 1060153 & IO38884 & 660230 & IO2273I & 1023936 \\
\hline & San Diego (GMC) & San Francisco & San Joaquin & San Luis Obispo & Santa Clara & Stanislaus & Tulare \\
\hline mandate & $\begin{array}{c}0.000964^{* * *} \\
(0.000262)\end{array}$ & $\begin{array}{c}0.000908^{* * *} \\
(0.00028 \mathrm{I})\end{array}$ & $\begin{array}{l}0.000814^{* *} \\
(0.000265)\end{array}$ & $\begin{array}{l}0.000746^{* *} \\
(0.000246)\end{array}$ & $\begin{array}{c}0.000970^{* * *} \\
(0.000243)\end{array}$ & $\begin{array}{c}0.000973^{* * *} \\
(0.00024 \mathrm{I})\end{array}$ & $\begin{array}{c}0.000858^{* * *} \\
(0.000265)\end{array}$ \\
\hline Time FE & $\mathrm{Y}$ & $\mathrm{Y}$ & $\mathrm{Y}$ & $\mathrm{Y}$ & $\mathrm{Y}$ & $\mathrm{Y}$ & $\mathrm{Y}$ \\
\hline County FE & $\mathrm{Y}$ & $\mathrm{Y}$ & $\mathrm{Y}$ & $\mathrm{Y}$ & $\mathrm{Y}$ & $\mathrm{Y}$ & $\mathrm{Y}$ \\
\hline Pre-Reform Mean(y) & 0.00748 & 0.00745 & 0.00747 & 0.00748 & 0.00752 & 0.00753 & 0.00747 \\
\hline Observations & 991674 & 991028 & 1060654 & 1062903 & 1059745 & 1062816 & 1071772 \\
\hline Panel B: COHS Control Group & All Counties & Alameda & Contra Costa & Kern & LA & Riverside & Sacramento (GMC) \\
\hline mandate & $\begin{array}{c}0.000798^{* * *} \\
(0.000172)\end{array}$ & $\begin{array}{c}0.000746^{* * *} \\
(0.000174)\end{array}$ & $\begin{array}{c}0.000842^{* * *} \\
(0.000169)\end{array}$ & $\begin{array}{c}0.000734^{* * *} \\
(0.000170)\end{array}$ & $\begin{array}{c}0.000804^{* * *} \\
(0.000260)\end{array}$ & $\begin{array}{l}0.0008 \mathrm{II}^{* * *} \\
(0.000179)\end{array}$ & $\begin{array}{l}0.000817^{* * *} \\
(0.000179)\end{array}$ \\
\hline Time FE & $\mathrm{Y}$ & $\mathrm{Y}$ & $\mathrm{Y}$ & $\mathrm{Y}$ & $\mathrm{Y}$ & $\mathrm{Y}$ & $\mathrm{Y}$ \\
\hline County FE & $\mathrm{Y}$ & $\mathrm{Y}$ & $\mathrm{Y}$ & $\mathrm{Y}$ & $\mathrm{Y}$ & $\mathrm{Y}$ & $\mathrm{Y}$ \\
\hline Pre-Reform Mean(y) & 0.00748 & 0.00752 & 0.00748 & 0.00755 & 0.00753 & 0.00747 & 0.00749 \\
\hline \multirow[t]{2}{*}{ Observations } & I232288 & $\operatorname{II75668}$ & 1196995 & 1175726 & 797072 & II59573 & $\mathrm{II} 60778$ \\
\hline & San Diego (GMC) & San Francisco & San Joaquin & San Luis Obispo & Santa Clara & Stanislaus & Tulare \\
\hline mandate & $\begin{array}{c}0.000838^{* * *} \\
(0.000179)\end{array}$ & $\begin{array}{c}0.000834^{* * *} \\
(0.000180)\end{array}$ & $\begin{array}{l}0.000755^{* * *} \\
(0.000172)\end{array}$ & $\begin{array}{l}0.000712^{* * *} \\
(0.000156)\end{array}$ & $\begin{array}{l}0.000852^{* * *} \\
(0.000166)\end{array}$ & $\begin{array}{l}0.000833^{* * *} \\
(0.000172)\end{array}$ & $\begin{array}{c}0.000776^{* * *} \\
(0.000174)\end{array}$ \\
\hline Time FE & $\mathrm{Y}$ & $\mathrm{Y}$ & $\mathrm{Y}$ & $\mathrm{Y}$ & $\mathrm{Y}$ & $\mathrm{Y}$ & $\mathrm{Y}$ \\
\hline County FE & $\mathrm{Y}$ & $\mathrm{Y}$ & $\mathrm{Y}$ & $\mathrm{Y}$ & $\mathrm{Y}$ & $\mathrm{Y}$ & $\mathrm{Y}$ \\
\hline Pre-Reform Mean(y) & 0.00745 & 0.00742 & 0.00744 & 0.00745 & 0.00749 & 0.00750 & 0.00744 \\
\hline Observations & II285I6 & II 27870 & II97496 & II99745 & $\operatorname{II} 96587$ & $\operatorname{II} 99658$ & $\mathrm{I} 2086 \mathrm{I} 4$ \\
\hline
\end{tabular}

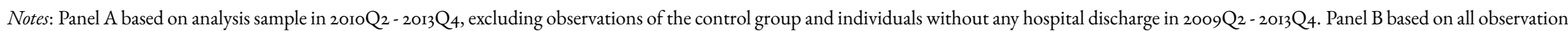
in the analysis sample in $2010 \mathrm{Q}_{2}-2013 \mathrm{Q}_{4}$, excluding individuals without any hospital discharge in $2009 \mathrm{Q}_{2}-2013 \mathrm{Q}_{4}$. The table contains the estimates from a leave-one-out analysis at the county level, with each column showing results excluding the respective county. The coefficients are from linear regression of outcome variable (o/I death indicator) on mandate indicators (shown in tables), quarter FEs, county FEs, age FEs, and gender indicator, with standard errors clustered at county level. ${ }^{*} p<0.10,{ }^{* *} p<0.05,{ }^{* * *} p<0.01$. 
Table As: Effect of MMC on Mortality by Baseline Health Condition (COHS Control Group)

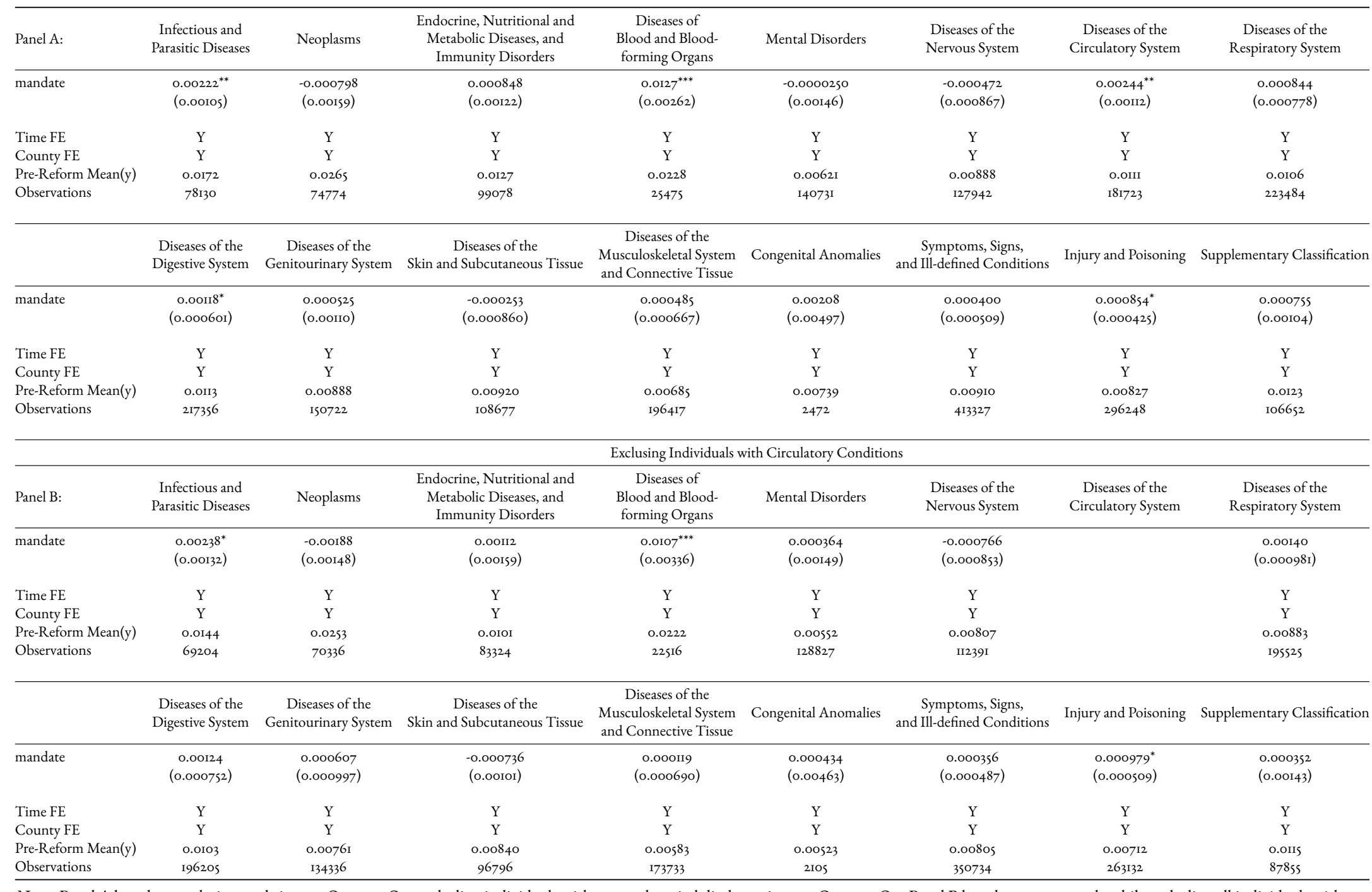

Notes: Panel A based on analysis sample in $2010 \mathrm{Q}_{2}-2013 \mathrm{Q}_{4}$, excluding individuals without any hospital discharge in $2009 \mathrm{Q}_{2}$ - 2013 $\mathrm{Q}_{4}$. Panel B based on same sample while excluding all individuals with any discharge/ER visit for circulatory conditions at baseline. The coefficients are from linear regression of outcome variable (o/I death indicator) on mandate indicator (shown in tables), quarter FEs, county FEs, age FEs, and gender indicator, with standard errors clustered at county level. ${ }^{*} p<0.10,{ }^{* *} p<0.05,{ }^{* * *} p<0.01$ 
Table A6: Heterogeneity in the use of Hospital Services by Baseline Elixhauser Score

\begin{tabular}{|c|c|c|c|c|c|c|c|c|c|c|c|c|}
\hline & $(\mathrm{I})$ & $(2)$ & $(3)$ & (4) & $(5)$ & (6) & (7) & $(8)$ & (9) & (IO) & (II) & (I2) \\
\hline $\begin{array}{l}\text { Panel A: } \\
\text { No Control Group }\end{array}$ & \multicolumn{2}{|c|}{ ER Visit } & \multicolumn{2}{|c|}{ Discharge } & \multicolumn{2}{|c|}{$\begin{array}{l}\text { Non-ER } \\
\text { Transfer }\end{array}$} & \multicolumn{2}{|c|}{$\begin{array}{c}\text { Non-ER } \\
\text { Non-transfer }\end{array}$} & \multicolumn{2}{|c|}{$\begin{array}{l}\text { Admitted from } \\
\text { Own ER }\end{array}$} & \multicolumn{2}{|c|}{ Scheduled } \\
\hline mandate (low Elixhauser) & $\begin{array}{l}0.0494 \\
(0.343)\end{array}$ & & $\begin{array}{l}-0.0535 \\
(0.128)\end{array}$ & & $\begin{array}{r}-0.00603 \\
(0.0226)\end{array}$ & & $\begin{array}{l}-0.0991^{\prime} \\
(0.0589\end{array}$ & & $\begin{array}{l}0.0517 \\
(0.104)\end{array}$ & & $\begin{array}{l}-0.0961^{*} \\
(0.0467\end{array}$ & \\
\hline mandate (high Elixhauser) & $\begin{array}{l}\text { I.65 }{ }^{* * *} \\
(0.599)\end{array}$ & $\begin{array}{l}\text { I.602 } \\
(0.690)\end{array}$ & $\begin{array}{l}0.138 \\
(0.332)\end{array}$ & $\begin{array}{c}0.191 \\
(0.356)\end{array}$ & $\begin{array}{l}\text { O.I81*** } \\
(0.0629)\end{array}$ & $\begin{array}{l}0.187^{* * *} \\
(0.0669)\end{array}$ & $\begin{array}{l}-0.10 I \\
(0.13 I)\end{array}$ & $\begin{array}{c}-0.00139 \\
(0.143)\end{array}$ & $\begin{array}{l}0.0575 \\
(0.279)\end{array}$ & $\begin{array}{l}0.00584 \\
(0.297)\end{array}$ & $\begin{array}{l}-0.0205 \\
(0.0931)\end{array}$ & $\begin{array}{l}0.0755 \\
(0.104)\end{array}$ \\
\hline
\end{tabular}

Time FE

Individual FE

$\begin{array}{ccc}\mathrm{Y} & \mathrm{Y} & \mathrm{Y} \\ \mathrm{Y} & \mathrm{Y} & \mathrm{Y} \\ 22.374 & 3.9 \mathrm{I} 8 & 0.155 \\ 4 \mathrm{I} .600 & 20.106 & 0.786 \\ \mathrm{II} 25482 & \mathrm{II} 25482 & \mathrm{II} 25482 \\ 8 \mathrm{I} 2600 & 8 \mathrm{I} 2600 & 8 \mathrm{I} 2600\end{array}$

$\mathrm{Y}$
$\mathrm{Y}$
$\mathrm{I} .063$
4.035
$\mathrm{II} 25482$
$8 \mathrm{I} 2600$

$\begin{array}{cc}\mathrm{Y} & \mathrm{Y} \\ \mathrm{Y} & \mathrm{Y} \\ 2.700 & 0.682 \\ \mathrm{I} 5.285 & 2.056 \\ \mathrm{II} 25482 & \mathrm{II} 25482 \\ 8 \mathrm{I} 2600 & 8 \mathrm{I} 2600\end{array}$

\begin{tabular}{|c|c|c|c|c|c|c|c|c|c|c|c|c|}
\hline $\begin{array}{l}\text { Panel B: } \\
\text { COHS Control Group }\end{array}$ & \multicolumn{2}{|c|}{ ER Visit } & \multicolumn{2}{|c|}{ Discharge } & \multicolumn{2}{|c|}{$\begin{array}{l}\text { Non-ER } \\
\text { Transfer }\end{array}$} & \multicolumn{2}{|c|}{$\begin{array}{l}\text { Non-ER } \\
\text { Non-transfer }\end{array}$} & \multicolumn{2}{|c|}{$\begin{array}{l}\text { Admitted from } \\
\text { Own ER }\end{array}$} & \multicolumn{2}{|c|}{ Scheduled } \\
\hline mandate (low Elixhauser) & $\begin{array}{c}0.518^{*} \\
(0.276)\end{array}$ & & $\begin{array}{c}0.08 \mathrm{I} 6 \\
(0.0954)\end{array}$ & & $\begin{array}{c}0.0138 \\
(0.0182)\end{array}$ & & $\begin{array}{r}-0.00926 \\
(0.0437)\end{array}$ & & $\begin{array}{c}0.0771 \\
(0.0754)\end{array}$ & & $\begin{array}{l}-0.0184 \\
(0.0345)\end{array}$ & \\
\hline mandate (high Elixhauser) & $\begin{array}{c}2.297^{* * *} \\
(0.594)\end{array}$ & $\begin{array}{c}\text { I. } 779^{* * *} \\
(0.655)\end{array}$ & $\begin{array}{c}-0.157 \\
(0.267)\end{array}$ & $\begin{array}{l}-0.238 \\
(0.283)\end{array}$ & $\begin{array}{l}0.126^{* * *} \\
(0.0486)\end{array}$ & $\begin{array}{c}0.113^{* *} \\
(0.0519)\end{array}$ & $\begin{array}{c}-0.0631 \\
(0.0973)\end{array}$ & $\begin{array}{l}-0.0538 \\
(0.107)\end{array}$ & $\begin{array}{l}-0.220 \\
(0.225)\end{array}$ & $\begin{array}{l}-0.297 \\
(0.237)\end{array}$ & $\begin{array}{c}0.0152 \\
(0.0696)\end{array}$ & $\begin{array}{c}0.0336 \\
(0.0777)\end{array}$ \\
\hline
\end{tabular}

Time FE

Individual FE

$\mathrm{Y}$
$\mathrm{Y}$

Pre-Reform Mean (y) (low Elixhauser)

Pre-Reform Mean (y) (high Elixhauser) $\quad 42.201$

$\mathrm{N}$ (low Elixhauser)

1297747

$\mathrm{N}$ (high Elixhauser)

915413

$\begin{array}{cc}\mathrm{Y} & \mathrm{Y} \\ \mathrm{Y} & \mathrm{Y} \\ 3.822 & 0.157 \\ 19.617 & 0.780 \\ \mathrm{I} 297747 & \mathrm{I} 297747 \\ 9154 \mathrm{I} 3 & 915413\end{array}$

$\mathrm{Y}$
$\mathrm{Y}$
$\mathrm{I} .056$
3.946
$\mathrm{I} 297747$
915413

$\mathrm{Y}$
$\mathrm{Y}$
2.609
$\mathrm{I} 4.890$
$\mathrm{I} 297747$
$9154 \mathrm{I} 3$

$\mathrm{Y}$
$\mathrm{Y}$
$0.68 \mathrm{I}$
$2.03 \mathrm{I}$
$\mathrm{I} 297747$
$9154 \mathrm{I} 3$

Notes: Panel A based on analysis sample in $2010 Q_{2}-2{ }_{3} Q_{4}$, excluding observations of the control group. Panel B based on all observations in the analysis sample in $2010 \mathrm{Q}_{2}$ - 2013 $\mathrm{Q}_{4}$. Outcome variables are multiplied by roo at each person-quarter cell for presentation purpose. The coefficients are from regressions of outcome variables on mandate indicators (shown in tables), quarter FEs, and individual FEs, with standard errors clustered at individual level. The odd-numbered columns show the coefficients for those with high and low Elixhauser scores separately by interacting all RHS variables with high Elixhauser score indicator, which is equivalent to running the regressions separately for the two groups. The even-numbered columns test for statistical significance of differences between the coefficients for those with high vs. low Elixhauser scores, by regressing outcome variables on mandate indicator and mandate indicator interacted with high Elixhauser score indicator. High severity patient is defined as individuals whose total unweighted number of chronic conditions (Elixhauser score) based on principal and co-diagnoses of all inpatient hospital discharges and ER visits at baseline is higher than the median (which equals $\mathrm{I}$ in the analysis sample). ${ }^{*} p<0.10,{ }^{* *} p<0.05,{ }^{* * *} p<0.01$. 
Table A7: Heterogeneity in the use of Hospital Services (Discharge by Facility Type)

\begin{tabular}{|c|c|c|c|c|c|c|c|c|c|c|}
\hline & (I) & (2) & (3) & (4) & (5) & (6) & (7) & (8) & (9) & (го) \\
\hline Panel A: No Control Group & Discharge & & For-Profit & & Non-Profit & & Government & & Teaching & \\
\hline mandate (low util) & $\begin{array}{l}-0.0655 \\
(0.16 \mathrm{I})\end{array}$ & & $\begin{array}{c}0.0863 \\
(0.0744)\end{array}$ & & $\begin{array}{c}-0.00140 \\
(0.115)\end{array}$ & & $\begin{array}{c}-0.123^{*} \\
(0.0704)\end{array}$ & & $\begin{array}{l}-0.082 \mathrm{I} \\
(0.0793)\end{array}$ & \\
\hline mandate (high util) & $\begin{array}{c}0.113 \\
(0.270)\end{array}$ & $\begin{array}{c}0.179 \\
(0.314)\end{array}$ & $\begin{array}{l}0.265^{* *} \\
(0.128)\end{array}$ & $\begin{array}{c}0.179 \\
(0.148)\end{array}$ & $\begin{array}{c}-0.138 \\
(0.196)\end{array}$ & $\begin{array}{c}-0.136 \\
(0.227)\end{array}$ & $\begin{array}{c}-0.0190 \\
\text { (o.II9) }\end{array}$ & $\begin{array}{l}\text { O.IO4 } \\
(0.138)\end{array}$ & $\begin{array}{l}0.0726 \\
(0.134)\end{array}$ & $\begin{array}{c}0.155 \\
(0.155)\end{array}$ \\
\hline
\end{tabular}

Time FE

Individual FE

\begin{tabular}{ccc}
\multicolumn{1}{c}{$\mathrm{Y}$} & $\mathrm{Y}$ & $\mathrm{Y}$ \\
$\mathrm{Y}$ & $\mathrm{Y}$ & $\mathrm{Y}$ \\
4.985 & 0.984 & 2.797 \\
16.353 & $3.5 \mathrm{II}$ & $8.8 \mathrm{O} 2$ \\
950686 & 950686 & 950686 \\
987396 & 987396 & 987396
\end{tabular}

$\begin{array}{cc}\mathrm{Y} & \mathrm{Y} \\ \mathrm{Y} & \mathrm{Y} \\ \mathrm{I.104} & \mathrm{I} .377 \\ 3.656 & 4.39 \mathrm{I} \\ 950686 & 950686 \\ 987396 & 987396\end{array}$

\begin{tabular}{|c|c|c|c|c|c|c|c|c|c|c|}
\hline Panel B: COHS Control Group & Discharge & & For-Profit & & Non-Profit & & Government & & Teaching & \\
\hline mandate (low util) & $\begin{array}{c}0.0444 \\
(0.12 I)\end{array}$ & & $\begin{array}{c}0.0705 \\
(0.0550)\end{array}$ & & $\begin{array}{l}0.00877 \\
(0.0900)\end{array}$ & & $\begin{array}{l}-0.0409 \\
(0.0465)\end{array}$ & & $\begin{array}{l}-0.0247 \\
(0.0533)\end{array}$ & \\
\hline mandate (high util) & $\begin{array}{c}-0.124 \\
(0.208)\end{array}$ & $\begin{array}{c}-0.168 \\
(0.240)\end{array}$ & $\begin{array}{l}0.294^{* * *} \\
(0.104)\end{array}$ & $\begin{array}{l}0.223^{*} \\
\text { (o.II8) }\end{array}$ & $\begin{array}{l}-0.169 \\
(0.153)\end{array}$ & $\begin{array}{c}-0.178 \\
(0.177)\end{array}$ & $\begin{array}{l}-0.250^{* * *} \\
(0.0790)\end{array}$ & $\begin{array}{l}-0.209^{* *} \\
(0.0916)\end{array}$ & $\begin{array}{c}-0.183^{* *} \\
(0.0900)\end{array}$ & $\begin{array}{l}-0.158 \\
(0.105)\end{array}$ \\
\hline
\end{tabular}

Time FE

Individual FE

Pre-Reform Mean (y) (low util)

Pre-Reform Mean (y) (high util)

$\mathrm{N}$ (low util)

$\mathrm{N}$ (high util)

Y
$Y$
4.827
15.798
1083760
II 29400

$\mathrm{Y}$
$\mathrm{Y}$
0.983
$3.49 \mathrm{I}$
$\mathrm{IO} 83760$
$\mathrm{II} 29400$

$\mathrm{Y}$
$\mathrm{Y}$
2.736
8.635
1083760
II29400

$\mathrm{Y}$
$\mathrm{Y}$
$\mathrm{I} .014$
3.324
$\mathrm{I083760}$
$\mathrm{II} 29400$

$\mathrm{Y}$
$\mathrm{Y}$
$\mathrm{I.264}$
4.042
1083760
$\mathrm{II} 29400$

Notes: Panel A based on analysis sample in $2 \mathrm{OIOQ}_{2}-{ }_{2} \mathrm{OI}_{3} \mathrm{Q}_{4}$, excluding observations of the control group. Panel B based on all observations in the analysis sample in $20 \mathrm{O}_{2} \mathrm{Q}_{2}$ - $20 \mathrm{O}_{3} \mathrm{Q}_{4}$. Outcome variables are multiplied by roo at each person-quarter cell for presentation purpose. The coefficients are from regressions of outcome variables on mandate indicators (shown in tables), quarter $\mathrm{FEs}$, and individual FEs, with standard errors clustered at individual level. The odd-numbered columns show the coefficients for high and low baseline utilizers separately by interacting all RHS variables with high utilizer indicator, which is equivalent to running the regressions separately for the two groups. The even-numbered columns test for statistical significance of the differences between high vs. low utilizer coefficients, by regressing outcome variables on mandate indicator and mandate indicator interacted with high utilizer indicator. High utilizer is defined as individuals whose total number of inpatient hospital discharge + ER visit is higher than or equal to the median (which equals 2 in the analysis sample). ${ }^{*} p<0.10,{ }^{* *} p<0.05,{ }^{* * *} p<0.01$. 
Table A8: Heterogeneity in the use of Hospital Services (ER Visit by Facility Type)

\begin{tabular}{|c|c|c|c|c|c|c|c|c|c|c|}
\hline & (I) & $(2)$ & $(3)$ & (4) & $(5)$ & (6) & (7) & $(8)$ & (9) & (го) \\
\hline Panel A: No Control Group & ER Visit & & For-Profit & & Non-Profit & & Government & & Teaching & \\
\hline mandate (low util) & $\begin{array}{c}-0.4 \mathrm{I} 3 \\
(0.295)\end{array}$ & & $\begin{array}{l}0.0350 \\
(0.107)\end{array}$ & & $\begin{array}{l}-0.545^{* *} \\
(0.223)\end{array}$ & & $\begin{array}{l}0.0571 \\
(0.142)\end{array}$ & & $\begin{array}{l}-0.102 \\
(0.129)\end{array}$ & \\
\hline mandate (high util) & $\begin{array}{c}\text { I. } 837^{* * *} \\
(0.563)\end{array}$ & $\begin{array}{l}2.250^{* * *} \\
(0.636)\end{array}$ & $\begin{array}{r}0.133 \\
(0.224)\end{array}$ & $\begin{array}{l}0.0980 \\
(0.249)\end{array}$ & $\begin{array}{l}0.949^{* *} \\
(0.42 \mathrm{I})\end{array}$ & $\begin{array}{l}\text { I. } 494^{* * *} \\
(0.477)\end{array}$ & $\begin{array}{l}0.624^{* *} \\
(0.256)\end{array}$ & $\begin{array}{l}0.567^{*} \\
(0.292)\end{array}$ & $\begin{array}{c}0.309 \\
(0.233)\end{array}$ & $\begin{array}{c}0.4 \mathrm{IO} \\
(0.267)\end{array}$ \\
\hline Time FE & $\mathrm{Y}$ & & $\mathrm{Y}$ & & $\mathrm{Y}$ & & $\mathrm{Y}$ & & $\mathrm{Y}$ & \\
\hline Individual FE & $\mathrm{Y}$ & & $\mathrm{Y}$ & & $\mathrm{Y}$ & & $\mathrm{Y}$ & & $\mathrm{Y}$ & \\
\hline Pre-Reform Mean (y) (low util) & 14.479 & & 2.037 & & 8.775 & & 3.477 & & 3.047 & \\
\hline Pre-Reform Mean (y) (high util) & 45.803 & & 7.508 & & 26.678 & & I0.884 & & 9.404 & \\
\hline $\mathrm{N}($ low util) & 950686 & & 950686 & & 950686 & & 950686 & & 950686 & \\
\hline $\mathrm{N}$ (high util) & 987396 & & 987396 & & 987396 & & 987396 & & 987396 & \\
\hline mandate (low util) & $\begin{array}{c}0.162 \\
(0.242)\end{array}$ & & $\begin{array}{c}0.206^{* *} \\
(0.0876)\end{array}$ & & $\begin{array}{l}-0.252 \\
(0.195)\end{array}$ & & $\begin{array}{c}\text { O.I5I } \\
\text { (0.IO2) }\end{array}$ & & $\begin{array}{c}-0.0283 \\
(0.0820)\end{array}$ & \\
\hline mandate (high util) & $\begin{array}{l}2.123^{* * *} \\
(0.516)\end{array}$ & $\begin{array}{l}\text { I.96I }{ }^{* * *} \\
(0.570)\end{array}$ & $\begin{array}{r}0.605^{* * *} \\
(0.2 \mathrm{I} 2)\end{array}$ & $\begin{array}{c}0.398^{*} \\
(0.229)\end{array}$ & $\begin{array}{l}\mathrm{I} .415^{* * *} \\
(0.397)\end{array}$ & $\begin{array}{l}\text { I. } 667^{* * *} \\
(0.442)\end{array}$ & $\begin{array}{l}-0.0960 \\
(0.200)\end{array}$ & $\begin{array}{l}-0.247 \\
(0.225)\end{array}$ & $\begin{array}{c}-0.526^{* * *} \\
(0.158)\end{array}$ & $\begin{array}{c}-0.497^{* * *} \\
(0.178)\end{array}$ \\
\hline Time FE & $\mathrm{Y}$ & & $\mathrm{Y}$ & & $\mathrm{Y}$ & & $\mathrm{Y}$ & & $\mathrm{Y}$ & \\
\hline Individual FE & $\mathrm{Y}$ & & $\mathrm{Y}$ & & $\mathrm{Y}$ & & $\mathrm{Y}$ & & $\mathrm{Y}$ & \\
\hline Pre-Reform Mean (y) (low util) & 14.595 & & 2.096 & & 8.998 & & 3.309 & & 2.776 & \\
\hline Pre-Reform Mean (y) (high util) & 46.095 & & 7.686 & & $27 \cdot 393$ & & 10.284 & & 8.575 & \\
\hline $\mathrm{N}$ (low util) & 1083760 & & 1083760 & & 1083760 & & 1083760 & & 1083760 & \\
\hline $\mathrm{N}$ (high util) & II 29400 & & II 29400 & & II 29400 & & II 29400 & & II 29400 & \\
\hline
\end{tabular}

Notes: Panel A based on analysis sample in $20 \mathrm{IOQ}_{2}-2 \mathrm{OI}_{3} \mathrm{Q}_{4}$, excluding observations of the control group. Panel B based on all observations in the analysis sample in $2010 \mathrm{Q}_{2}-2 \mathrm{OI} 3 \mathrm{Q}_{4}$. Outcome variables are multiplied by roo at each person-quarter cell for presentation purpose. The coefficients are from regressions of outcome variables on mandate indicators (shown in tables), quarter FEs, and individual FEs, with standard errors clustered at individual level. The odd-numbered columns show the coefficients for high and low baseline utilizers separately by interacting all RHS variables with high utilizer indicator, which is equivalent to running the regressions separately for the two groups. The even-numbered columns test for statistical significance of the differences between high vs. low utilizer coefficients, by regressing outcome variables on mandate indicator and mandate indicator interacted with high utilizer indicator. High utilizer is defined as individuals whose total number of inpatient hospital discharge + ER visit is higher than or equal to the median (which equals 2 in the analysis sample). ${ }^{*} p<0.10,{ }^{* *} p<0.05,{ }^{* * *} p<0.01$. 
Table A9: Heterogeneity in the use of Hospital Services by Baseline Charlson Comorbidity Index

\begin{tabular}{|c|c|c|c|c|c|c|c|c|c|c|c|c|}
\hline & (I) & $(2)$ & (3) & (4) & (s) & (6) & (7) & $(8)$ & (9) & (го) & (II) & (I2) \\
\hline $\begin{array}{l}\text { Panel A: } \\
\text { No Control Group }\end{array}$ & \multicolumn{2}{|c|}{ ER Visit } & \multicolumn{2}{|c|}{ Discharge } & \multicolumn{2}{|c|}{$\begin{array}{l}\text { Non-ER } \\
\text { Transfer }\end{array}$} & \multicolumn{2}{|c|}{$\begin{array}{l}\text { Non-ER } \\
\text { Non-transfer }\end{array}$} & \multicolumn{2}{|c|}{$\begin{array}{l}\text { Admitted from } \\
\text { Own ER }\end{array}$} & \multicolumn{2}{|c|}{ Scheduled } \\
\hline mandate (high Charlson) & $\begin{array}{l}\text { I. } 73 \mathrm{I}^{* * *} \\
(0.563)\end{array}$ & $\begin{array}{l}\text { I. } 774^{* * *} \\
(0.673)\end{array}$ & $\begin{array}{l}0.378 \\
(0.319)\end{array}$ & $\begin{array}{l}0.618^{*} \\
(0.347)\end{array}$ & $\begin{array}{l}0.176^{* * *} \\
(0.0600)\end{array}$ & $\begin{array}{l}0.182^{* * *} \\
(0.0650)\end{array}$ & $\begin{array}{c}-0.0663 \\
(0.124)\end{array}$ & $\begin{array}{l}0.0590 \\
(0.139)\end{array}$ & $\begin{array}{c}0.269 \\
(0.269)\end{array}$ & $\begin{array}{c}0.377 \\
(0.290)\end{array}$ & $\begin{array}{l}-0.0068 \mathrm{I} \\
(0.0899)\end{array}$ & $\begin{array}{c}\text { O.IOI } \\
(\mathrm{o.IO2})\end{array}$ \\
\hline Time FE & $\mathrm{Y}$ & & $\mathrm{Y}$ & & $\mathrm{Y}$ & & $\mathrm{Y}$ & & $\mathrm{Y}$ & & $\mathrm{Y}$ & \\
\hline Individual FE & $\mathrm{Y}$ & & $\mathrm{Y}$ & & $\mathrm{Y}$ & & $\mathrm{Y}$ & & $\mathrm{Y}$ & & $\mathrm{Y}$ & \\
\hline Pre-Reform Mean (y) (low Charlson) & 23.609 & & 4.375 & & 0.184 & & I.227 & & 2.963 & & 0.712 & \\
\hline Pre-Reform Mean (y) (high Charlson) & 39.530 & & 19.113 & & 0.732 & & 3.749 & & $14.63 \mathrm{I}$ & & I.984 & \\
\hline $\mathrm{N}$ (low Charlson) & IIO4I22 & & IIO4I22 & & IIO4I22 & & IIO4I22 & & IIO4I22 & & IIO4I22 & \\
\hline N (high Charlson) & 833960 & & 833960 & & 833960 & & 833960 & & 833960 & & 833960 & \\
\hline $\begin{array}{l}\text { Panel B: } \\
\text { COHS Control Group }\end{array}$ & ER & Visit & Disch & $\operatorname{arge}$ & $\begin{array}{l}\text { Non } \\
\text { Trar }\end{array}$ & $\begin{array}{l}\text {-ER } \\
\text { sfer }\end{array}$ & $\begin{array}{l}\text { Non } \\
\text { Non-t }\end{array}$ & $\begin{array}{l}\text { ER } \\
\text { ansfer }\end{array}$ & $\begin{array}{r}\text { Admitte } \\
\text { Own }\end{array}$ & $\begin{array}{l}\text { d from } \\
\text { ER }\end{array}$ & Sched & aled \\
\hline mandate (low Charlson) & $\begin{array}{l}0.629^{* *} \\
(0.316)\end{array}$ & & $\begin{array}{c}-0.112 \\
(0.102)\end{array}$ & & $\begin{array}{c}\text { O.OIII } \\
(0.0201)\end{array}$ & & $\begin{array}{c}-0.038 \mathrm{I} \\
(0.0469)\end{array}$ & & $\begin{array}{l}-0.0855 \\
(0.0801)\end{array}$ & & $\begin{array}{l}-0.0286 \\
(0.0359)\end{array}$ & \\
\hline mandate (high Charlson) & $\begin{array}{l}2.019^{* * *} \\
(0.538)\end{array}$ & $\begin{array}{l}\text { I. } 390^{* *} \\
(0.624)\end{array}$ & $\begin{array}{l}0.0962 \\
(0.255)\end{array}$ & $\begin{array}{l}0.209 \\
(0.275)\end{array}$ & $\begin{array}{l}0.128^{* * *} \\
(0.0458)\end{array}$ & $\begin{array}{l}0.117^{* *} \\
(0.0500)\end{array}$ & $\begin{array}{l}-0.03 \mathrm{II} \\
(0.092 \mathrm{I})\end{array}$ & $\begin{array}{l}0.00696 \\
(0.103)\end{array}$ & $\begin{array}{c}-0.00103 \\
(0.215)\end{array}$ & $\begin{array}{l}0.0844 \\
(0.230)\end{array}$ & $\begin{array}{c}0.0254 \\
(0.0668)\end{array}$ & $\begin{array}{c}0.054 \mathrm{I} \\
(0.0758)\end{array}$ \\
\hline Time FE & $\mathrm{Y}$ & & $\mathrm{Y}$ & & $\mathrm{Y}$ & & $\mathrm{Y}$ & & $\mathrm{Y}$ & & $\mathrm{Y}$ & \\
\hline Individual FE & $\mathrm{Y}$ & & $\mathrm{Y}$ & & $\mathrm{Y}$ & & $\mathrm{Y}$ & & $\mathrm{Y}$ & & $\mathrm{Y}$ & \\
\hline Pre-Reform Mean (y) (low Charlson) & 23.857 & & 4.270 & & 0.183 & & $\mathrm{I} .2 \mathrm{I} 3$ & & 2.874 & & 0.712 & \\
\hline Pre-Reform Mean (y) (high Charlson) & 39.928 & & I8.6IO & & 0.728 & & 3.664 & & 14.217 & & I.955 & \\
\hline $\mathrm{N}$ (low Charlson) & 1272245 & & I272245 & & 1272245 & & 1272245 & & I272245 & & 1272245 & \\
\hline N (high Charlson) & 940915 & & 940915 & & 940915 & & 940915 & & 940915 & & 940915 & \\
\hline
\end{tabular}

Notes: Panel A based on analysis sample in $2 \mathrm{O}_{10} \mathrm{Q}_{2}-2 \mathrm{I}_{3} \mathrm{Q}_{4}$, excluding observations of the control group. Panel $\mathrm{B}$ based on all observations in the analysis sample in $2010 \mathrm{Q}_{2}-2 \mathrm{O} 33 \mathrm{Q}_{4}$. Outcome variables are multiplied by roo at each person-quarter cell for presentation purpose. The coefficients are from regressions of outcome variables on mandate indicators (shown in tables), quarter FEs, and individual FEs, with standard errors clustered at individual level. The odd-numbered columns show the coefficients for those with high and low Charlson comorbidity indices separately by interacting all RHS variables with high Charlson comorbidity index indicator, which is equivalent to running the regressions separately for the two groups. The even-numbered columns test for statistical significance of differences between the coefficients for those with high vs. low Charlson comorbidity indices, by regressing outcome variables on mandate indicator and mandate indicator interacted with high Charlson comorbidity index indicator. High severity patient is defined as individuals whose total weighted number of chronic conditions (Charlson comorbidity index) based on principal and co-diagnoses of all inpatient hospital discharges and ER visits at baseline is higher than the median (which equals o in the analysis sample). ${ }^{*} p<0.10,{ }^{* *} p<0.05,{ }^{* * *} p<0.01$. 
Table Aıo: Mortality by Baseline Charlson Comorbidity Index

\begin{tabular}{|c|c|c|c|}
\hline Panel A: No Control Group & (I) & $(2)$ & (3) \\
\hline mandate & $\begin{array}{c}0.000884^{* * *} \\
(0.000257)\end{array}$ & & \\
\hline mandate (low Charlson) & & $\begin{array}{l}-0.000486 \\
(0.000298)\end{array}$ & \\
\hline mandate (high Charlson) & & $\begin{array}{l}0.00185^{* * *} \\
(0.000350)\end{array}$ & $\begin{array}{l}0.00233^{* * *} \\
(0.00043 \mathrm{I})\end{array}$ \\
\hline Time FE & $\mathrm{Y}$ & $\mathrm{Y}$ & \\
\hline County FE & Y & $\mathrm{Y}$ & \\
\hline Pre-Reform Mean (y) & $0.0075 \mathrm{I}$ & & \\
\hline Pre-Reform Mean (y) (low Charlson) & & 0.00222 & \\
\hline Pre-Reform Mean (y) (high Charlson) & & O.OIII & \\
\hline $\mathrm{N}$ & 1095446 & & \\
\hline N (low Charlson) & & $45 \mathrm{IO} 44$ & \\
\hline $\mathrm{N}$ (high Charlson) & & 644402 & \\
\hline
\end{tabular}

\begin{tabular}{|c|c|c|c|}
\hline Panel B: COHS Control Group & & & \\
\hline mandate & $\begin{array}{c}0.000798^{* * *} \\
(0.000172)\end{array}$ & & \\
\hline mandate (low Charlson) & & $\begin{array}{c}-0.000187 \\
(0.000249)\end{array}$ & \\
\hline mandate (high Charlson) & & $\begin{array}{l}0.00161^{* * *} \\
(0.000272)\end{array}$ & $\begin{array}{l}0.00180^{* * *} \\
(0.000399)\end{array}$ \\
\hline Time FE & $\mathrm{Y}$ & $\mathrm{Y}$ & \\
\hline County FE & Y & $\mathrm{Y}$ & \\
\hline Pre-Reform Mean (y) & 0.00748 & & \\
\hline Pre-Reform Mean (y) (low Charlson) & & 0.00220 & \\
\hline Pre-Reform Mean (y) (high Charlson) & & o.oIII & \\
\hline $\mathrm{N}$ & I232288 & & \\
\hline N (low Charlson) & & 511992 & \\
\hline $\mathrm{N}$ (high Charlson) & & 720296 & \\
\hline
\end{tabular}

Notes: Panel A based on analysis sample in $2010 \mathrm{Q}_{2}-{ }_{2} \mathrm{O}_{3} \mathrm{Q}_{4}$, excluding observations of the control group and individuals without any hospital discharge in ${ }_{2009} \mathrm{Q}_{2}-{ }_{2} \mathrm{O}_{3} \mathrm{Q}_{4}$. Panel $\mathrm{B}$ based on all observations in the analysis sample in $2010 \mathrm{Q}_{2}-2013 \mathrm{Q}_{4}$, excluding individuals without any hospital discharge in ${ }_{2009} \mathrm{Q}_{2}-2 \mathrm{I}_{3} \mathrm{Q}_{4}$. The coefficients are from linear regression of outcome variable ( $\mathrm{o} / \mathrm{I}$ death indicator) on mandate indicators (shown in tables), quarter FEs, county FEs, age FEs, and gender indicator, with standard errors clustered at county level. Column I shows the results from full sample. Column 2 shows the coefficients for those with high and low baseline Charlson comorbidity indices separately by interacting all RHS variables with high Charlson comorbidity index indicator, which is equivalent to running the regressions separately for the two groups. Column 3 tests for statistical significance of differences between the coefficients for those with high and low baseline Charlson comorbidity indices, by regressing outcome variables on mandate indicator and mandate indicator interacted with high Charlson comorbidity index indicator. High severity patient is defined as individuals whose total weighted number of chronic conditions (Charlson comorbidity index) based on principal and co-diagnoses of all inpatient hospital discharges and ER visits at baseline is higher than the median (which equals o in the analysis sample). ${ }^{*} p<0.10,{ }^{* *} p<0.05,{ }^{* * *} p<0.01$. 
Figure Ar: Hospital Service Stacked Event Study

(a) ER Visit

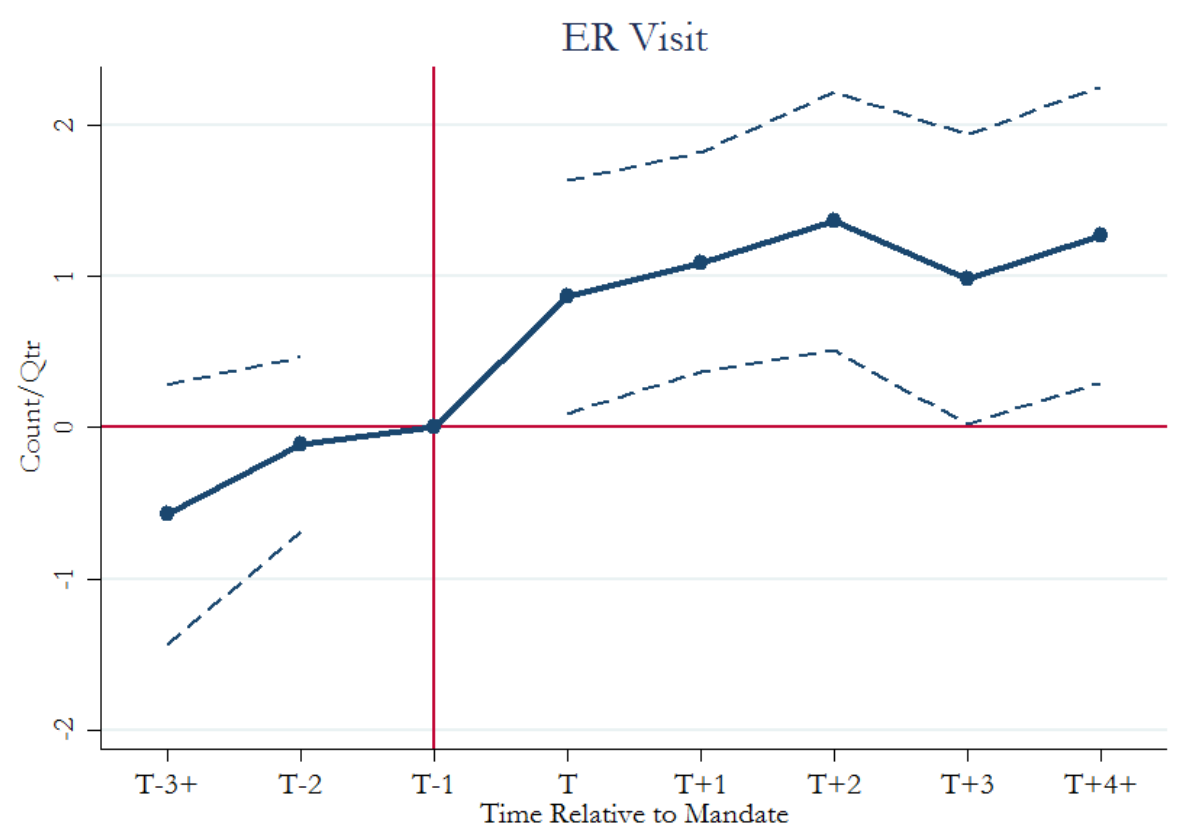

(b) Non ER Transfer Hospitalization

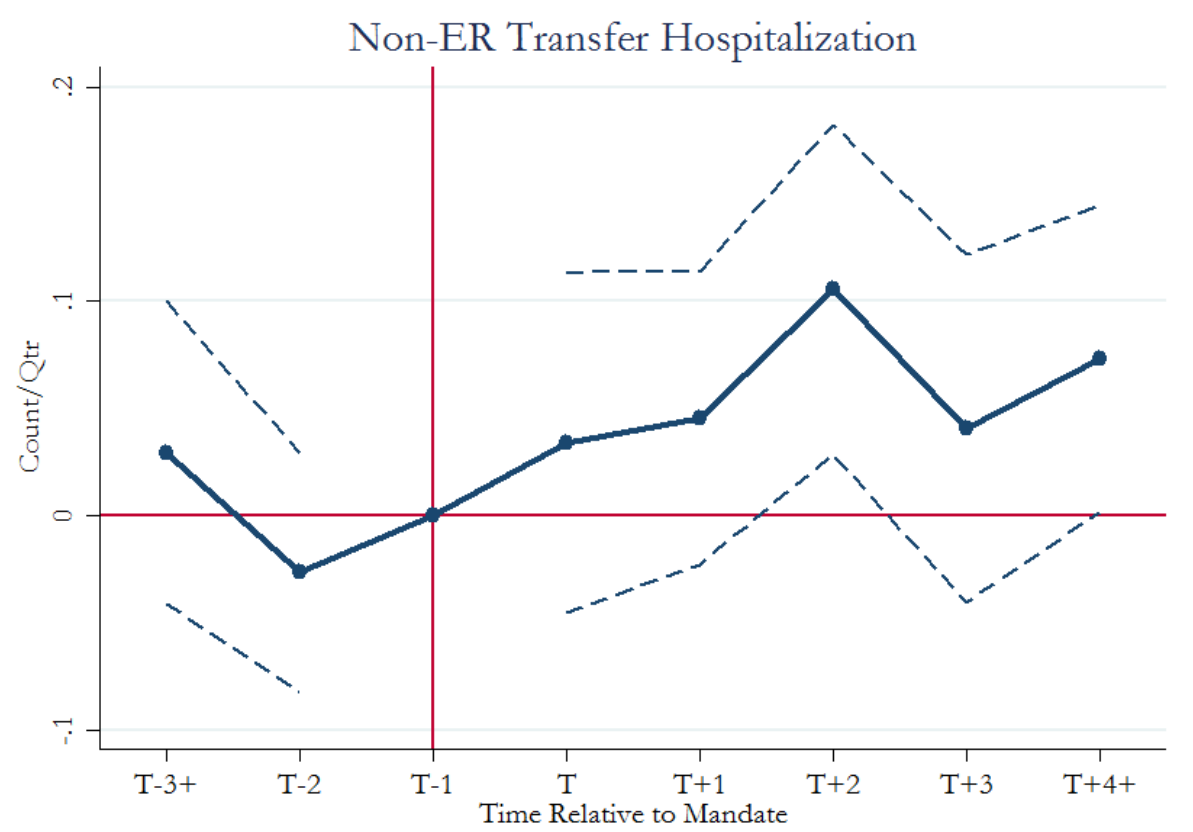

Notes: Based on stacked analysis sample in $2 \mathrm{OIOQ}_{2}-2 \mathrm{OI}_{3} \mathrm{Q}_{4}$, constructed by stacking together the $\mathrm{I}_{2}$ treatment cohorts, within which the treatment group includes all individuals of a particular birth month in Two-Plan/GMC counties, and the control group includes all individuals in the COHS counties. Outcome variables are multiplied by roo at each person-quarter cell for presentation purpose. The coefficients are from regressions of outcome variables on mandate indicators, and quarter FEs and individual FEs both interacted with treatment cohort indicators, with standard errors clustered at individual level. 
Figure A2: Discharge at For-Profit Hospital

(a) Main Specification

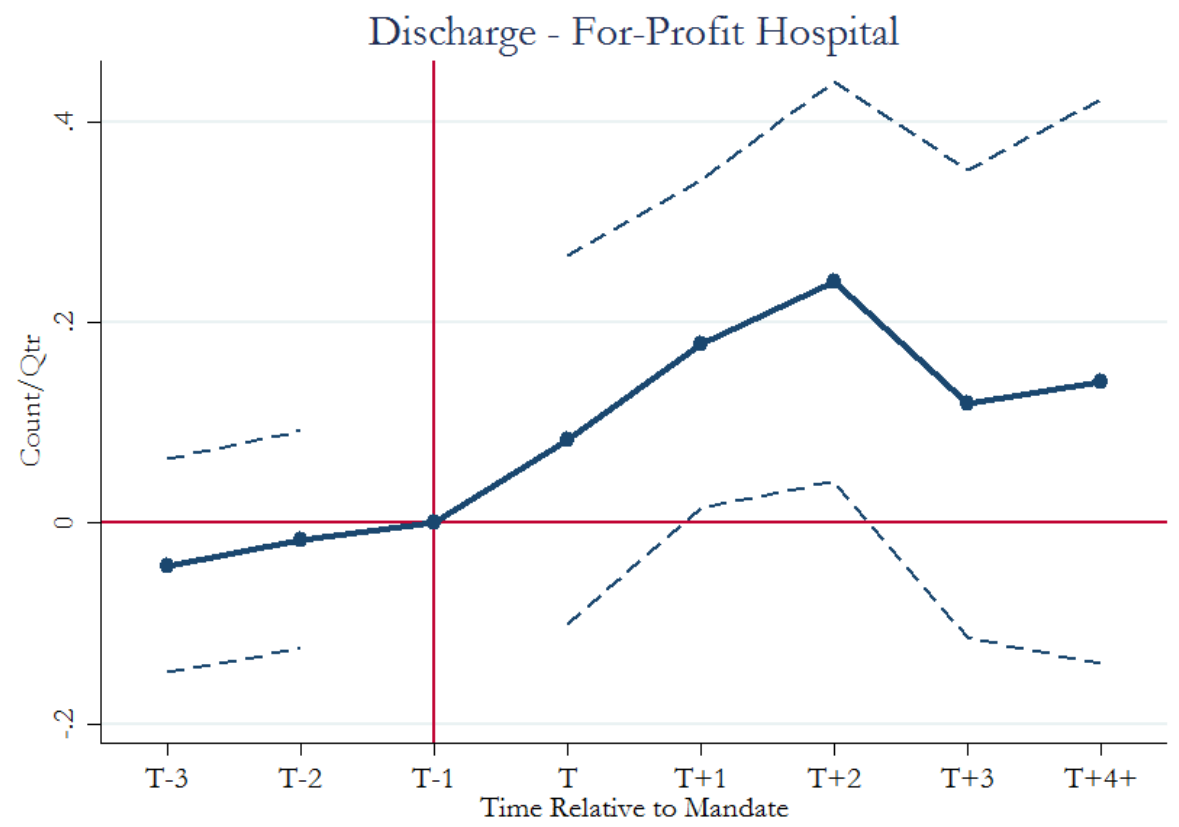

(b) COHS Specification

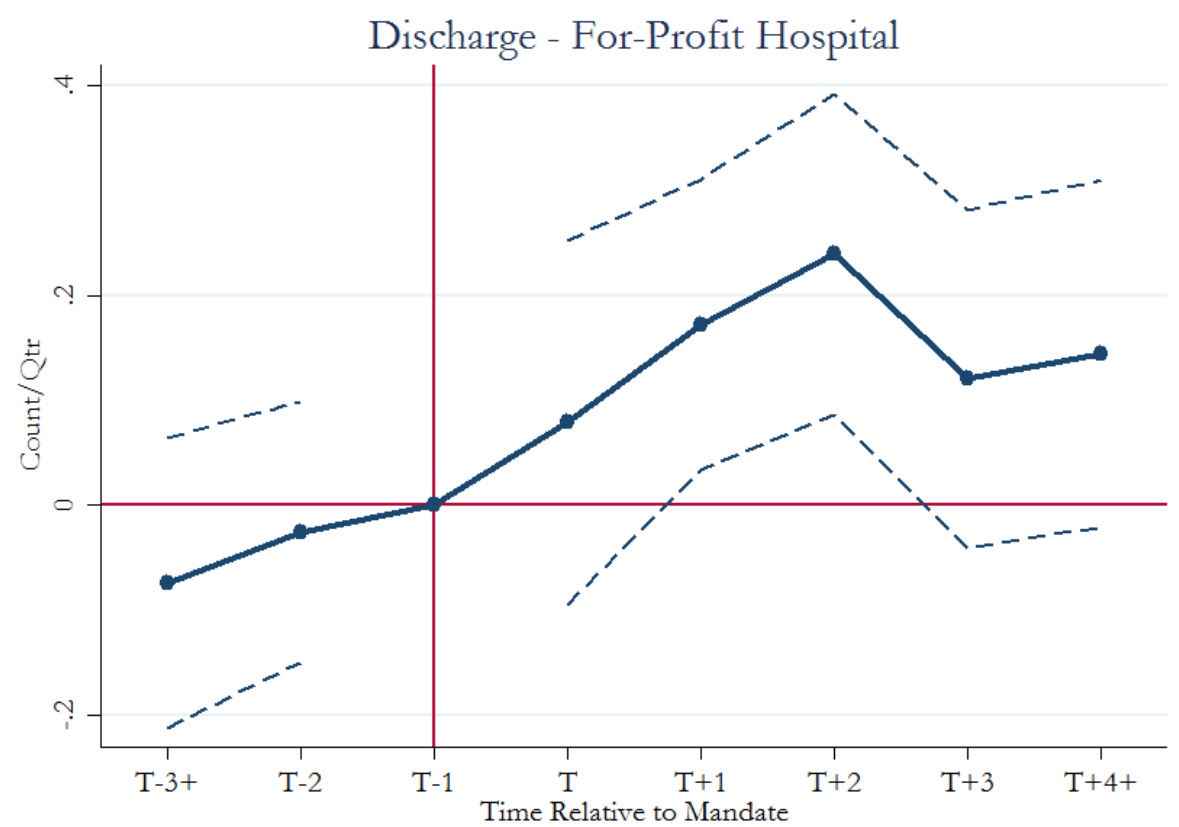

Notes: Panel A based on analysis sample in $2 \mathrm{OroQ}_{2}-\mathrm{2}_{3} \mathrm{Q}_{4}$, excluding observations of the control group. Panel B based on all observations in the analysis sample in $2010 Q_{2}-2013 Q_{4}$. Outcome variables are multiplied by roo at each person-quarter cell for presentation purpose. The coefficients are from regressions of outcome variables on mandate indicators, quarter FEs, and individual FEs, with standard errors clustered at individual level. 


\section{Figure $\mathrm{A}_{3}$ : ER Visit at For-Profit Hospital}

\section{(a) Main Specification}

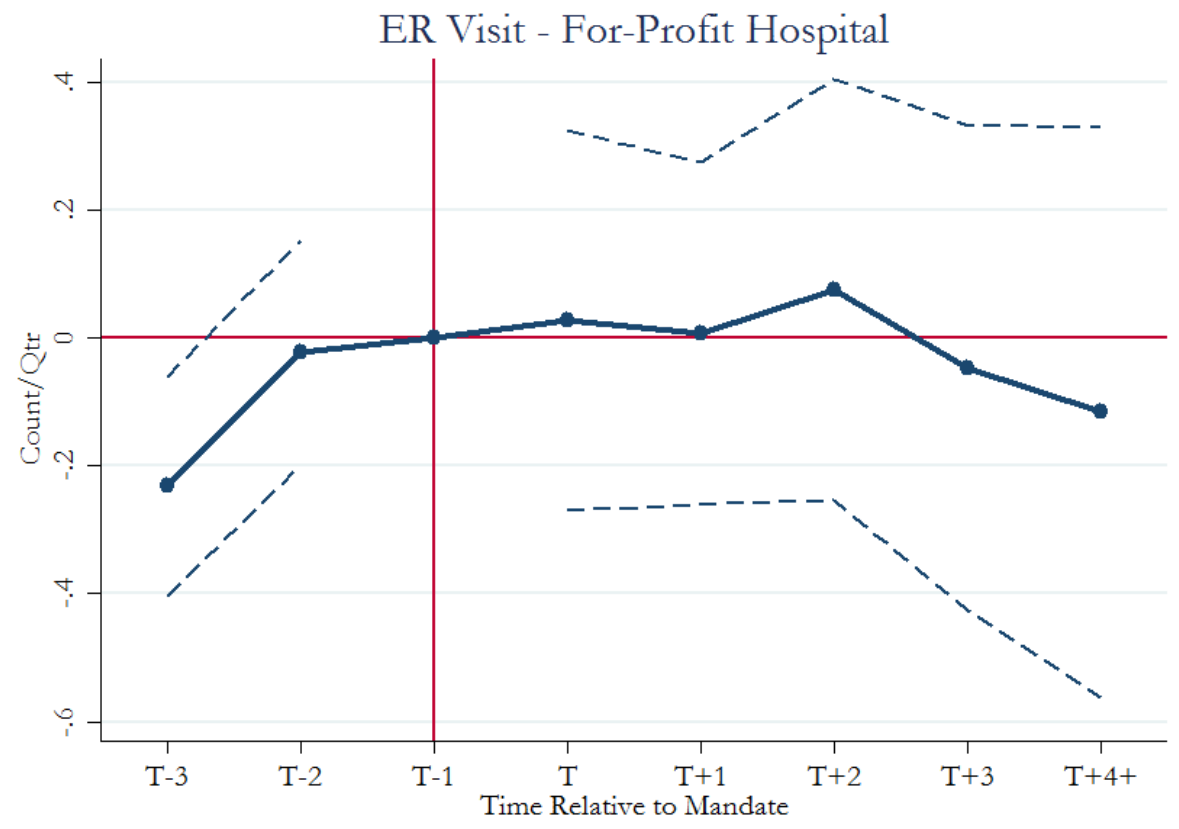

(b) COHS Specification

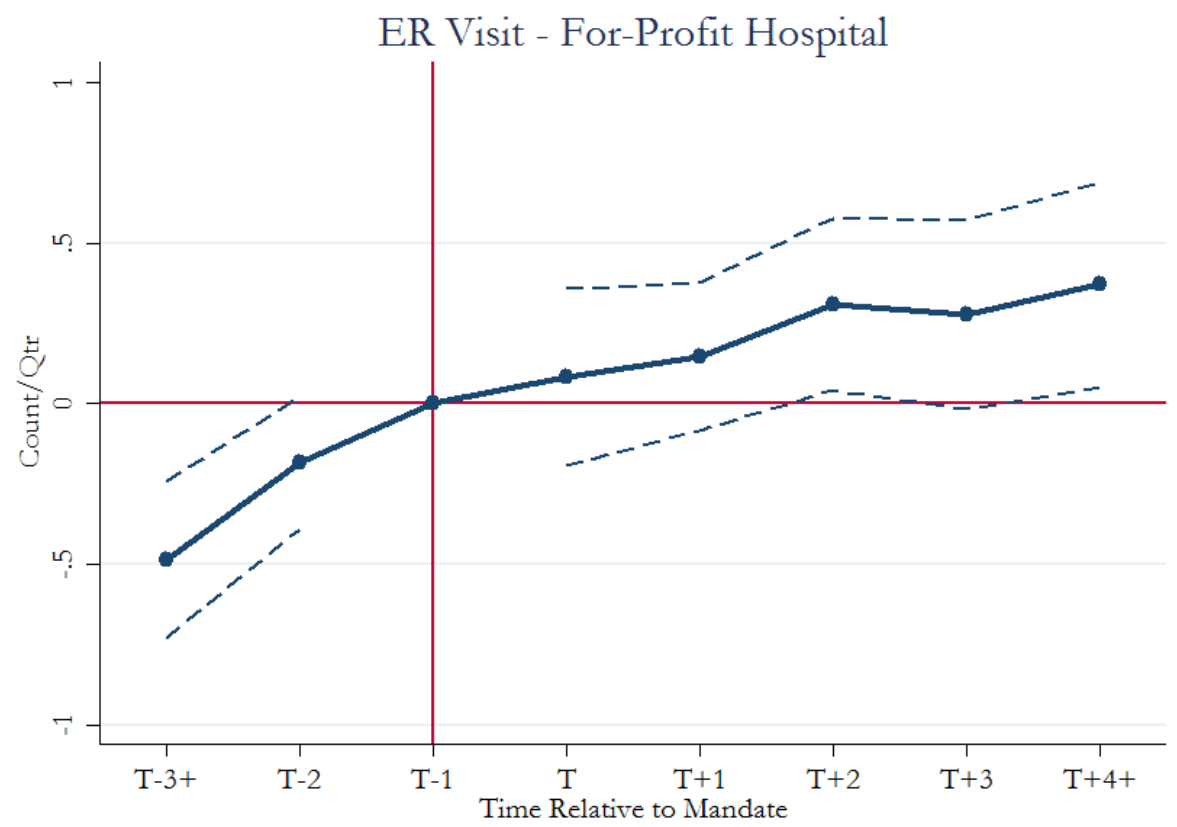

Notes: Panel A based on analysis sample in $2 \mathrm{OIOQ}_{2}-2 \mathrm{O}_{3} \mathrm{Q}_{4}$, excluding observations of the control group. Panel B based on all observations in the analysis sample in $2010 Q_{2}-2013 Q_{4}$. Outcome variables are multiplied by 100 at each person-quarter cell for presentation purpose. The coefficients are from regressions of outcome variables on mandate indicators, quarter FEs, and individual FEs, with standard errors clustered at individual level. 


\section{Figure $\mathrm{A}_{4}$ : Discharge at Non-Profit Hospital}

\section{(a) Main Specification}

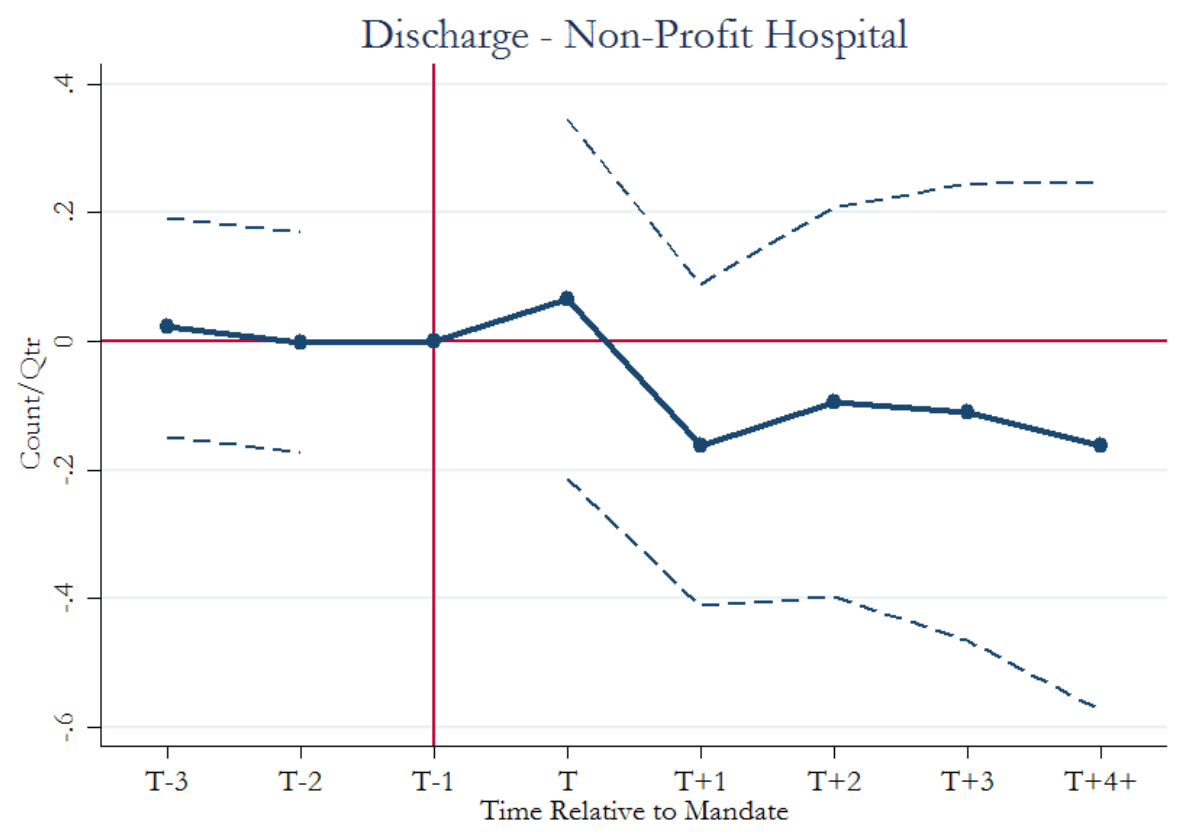

(b) COHS Specification

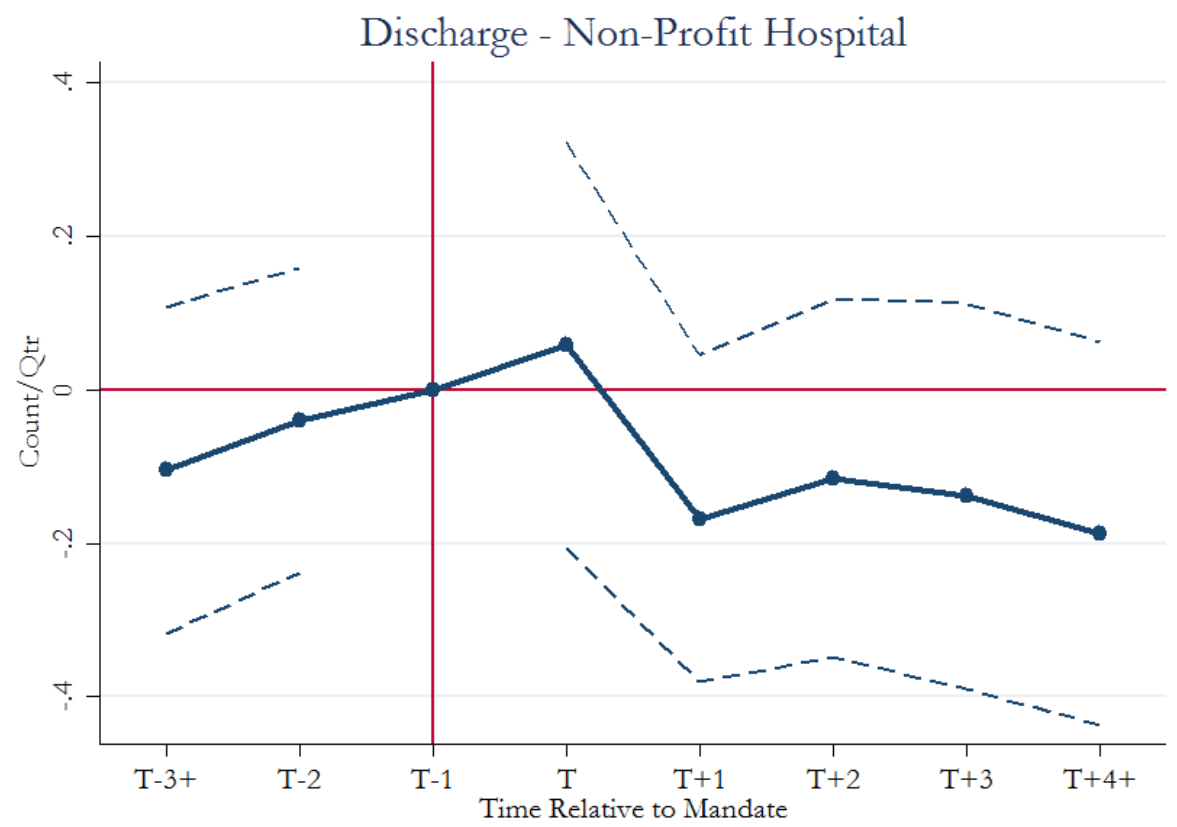

Notes: Panel A based on analysis sample in $2010 \mathrm{Q}_{2}-{ }_{2} \mathrm{O}_{3} \mathrm{Q}_{4}$, excluding observations of the control group. Panel B based on all observations in the analysis sample in $2010 \mathrm{Q}_{2}-{ }_{2} \mathrm{OI}_{3} \mathrm{Q}_{4}$. Outcome variables are multiplied by 100 at each person-quarter cell for presentation purpose. The coefficients are from regressions of outcome variables on mandate indicators, quarter FEs, and individual FEs, with standard errors clustered at individual level. 


\section{Figure A5: ER Visit at Non-Profit Hospital}

\section{(a) Main Specification}

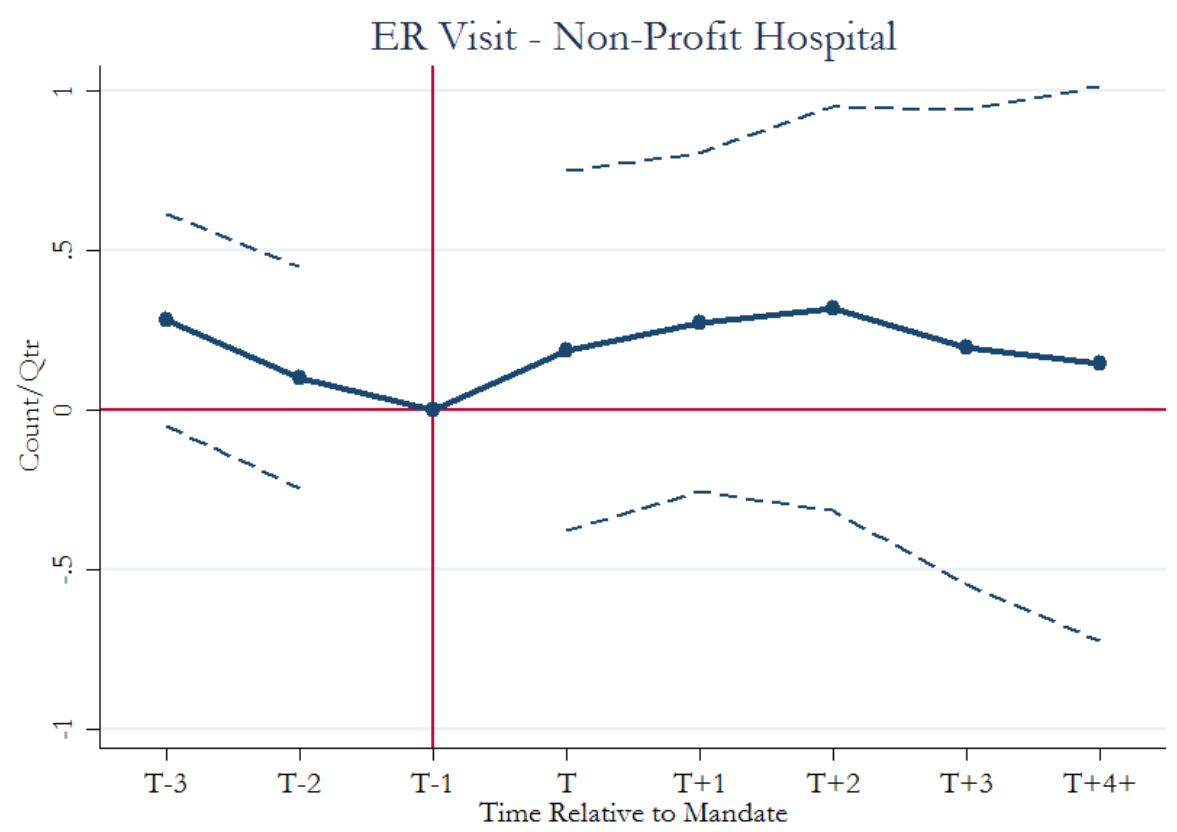

(b) COHS Specification

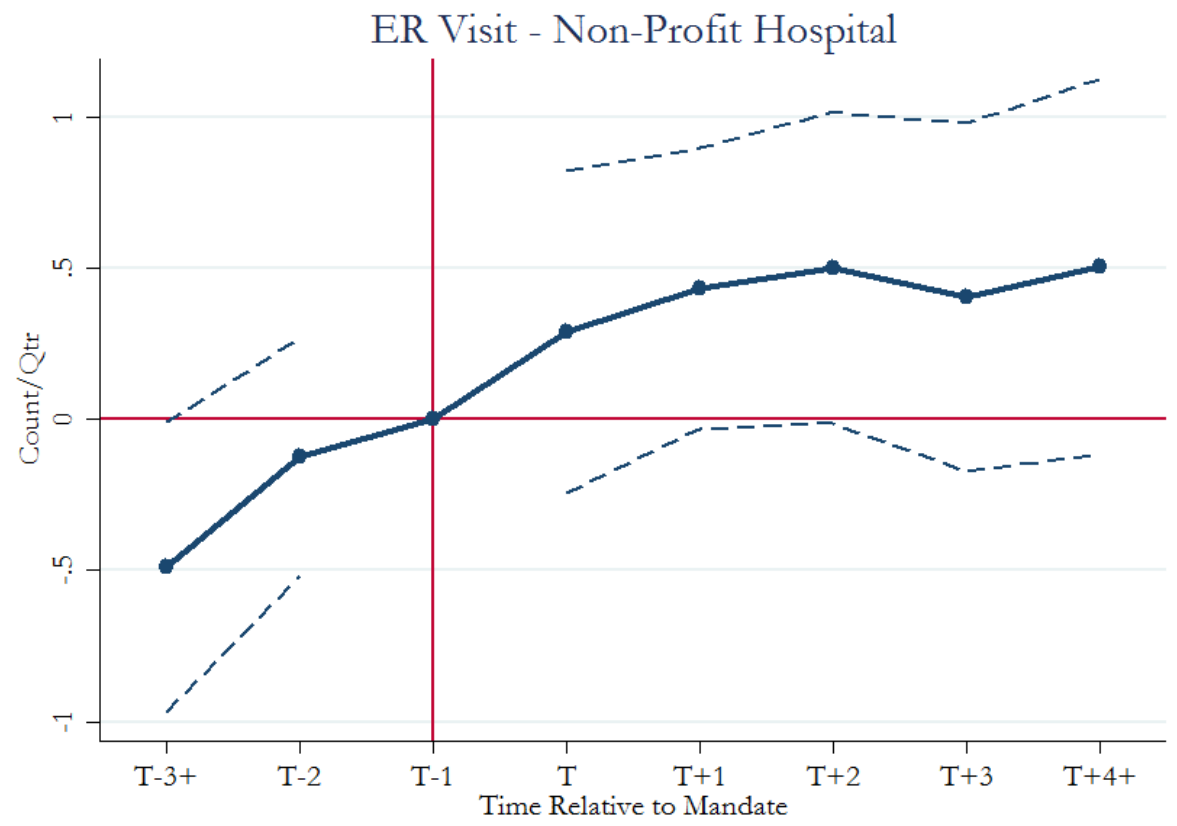

Notes: Panel A based on analysis sample in $2 \mathrm{OIOQ}_{2}-2 \mathrm{O}_{3} \mathrm{Q}_{4}$, excluding observations of the control group. Panel B based on all observations in the analysis sample in $2010 Q_{2}-2013 Q_{4}$. Outcome variables are multiplied by 100 at each person-quarter cell for presentation purpose. The coefficients are from regressions of outcome variables on mandate indicators, quarter FEs, and individual FEs, with standard errors clustered at individual level. 
Figure A6: Discharge at Government Hospital

(a) Main Specification

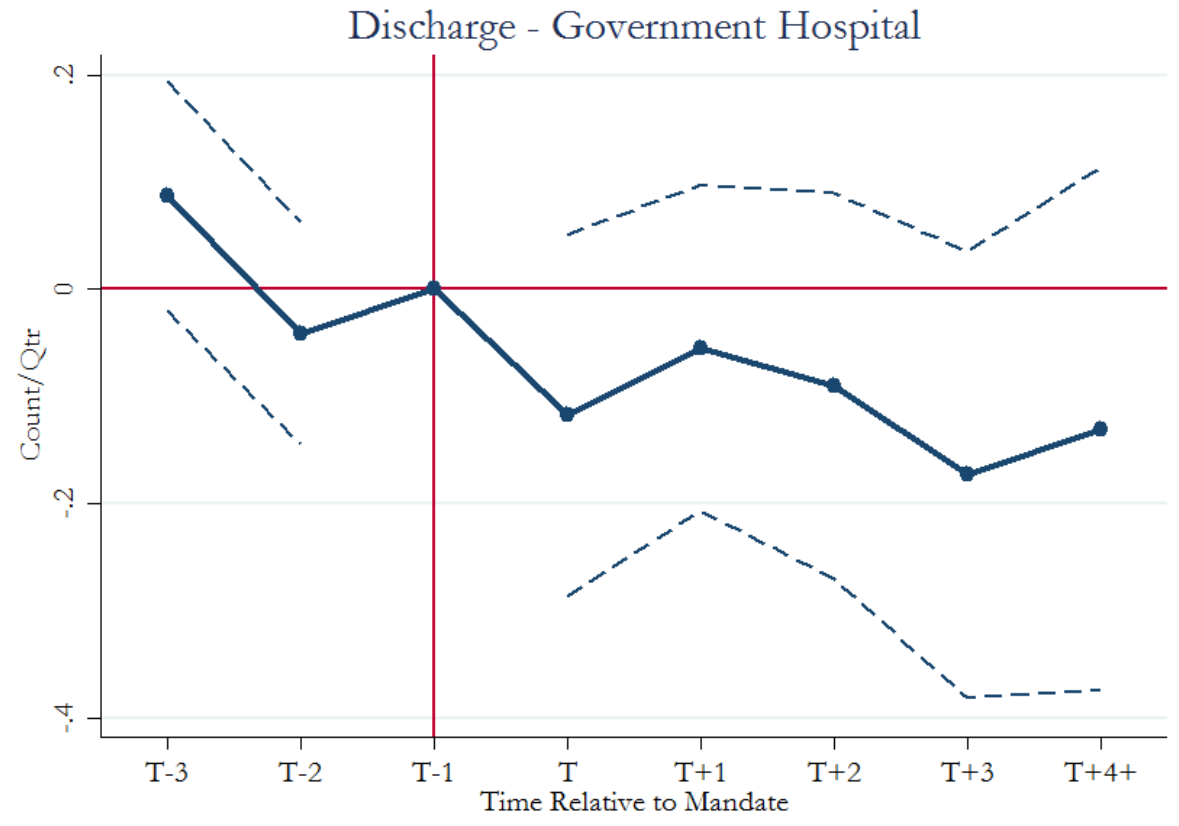

(b) COHS Specification

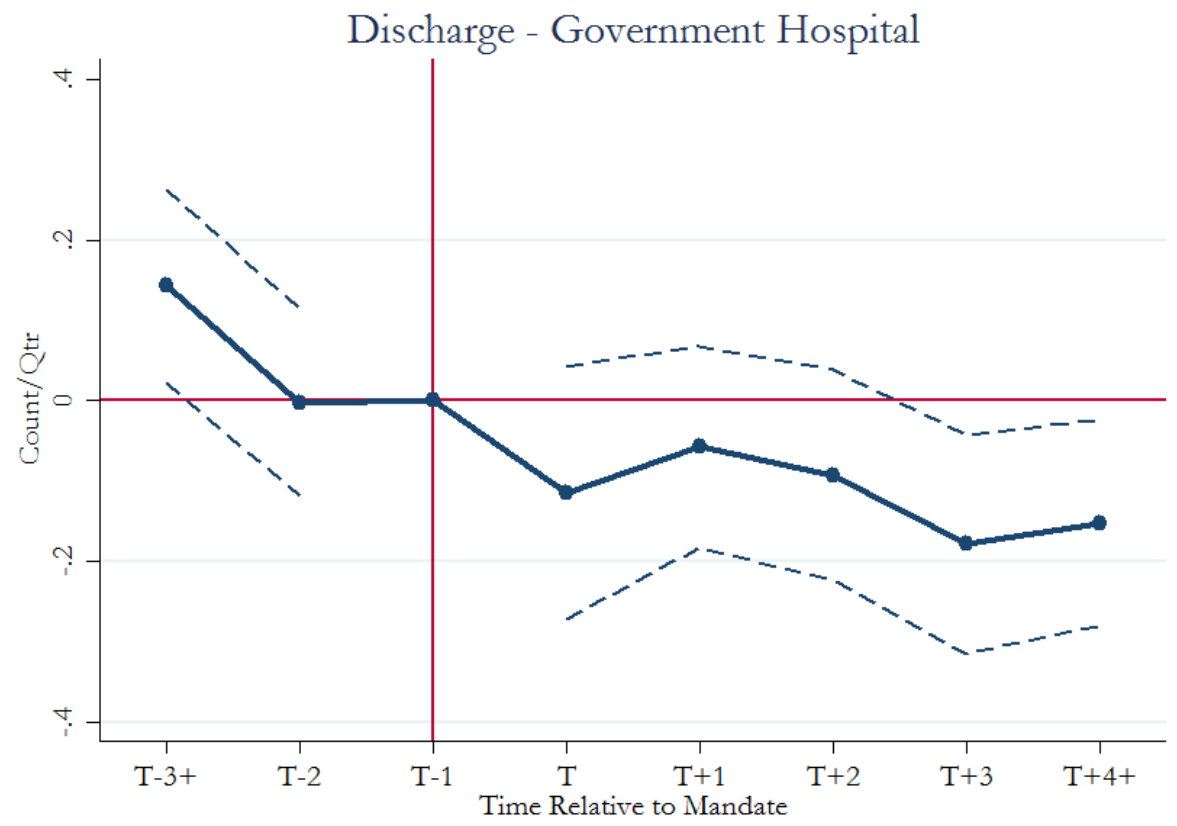

Notes: Panel A based on analysis sample in $2 \mathrm{OIOQ}_{2}-2 \mathrm{O}_{3} \mathrm{Q}_{4}$, excluding observations of the control group. Panel B based on all observations in the analysis sample in $2010 Q_{2}-2013 Q_{4}$. Outcome variables are multiplied by 100 at each person-quarter cell for presentation purpose. The coefficients are from regressions of outcome variables on mandate indicators, quarter FEs, and individual FEs, with standard errors clustered at individual level. 
Figure A7: ER Visit at Government Hospital

(a) Main Specification

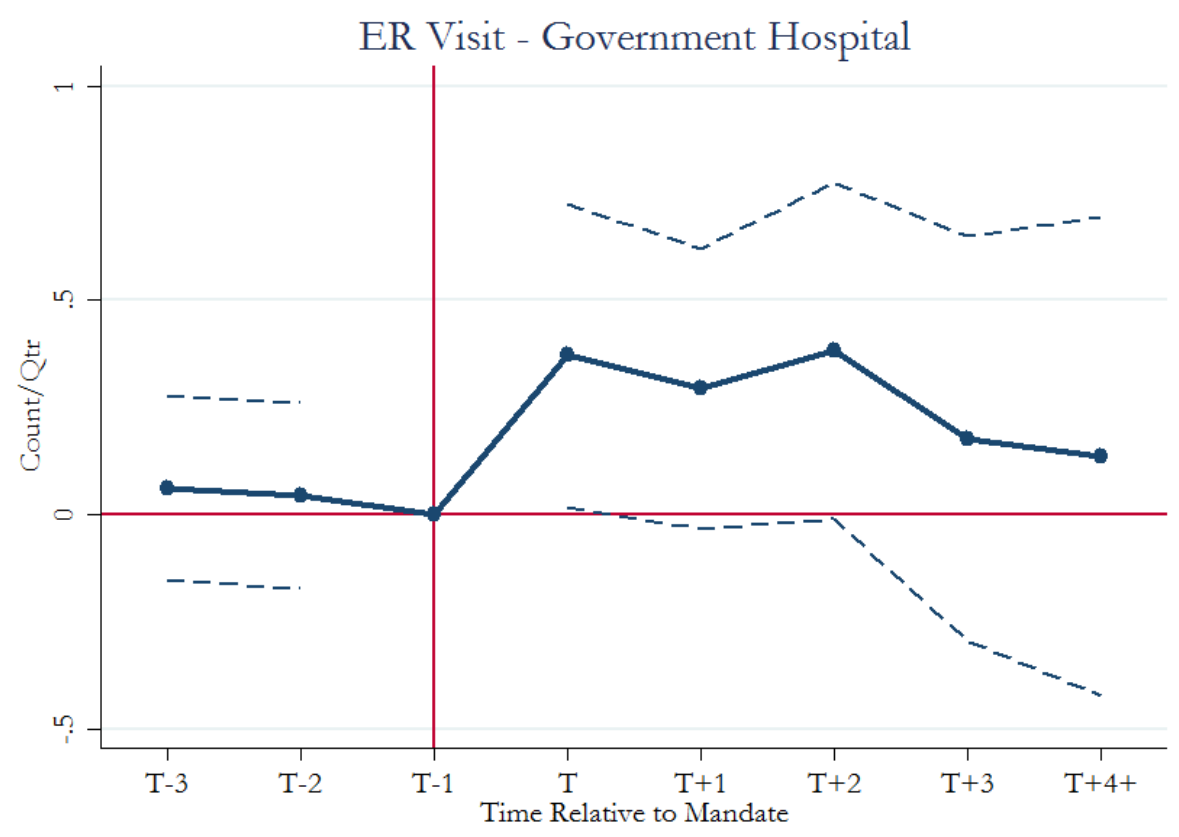

(b) COHS Specification

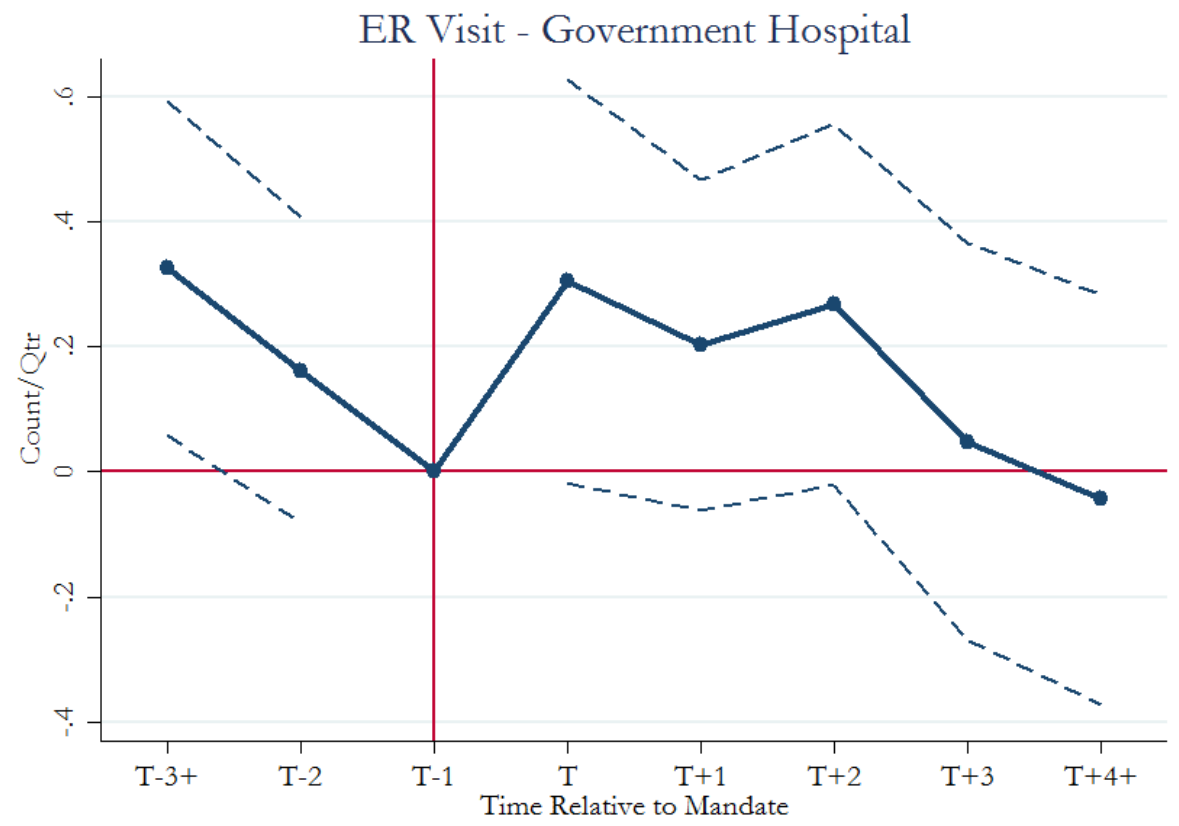

Notes: Panel A based on analysis sample in $2 \mathrm{OIOQ}_{2}-2 \mathrm{O}_{3} \mathrm{Q}_{4}$, excluding observations of the control group. Panel B based on all observations in the analysis sample in $2010 Q_{2}-2013 Q_{4}$. Outcome variables are multiplied by 100 at each person-quarter cell for presentation purpose. The coefficients are from regressions of outcome variables on mandate indicators, quarter FEs, and individual FEs, with standard errors clustered at individual level. 


\section{Figure A8: Discharge at Teaching Hospital}

(a) Main Specification

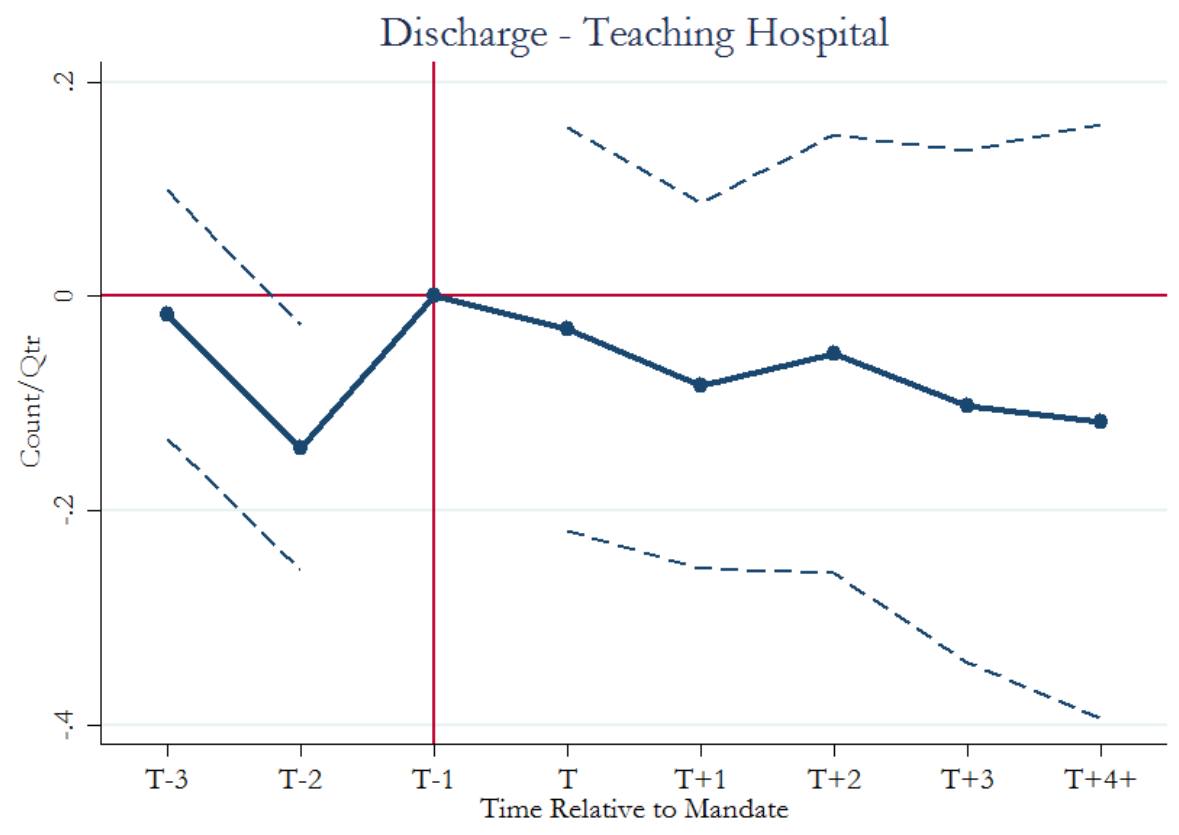

(b) COHS Specification

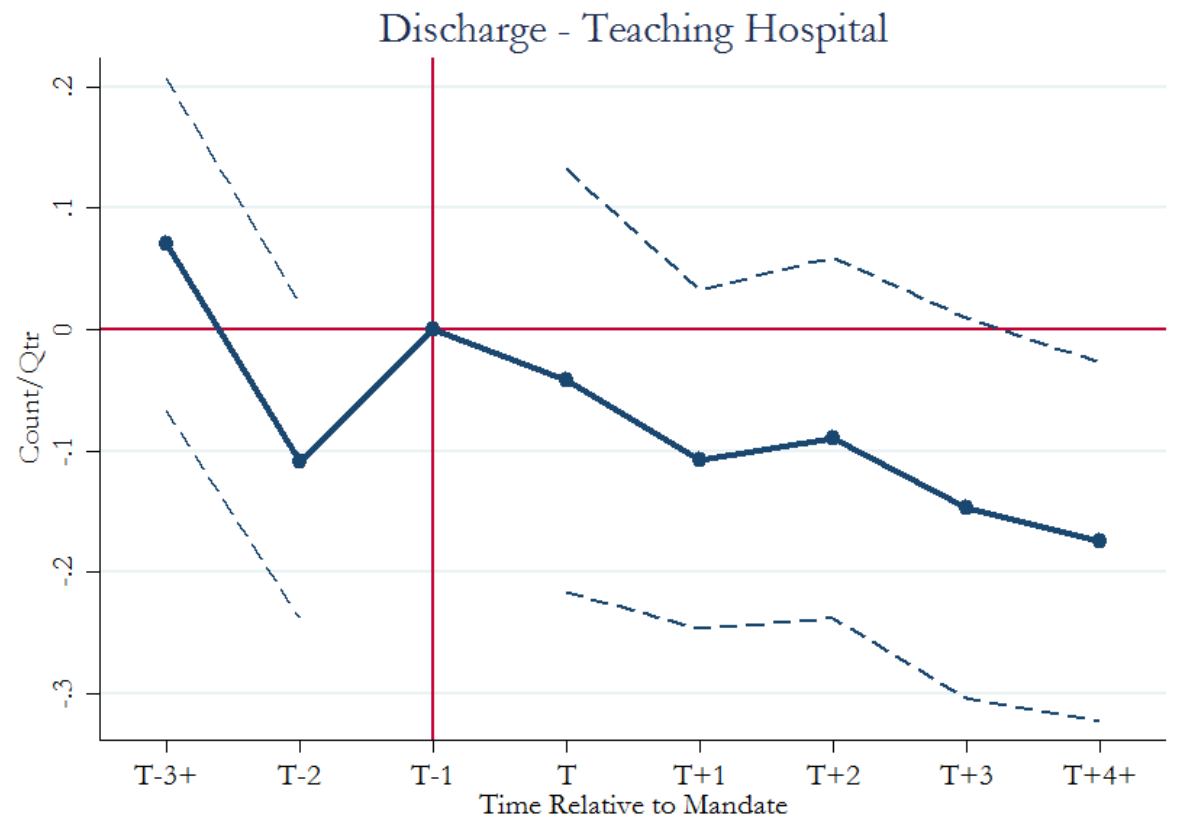

Notes: Panel A based on analysis sample in $2 \mathrm{OIOQ}_{2}-2 \mathrm{O}_{3} \mathrm{Q}_{4}$, excluding observations of the control group. Panel B based on all observations in the analysis sample in $2010 Q_{2}-2013 Q_{4}$. Outcome variables are multiplied by 100 at each person-quarter cell for presentation purpose. The coefficients are from regressions of outcome variables on mandate indicators, quarter FEs, and individual FEs, with standard errors clustered at individual level. 


\section{Figure A9: ER Visit at Teaching Hospital}

\section{(a) Main Specification}

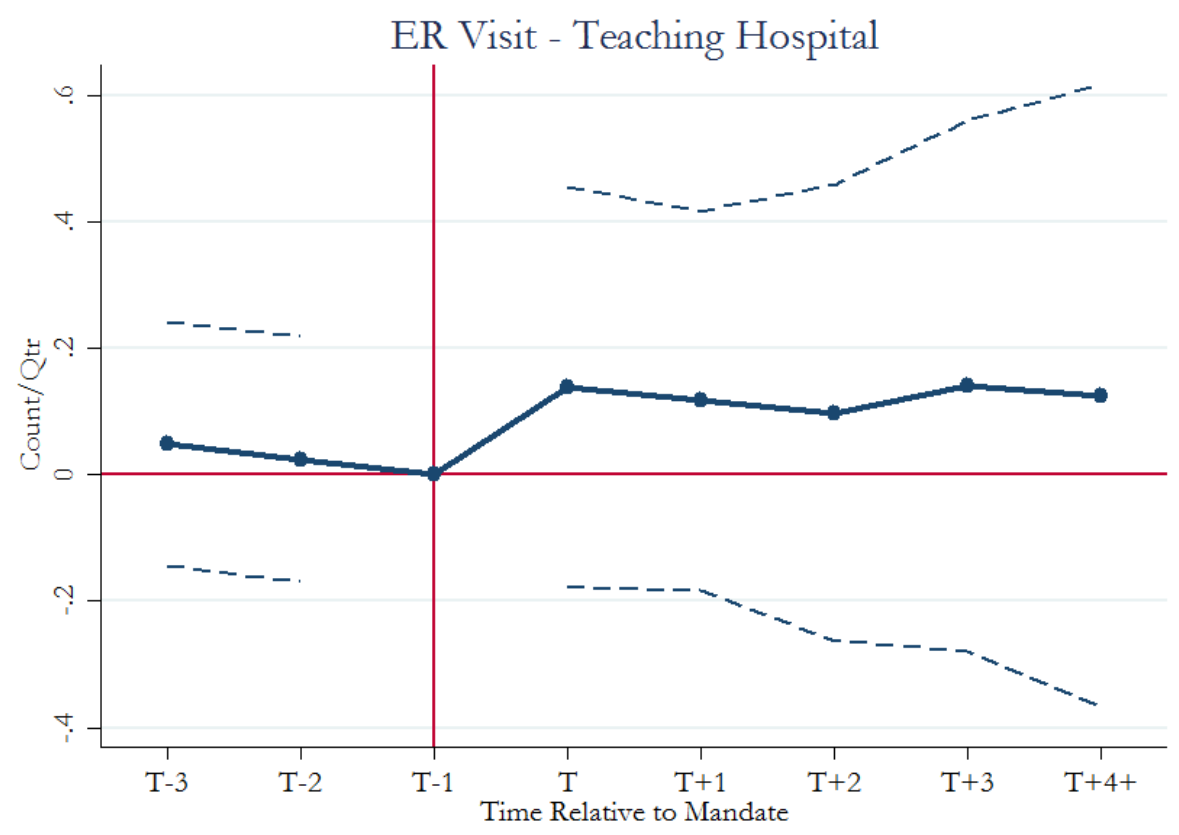

(b) COHS Specification

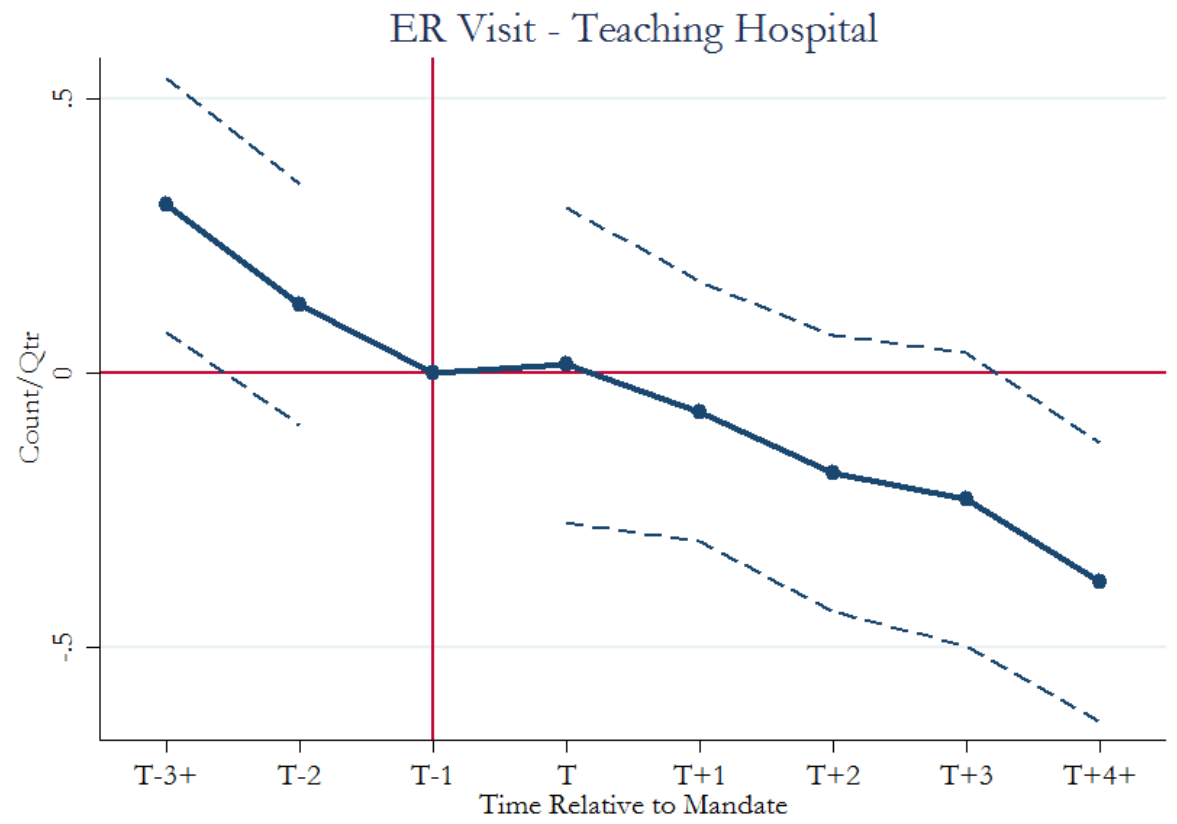

Notes: Panel A based on analysis sample in $2 \mathrm{OIOQ}_{2}-2 \mathrm{O}_{3} \mathrm{Q}_{4}$, excluding observations of the control group. Panel B based on all observations in the analysis sample in $2010 Q_{2}-2013 Q_{4}$. Outcome variables are multiplied by 100 at each person-quarter cell for presentation purpose. The coefficients are from regressions of outcome variables on mandate indicators, quarter FEs, and individual FEs, with standard errors clustered at individual level. 
Figure Aıo: Mortality Stacked Event Study

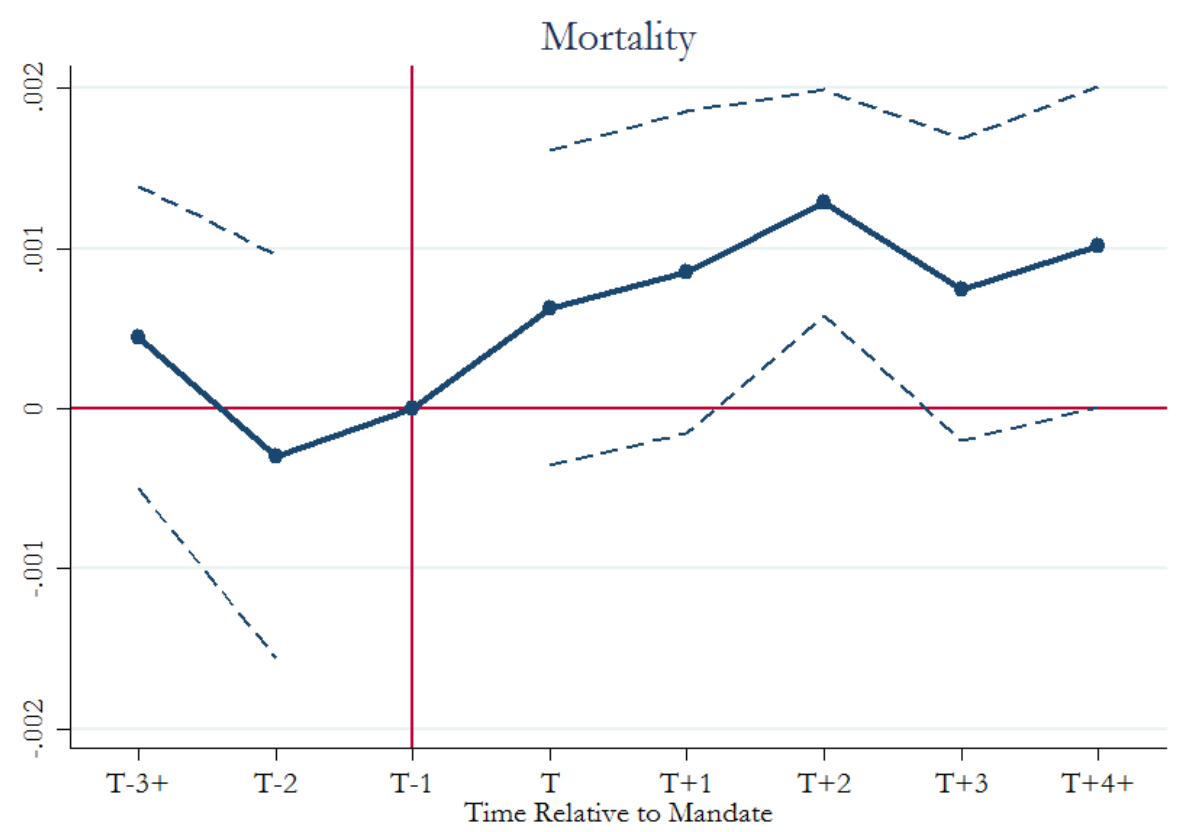

Notes: Based on stacked analysis sample in ${ }_{2010} \mathrm{Q}_{2}-{ }_{2013} \mathrm{Q}_{4}$ (excluding individuals without any hospital discharge in $2009 \mathrm{Q}_{2}-{ }_{2013} \mathrm{Q}_{4}$ ), constructed by stacking together the I2 treatment cohorts, within which the treatment group includes all individuals of a particular birth month in Two-Plan/GMC counties, and the control group includes all individuals in the COHS counties. The coefficients are from linear regression of the outcome variable (o/r death indicator) on mandate indicators, and quarter FEs, county FEs, age FEs, and gender indicator all interacted with treatment cohort indicators, with standard errors clustered at county level. 


\section{Figure Aır: Mortality Event Study - Average Marginal Effects from Logit Regressions}

\section{(a) Main Specification}

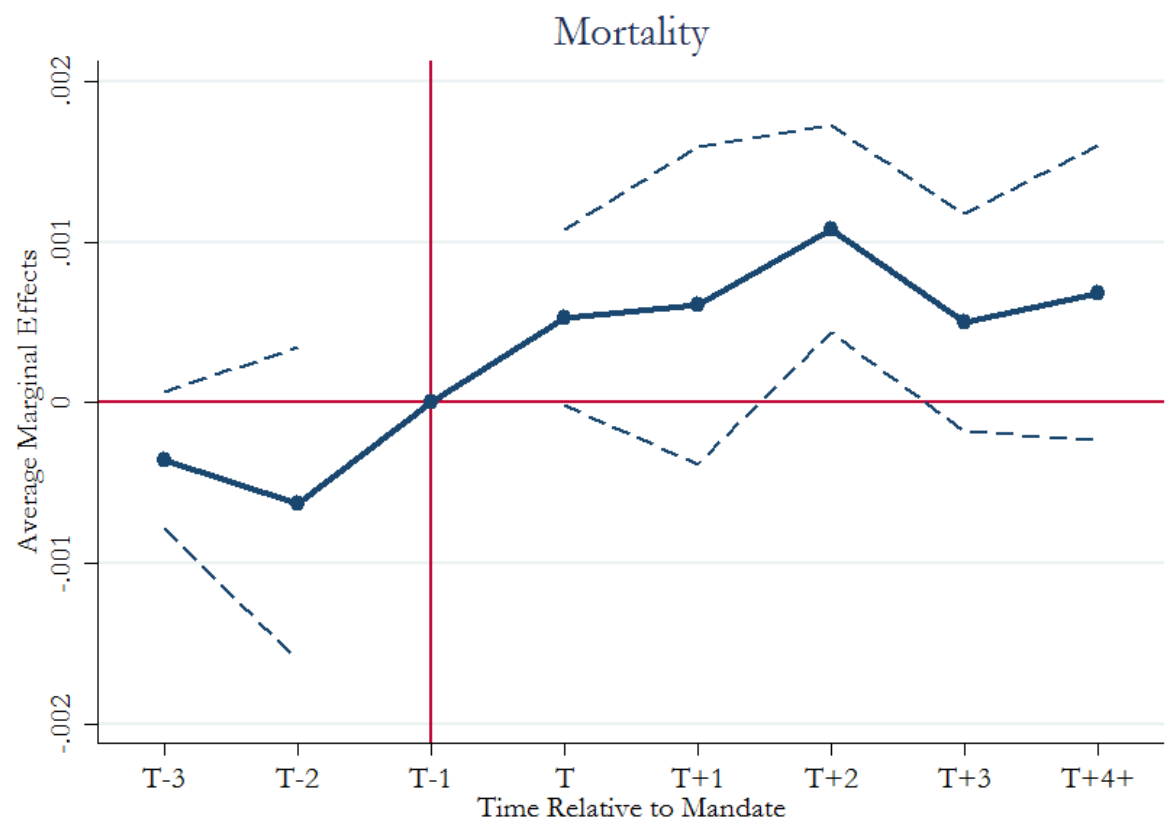

(b) COHS Specification

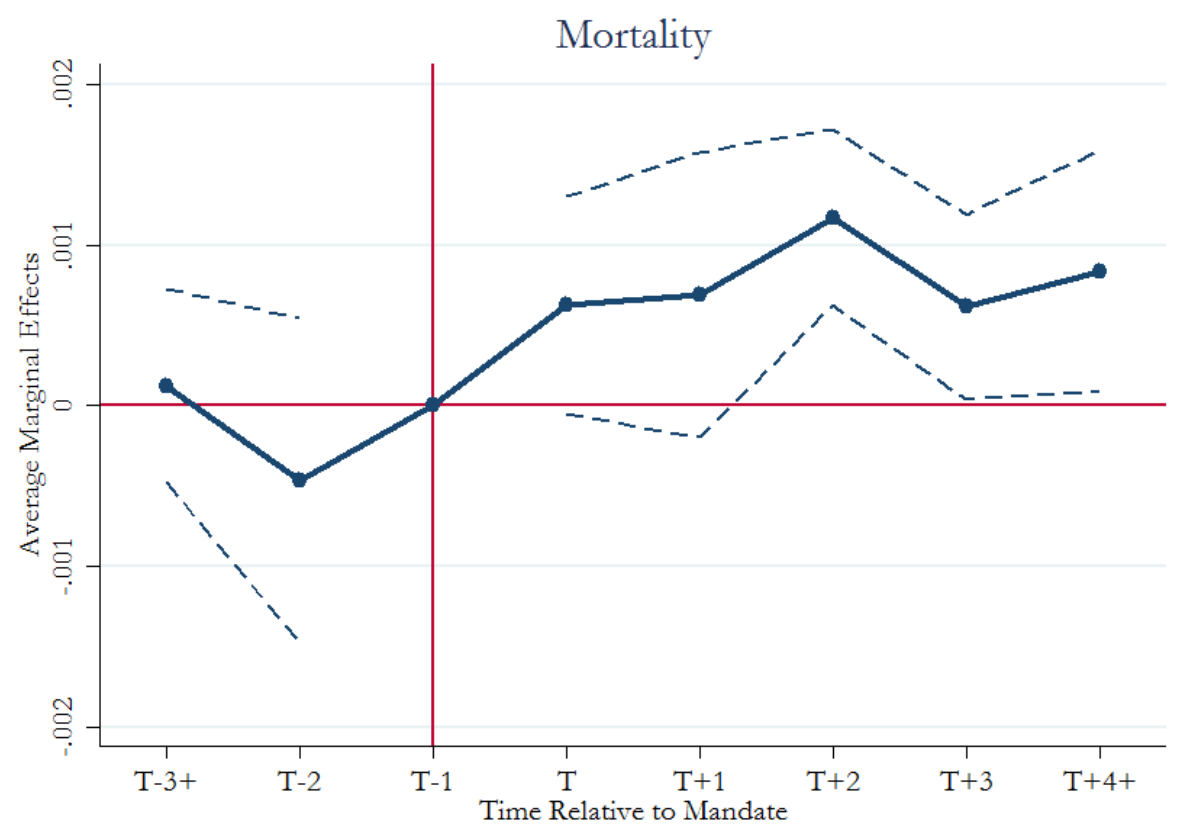

Notes: Panel A based on analysis sample in ${ }_{2} \mathrm{O}_{10} \mathrm{Q}_{2}-{ }_{2} \mathrm{O}_{3} \mathrm{Q}_{4}$, excluding observations of the control group and individuals without any hospital discharge in ${ }_{2009} \mathrm{Q}_{2}-{ }_{2} \mathrm{O}_{3} \mathrm{Q}_{4}$. Panel B based on all observations in the analysis sample in $2010 \mathrm{Q}_{2}-20{ }_{3} \mathrm{Q}_{4}$, excluding individuals without any hospital discharge in ${ }_{2009} Q_{2}-{ }_{2}{ }_{13} Q_{4}$. The figure plots average marginal effects from logit regression of outcome variable (o/I death indicator) on mandate indicators, quarter FEs, county FEs, age FEs, and gender indicator, with standard errors clustered at county level. 


\section{Figure Aı2: Stacked Event Study by High vs. Low Baseline Utilization}

(a) ER Visit

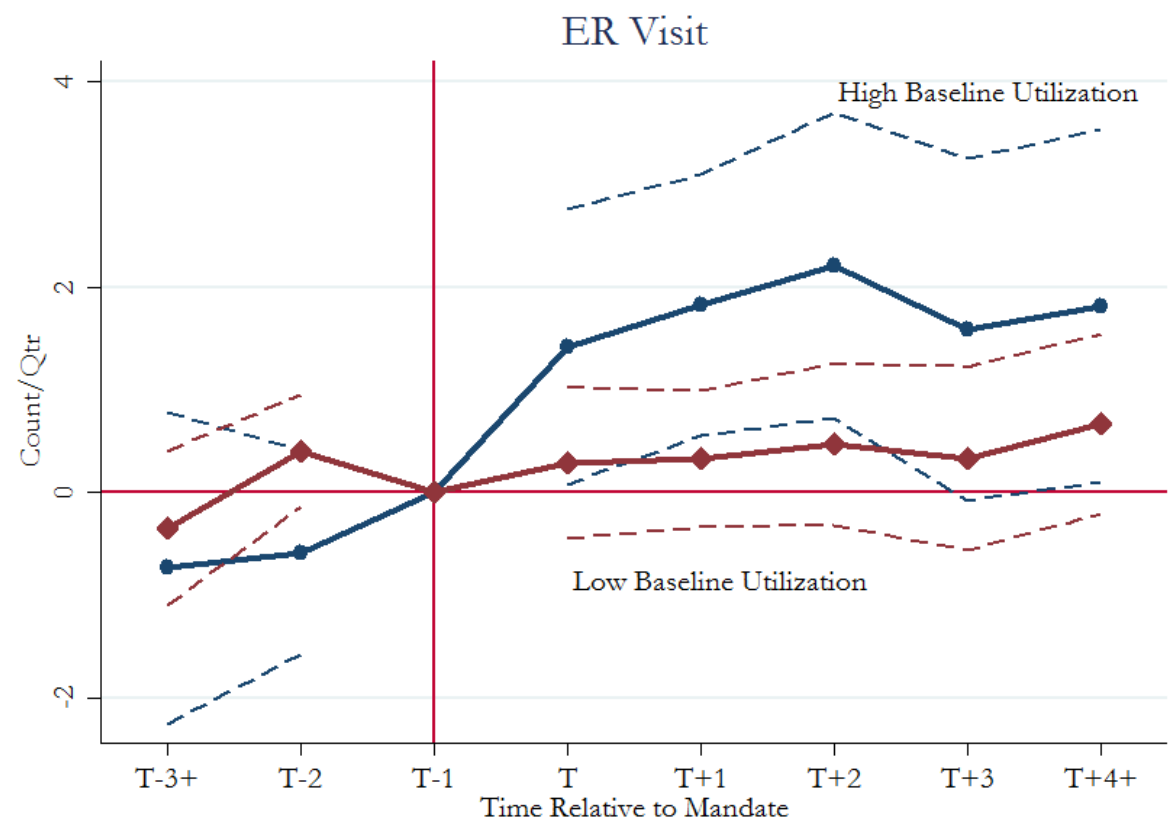

(b) Mortality

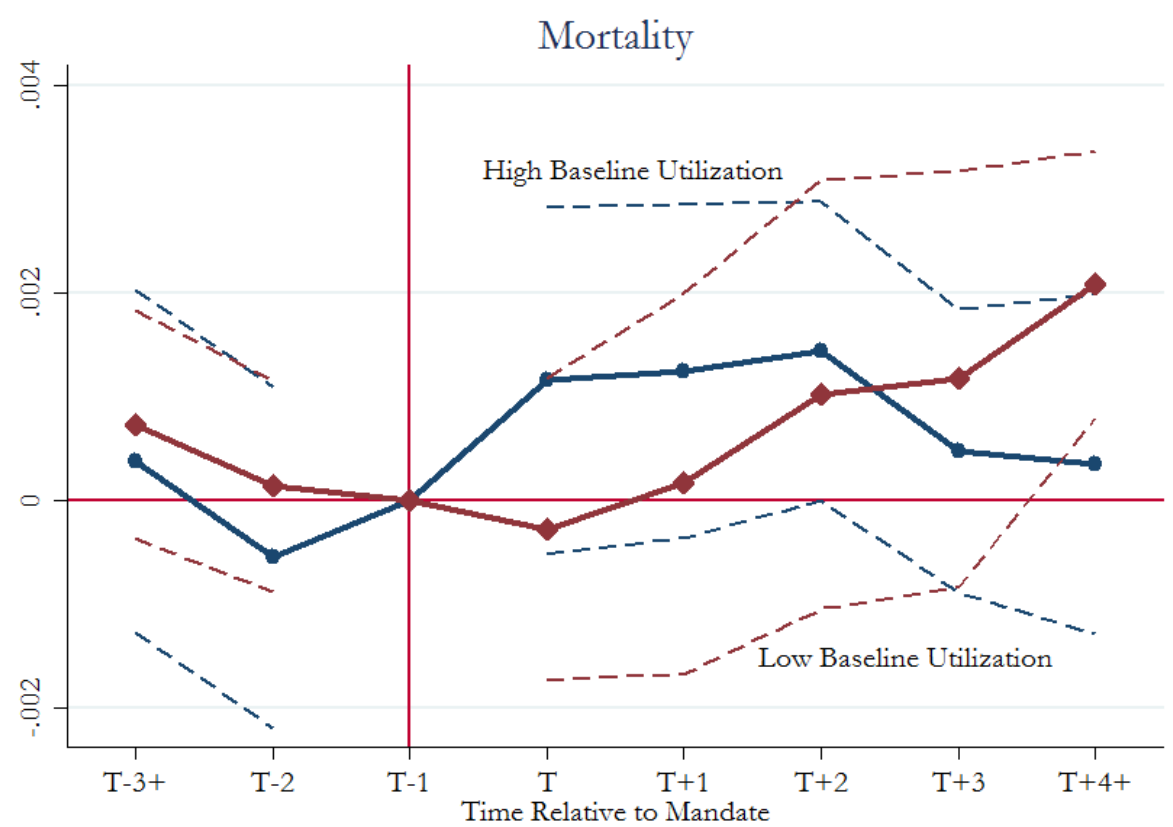

Notes: Panel A based on stacked analysis sample in $2010 \mathrm{Q}_{2}-2 \mathrm{O}_{3} \mathrm{Q}_{4}$, constructed by stacking together the $\mathrm{I} 2$ treatment cohorts, within which the treatment group includes all individuals of a particular birth month in Two-Plan/GMC counties, and the control group includes all individuals in the COHS counties. The outcome variable is multiplied by 100 at each person-quarter cell for presentation purpose. The coefficients are from separate regressions by baseline utilization of outcome variable on mandate indicators, and quarter FEs and individual FEs both interacted with treatment cohort indicators, with standard errors clustered at individual level. Panel B based on the same stacked analysis sample as Panel A, except also excluding individuals without any hospital discharge in $2009 \mathrm{Q}_{2}-2013 \mathrm{Q}_{4}$. The coefficients are from separate linear regression by baseline utilization of the outcome variable (o/r death indicator) on mandate indicators, and quarter FEs, county FEs, age FEs, and gender indicatg 5 all interacted with treatment cohort indicators, with standard errors clustered at county level. High utilizer is defined as individuals whose total number of inpatient hospital discharge + ER visit is higher than or equal to the median (which equals 2 in the analysis sample). 
Figure Aı3: ER Visit Event Study by High vs. Low Baseline Elixhauser Score

(a) Main Specification

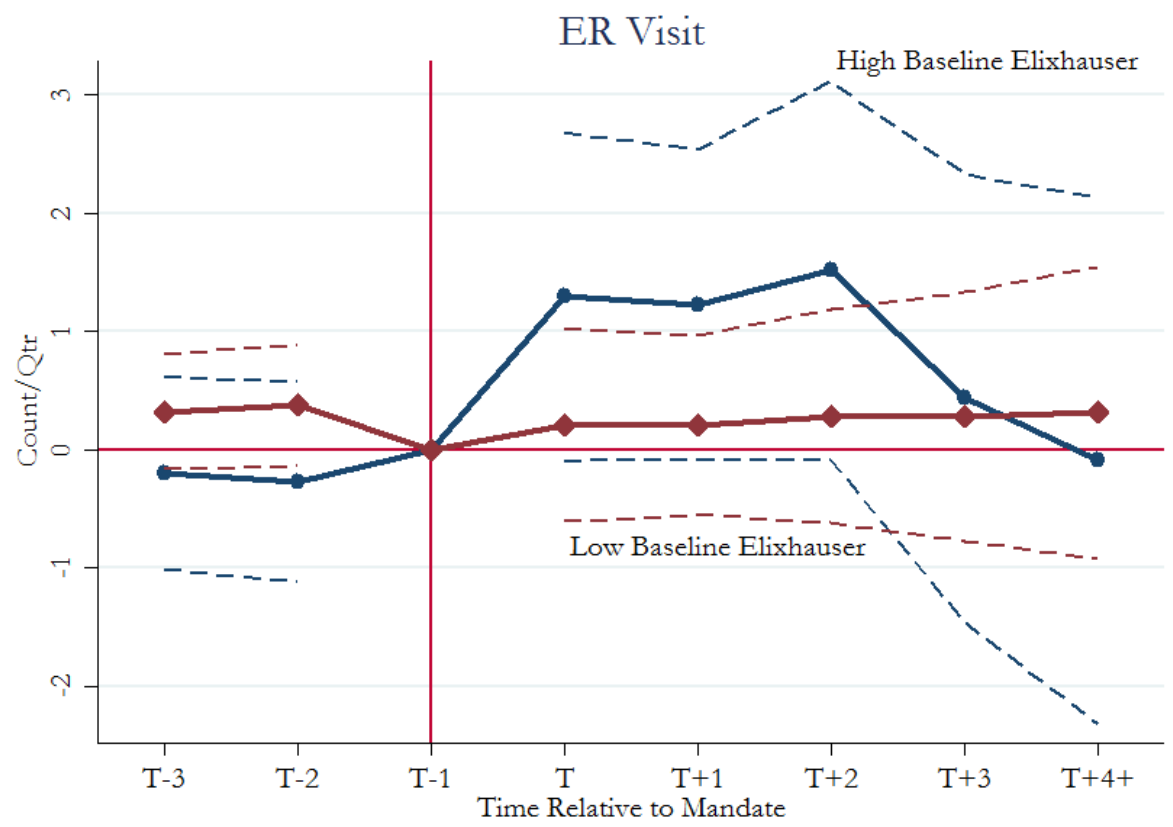

(b) COHS Specification

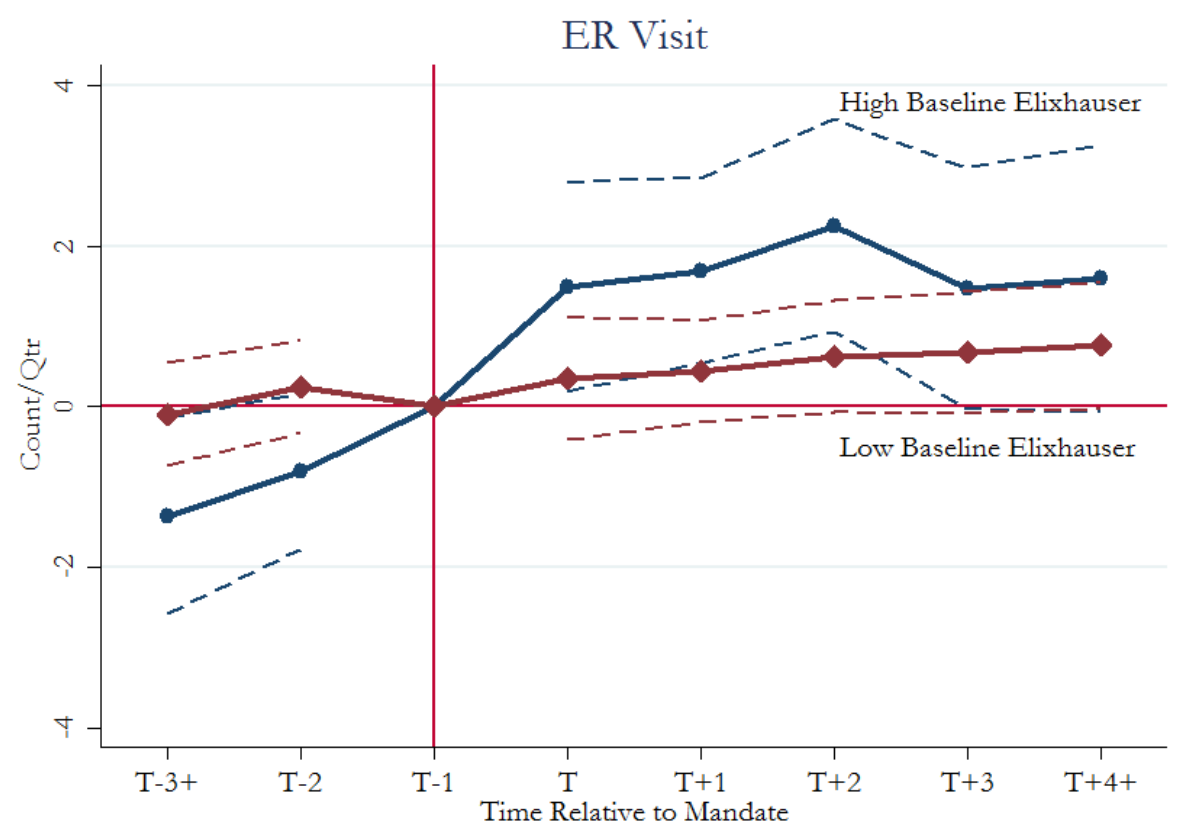

Notes: Panel A based on analysis sample in $2010 \mathrm{Q}_{2}-{ }_{2} \mathrm{O}_{3} \mathrm{Q}_{4}$, excluding observations of the control group. Panel B based on all observations in the analysis sample in $2 \mathrm{OIOQ}_{2}-\mathrm{2OI}_{3} \mathrm{Q}_{4}$. Outcome variables are multiplied by 100 at each person-quarter cell for presentation purpose. The coefficients are from separate regressions by baseline Elixhauser score of outcome variables on mandate indicators, quarter FEs, and individual FEs, with standard errors clustered at individual level. High severity patient is defined as individuals whose total unweighted number of chronic conditions (Elixhauser score) based on principal and co-diagnoses of all inpatient hospital discharges and ER visits at baseline is higher than the median (which equals $\mathrm{I}$ in the analysis sample). 


\section{Figure Aı4: Stacked Event Study by High vs. Low Baseline Elixhauser Score}

(a) ER Visit

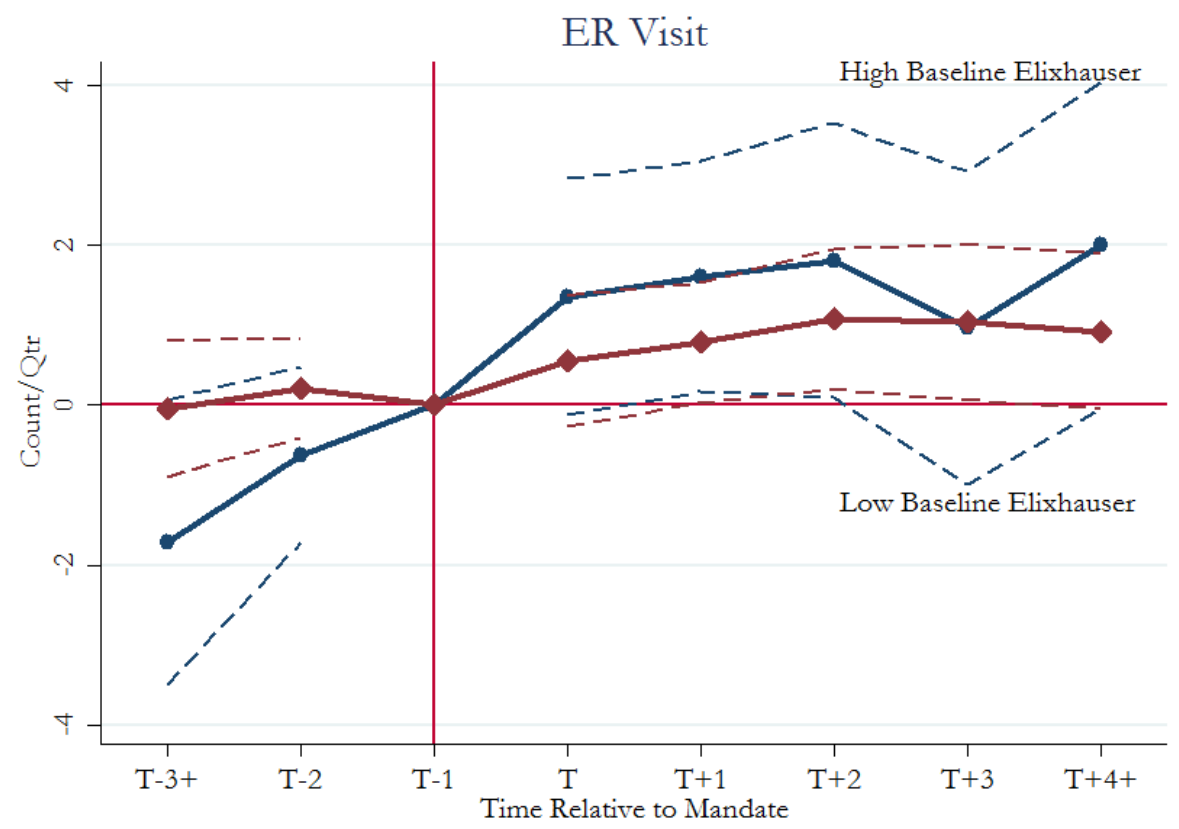

(b) Mortality

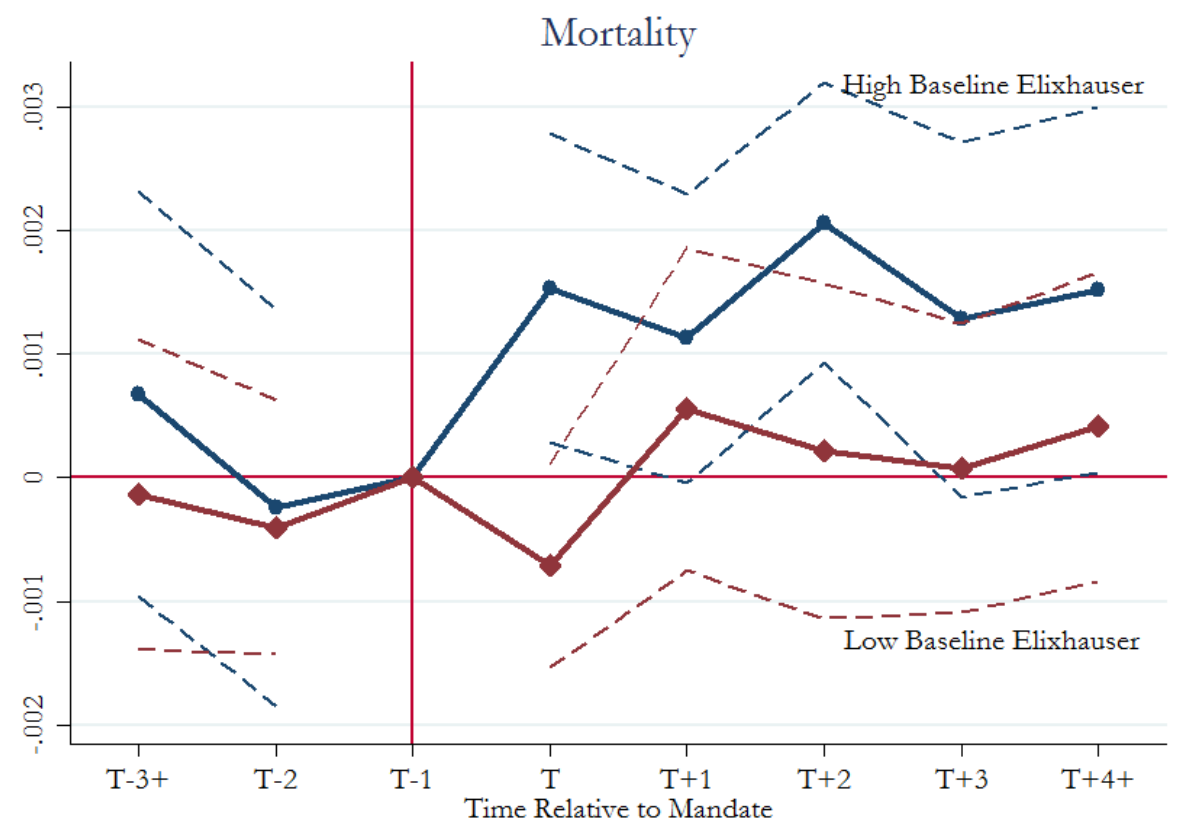

Notes: Panel A based on stacked analysis sample in $2010 \mathrm{Q}_{2}-2 \mathrm{O}_{3} \mathrm{Q}_{4}$, constructed by stacking together the $\mathrm{I} 2$ treatment cohorts, within which the treatment group includes all individuals of a particular birth month in Two-Plan/GMC counties, and the control group includes all individuals in the COHS counties. The outcome variable is multiplied by 100 at each person-quarter cell for presentation purpose. The coefficients are from separate regressions by baseline Elixhauser score of outcome variable on mandate indicators, and quarter FEs and individual FEs both interacted with treatment cohort indicators, with standard errors clustered at individual level. Panel B based on the same stacked analysis sample as Panel A, except also excluding individuals without any hospital discharge in ${ }_{2009} \mathrm{Q}_{2}-2013 \mathrm{Q}_{4}$. The coefficients are from separate linear regression by baseline Elixhauser score of the outcome variable (o/r death indicator) on mandate indicators, and quarter FEs, county FEs, age FEs, andggender indicator all interacted with treatment cohort indicators, with standard errors clustered at county level. High severity patient is defined as individuals whose total unweighted number of chronic conditions (Elixhauser score) based on principal and co-diagnoses of all inpatient hospital discharges and ER visits at baseline is higher than the median (which equals I in the analysis sample). 